BHI/ONWI - -538

Distribution Category UC-70

DE84 016284

\title{
A Study of Thermal-Gradient-Induced Migration of Brine Inclusions in Salt: Final Report
}

\author{
Technical Report \\ August 1984 \\ D. R. Olander \\ of \\ Regents of the University of California \\ prepared for \\ Office of Nuclear Waste Isolation \\ Battelle Memorial Institute \\ 505 King Avenue \\ Columbus, OH 43201-2693
}

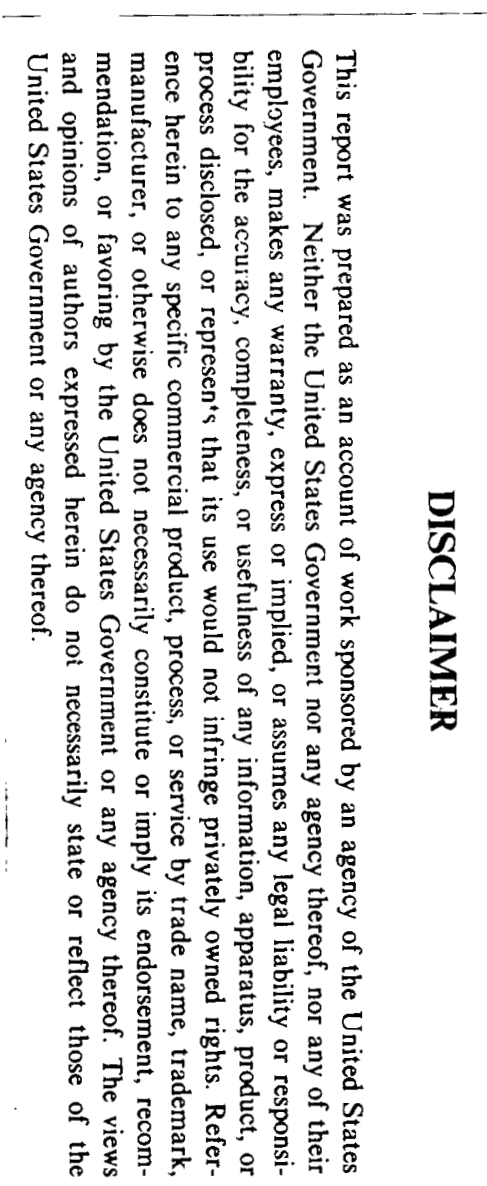

The content of this report was effective as of September 1982. This report was prepared by Regents of the University of California under Subcontract E512-03700 with Battelle Project Management Division, Office of Nuclear Waste Isolation under Contract Nos. DE-AC06-76RLO1830 and DE-AC02-83CH10140 with the U.S. Department of Energy. 


\section{DISCLAIMER}

This report was prepared as an account of work sponsored by an agency of the United States Government. Neither the United States Government nor any agency Thereof, nor any of their employees, makes any warranty, express or implied, or assumes any legal liability or responsibility for the accuracy, completeness, or usefulness of any information, apparatus, product, or process disclosed, or represents that its use would not infringe privately owned rights. Reference herein to any specific commercial product, process, or service by trade name, trademark, manufacturer, or otherwise does not necessarily constitute or imply its endorsement, recommendation, or favoring by the United States Government or any agency thereof. The views and opinions of authors expressed herein do not necessarily state or reflect those of the United States Government or any agency thereof. 


\section{DISCLAIMER}

Portions of this document may be illegible in electronic image products. Images are produced from the best available original document. 


\section{ABSTRACT}

It has been proposed that high-level nuclear waste be disposed of in a geologic repository. Natural salt deposits, which are being considered for this purpose, contain a small volume fraction of water in the form of brine inclusions distributed throughout the salt. Radioactive decay heating of the nuclear wastes will impose a temperature gradient on the surrounding salt which mobilizes the brine inclusions. Inclusions filled completely with brine (the all-liquid inclusions) migrate up the temperature gradient and eventually accumulate brine near the buried waste forms. The brine may slowly corrode or degrade the waste forms, which is undesirable.

Therefore it is important to consider the migration of brine inclusions in salt under imposed temperature gradients to properly evaluate the performance of a future salt repository for nuclear wastes. The migration velocities of the inclusions were found to be dependent on temperature, temperature gradient, and inclusion shape and size. The velocities were also dictated by the interfacial mass transfer resistance at brine/solid interface. This interfacial resistance depends on the dislocation density in the crystal, which in turn, depends on the axial compressive loading of the crystal. At low axial loads, the dependence between the velocity and temperature gradient is nonlinear. At high axial loads, however, the interfacial resistance is reduced and the migration velocity depends linearly on the temperature gradient.

All-liquid inclusions filled with mixed brines were also studied. For gas-liquid inclusions, three different gas phases (helium, air and argon) were compared. Migration studies were also conducted on single crystallites of natural salt as well as in polycrystalline natural salt samples. The behavior of the inclusions at large-angle grain boundaries was observed. 


\section{PROJECT DESCRIPTION}

The objective of the project is to elucidate the fundamental phenomena responsible for the migration of brine inclusions in salt subjected to a temperature gradient. Both a 11-1iquid and gas-1iquid inclusions are considered. Thermal gradient migration of both all-liquid and gas-liquid inclusions was experimentally studied in synthetic single crystals of $\mathrm{NaCl}$ and $\mathrm{KCl}$ using a hot-stage attachment to an optical microscope which was capable of imposing temperature gradients and axial compressive loads on the crystals.

Modeling and testing of all-liquid inclusions considered the effects of temperature, temperature gradient (both magnitude and crystallographic direction), and mechanical loading on the shapes and migration speeds of inclusions. To provide the best characterized solids, synthetic single crystals of $\mathrm{KCl}$ and $\mathrm{NaCl}$ were studied. In addition, natural salt from the Richton Dome was investigated.

Modeling of the gas-liquid inclusions included detailed analyses of heat and mass transfer in the three-phase salt-brine-air system and, treatment of interface kinetics and liquid convection due to surface tension gradients at the gas-liquid boundary. 
CONTENTS

Page

ABSTRACT . . . . . . . . . . . . . . . . . . . .

PROJECT DESCRIPTION. . . . . . . . . . . . . . . . . . . . . .

EXECUTIVE SUMMARY. . . . . . . . . . . . . . . . . . . .

Chapter

1. INTRODUCTION . . . . . . . . . . . . . . . . . . . . . 1

2. THE MECHANISM OF THERMOMIGRATION . . . . . . . . . . . . . . . 5

2.1 A11-Liquid Inclusions . . . . . . . . . . . . . . 5

2.2 Gas-Liquid Inclusions . . . . . . . . . . . . . . 8

3. EXPERIMENTAL PROCEDURE . . . . . . . . . . . . . . . . . 10

3.1 Sample Preparation. ................. . . 10

3.1.1 Synthetic Crystals ............... 10

3.1.2 Natural Salt................... 13

3.2 Optical Hot Stage ................... . . . 14

3.2.1 Description. ................. 14

3.2.2 Temperature Profile in the Crystal . . . . . . 16

3.2.3 Migration Velocity Measurements. . . . . . . . 19

3.3 Dislocation Density in the Crystal. . . . . . . . . 19

3.3.1 Polishing. . . . . . . . . . . . . . . . 20

3.3.2 Etching. . . . . . . . . . . . . . . . 20

3.3.3 Rinsing. . . . . . . . . . . . . . . . 21

4. THEORY OF THERMOMIGRATION. . . . . . . . . . . . . . . . . 23

4.1 All-Liquid Inclusions . . . . . . . . . . . . . . . 23

4.1.1 Inclusion Velocity ................. . . . 23

4.1.2 Crystal Growth/Dissolution Principles. . . . . . . . 25 
4.1.2.1 Nucleation Growth Theory. . . . . . . 25

4.1.2.2 Surface Diffusion Growth Theory ...... 26

4.1.2.3 Impurity Effect ........... . . 31

4.7.3 Interfacial Kinetics ............. 32

4.1.3.1 Linear Interfacial Kinetics ........ 35

4.1.3.2 Non-Linear Interfacial Kinetics ...... 36

4.1.3.3 Threshold Temperature Gradient for
No Migration. ................ 37

4.2 Gas-Liquid Inclusions . . . . . . . . . . . . . 38

5. INTERFACIAL STABILITY OF MIGRATION ALL-LIQUID INCLUSIONS . . . . 42

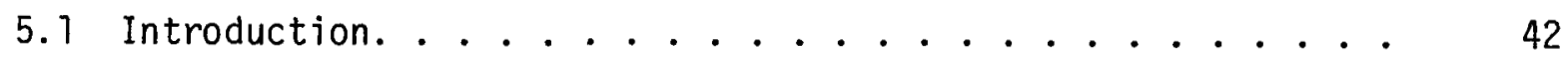

5.2 Perturbation Method for Stability Analysis. . . . . . 44

5.2.1 Temperature and Concentration Fields....... 47

5.2.1.1 The Unperturbed Case. . . . . . . . 47

5.2.1.2 The Perturbed Case.......... 49

5.2.2 Determination of the Parameters $a$ and b. ..... 51

5.2.2.1 Method 1............. 51

5.2.2.2 Method 2.............. 52

5.2 .3 Interfacial Kinetics .............. 53

5.2 .4 Interfacial Energy . . . . . . . . . . 54

5.3 Application to Migrating Inclusions ......... 57

5.4 Discussion. . . . . . . . . . . . . 59

5.4 .1 Special Cases. .................. 59

5.4 .2 General Case................. 62

5.4.3 Comparison with Experimental Data. . . . . . . 64

5.4.4 Comparison with the Work of Anthony and Cline. . . . 69

5.5 summary......................... 70 
6. RESULTS AND DISCUSSIONS. . . . . . . . ...... 71

6.1 All-Liquid Inclusions . . . . . . . . . . 71

6.1.1 Potassium Chloride Single Crystals ......... 71

6.1.1.1 Solid Unstressed. ............ 71

6.1.1.2 Effect of Stress. ........... 80

6.1.1.3 Evaluation of Interfacial Kinetics

Parameters. ........... 82

6.1.2 Sodium Chloride Single Crystals. . . . . . . . 85

6.1.2.1 Self Brine Inclusions . . . . . . . . 85

6.1.2.2 Mixed Brine Inclusions. . . . . . . . . 89

6.1 .3 Natural Salt . . . . . . . . . . . . 90

6.2 Gas-Liquid Inclusions . . . . . . . . . . . . 93

6.2.1 Transport of Radioactivity ........... 93

6.2.2 Comparison of Different Gas-Phases . . . . . . 96

6.3 Inclusions at Grain Boundary. . . . . . . . . . 100

7. CONCLUSIONS. . . . . . . . . . . . . . 106

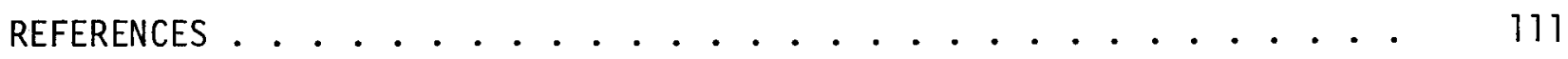

APPENDICES . . . . . . . . . . . . . . . 117

A. Temperature Gradients in an A11-Liquid Inclusion . . . . . 117

B. Impurity Effects and the Order of Interfacial Kinetics . . . 121 
viji

\section{LIST OF FIGURES}

2-1. Section of an all-liquid inclusion in a solid supporting a temperature gradient

2-2. Schematic of the migration mechanisms of gas-liquid inclusions in a temperature gradient $\ldots \ldots \ldots \ldots \ldots \ldots \ldots . . . .$.

3-1. A photomicrograph of a17-1iquid and gas-liquid inclusions

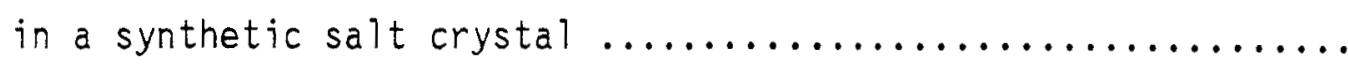

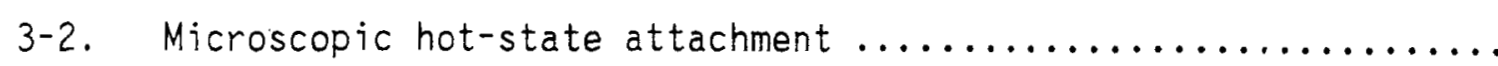

3-3. Temperature profiles in the salt crystal computed under

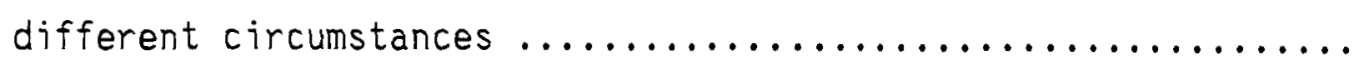

3-4. Temperature profile measurements in a $\mathrm{NaCl}$ single crystal .....

3-5. Dislocation etch pits on the $\mathrm{NaCl}(100)$ surface $\ldots . . . \ldots \ldots$

4-1. (100) Surface of a crystal with single cubic lattice ..........

4-2. A screw dislocation intersecting surface of a simple cubic

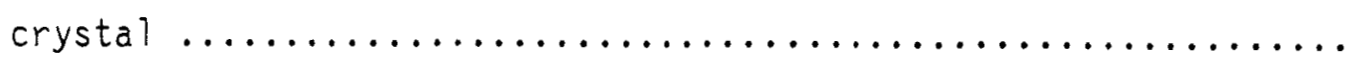

4-3. Effect of immobile adsorbed impurities on the lateral motion of ledges on the crystal surface $\ldots . \ldots \ldots \ldots . . . . .$.

4-4. Spherical model of a gas-liquid inclusion showing the water flux crossing the bubble from hot to cold and the salt disposition or dissolution flux at the solid liquid boundary

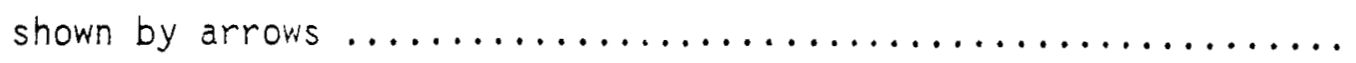


LIST OF FIGURES

(Cont inued)

5-1. Photomicrograph of inclusions showing interfacial instabilities in an applied temperature gradient of $40^{\circ} \mathrm{C} / \mathrm{cm}$ and compressive axial load of $s 4 \mathrm{MPa} \ldots \ldots \ldots \ldots \ldots \ldots$

5-2. A typical sequence of events leading to breakdown of an

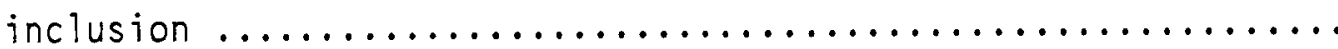

5-3. Temperature and concentration fields at an unperturbed planar interface under growth conditions $\ldots . . . . . . . . . . .$.

5-4. Small sections of unperturbed and perturbed interfaces to compute the effect of interfacial energy on the boundary conditions

5-5 Schematic representation of the region of stability for an inclusion with specific values of $L$ and $W$ migrating under the combined influence of diffusion and interfacial kinetics .......

5-6. Experimental data for several stable and unstable inclusions migrating with diffusion-controlled velocities in a $\mathrm{KCl}$ single crystal

6-1. Migration velocity of an inclusion in $\mathrm{KCl}$ as a function of time

6-2. Schematic sketch of dislocations in the crystal as they encounter migrating inclusions $\ldots \ldots \ldots \ldots \ldots \ldots \ldots \ldots \ldots \ldots \ldots$

6-3. The variation in inclusion size with applied temperature.....

6-4. Variation of migration velocity of five inclusions in $\mathrm{KCl}$ with the applied temperature gradients 


\section{LIST OF FIGURES}

(Continued)

6-5. Effect of increasing the mechanical load on a salt crystal containing inclusions migrating in a temperature gradient

6-6. Effect of applied axial load on the inclusion migration speeds

6-7. Migration velocities of all-liquid inclusion in $\mathrm{NaCl}$ and $\mathrm{KCl}$ single crystals as reported by Anthony and $\mathrm{Cl}$ ine, Geguzin et $\mathrm{a}$, and $\mathrm{Ba}$ looch and 01 ander $\ldots \ldots \ldots \ldots \ldots \ldots \ldots$

6-8. Variation of the migration velocity of four inclusions in $\mathrm{NaCl}$ with applied temperature gradient $\ldots \ldots \ldots \ldots \ldots \ldots$.

6-9. Variation of migration velocity of four inclusions in a natural salt crystal with the applied temperature gradient .....

6-10. Variation of migration velocity of four inclusions in a natural salt crystal with the applied temperature gradient....

6-11. Linear plot of $V$ versus $L \Delta / T$ l for an inclusion in a

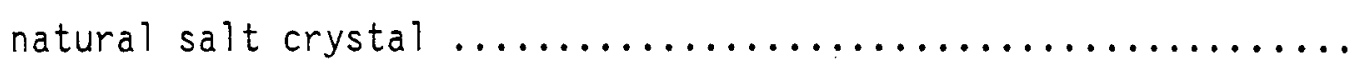

6-12. Effect of increasing applied axial load on the velocity of four inclusions in natural salt single crystal ..............

6-13. Migration velocity of air-water inclusions in $\mathrm{NaCl}$ single crystal as predicted by the approximate model of

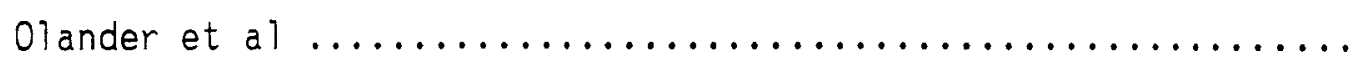

6-14. Comparison of three different gas phase inclusions in $\mathrm{NaCl}$

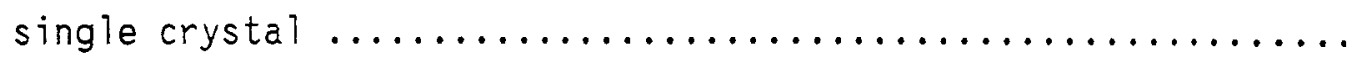




\section{LIST OF FIGURES}

(Continued)

6-15. Al1-1iquid inclusions at a large angle grain boundary

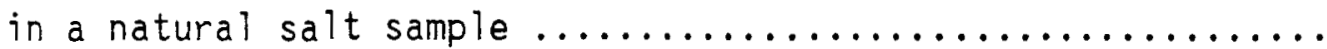

6-16. Gas-liquid inclusions at a large angle gra in boundary in natural salt sample

6-17. Two-dimensional motion of an all-liquid inclusion at and near a large angle grain boundary in natural salt sample supporting a temperature gradient...

A-1. Temperature gradient amplification factor in an all-liquid

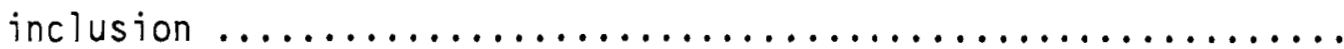

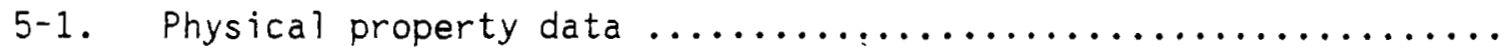

5-2. Stability parameters for inclusions in $\mathrm{NaCl}$ and $\mathrm{KCl} \ldots \ldots 6$

6-1. Interfacial parameters of $\mathrm{KCl}$ (self brine) $\ldots \ldots \ldots \ldots \ldots \ldots$ 


\section{EXECUTIVE SUMMARY}

Two types of inclusions in salt were investigated, namely gas-liquid and all-liquid. The latter moves up the temperature gradient, and the former moves downward. Certain phenomena are common to both inclusion types. First, heat is transported in a multiphase system. Second, salt is diffused in the liquid. Third, at the solid-liquid interface, processes of dissolution and crystallization may control the migration velocity. Finally, the stability of low-index crystal planes dictates the geometry of the cavity.

There are, however, basic differences between the two types of inclusions. In particular, shape changes from cubical in the absence of a temperature gradient to a flattened square platelet in the presence of temperature nonuniformities. This shape change is more marked in the all-liquid inclusions than in the two-phase inclusions.

The inclusions were trapped when the salt originally crystallized some 200 million years ago. Inclusions of various sizes and shapes occur in natural salt. Often the inclusions may contain a gas phase such as water, vapor $\mathrm{H}_{2} \mathrm{~S}, \mathrm{CH}_{4}$ or $\mathrm{N}_{2}$. This type of inclusions migrate down the temperature gradient. It is possible that the gas-liquid inclusions may act as a pathway for radionuclides leached from the wastes to the biosphere.

It is not certain whether gas-liquid inclusions exist at the high-pressure conditions of a subsurface salt repository. However, if an al1-1iquid inclusion migrates to a heat source such as a nuclear waste canister, it can be transformed into a gas-liquid inclusion and return down the temperature gradient. In so doing, it may pick up some radioactivity from a defective waste package. The process thus provides a means of dispersing radionuclides from the initial emplacement site. 
The mechanism of thermal gradient migration of gas-liquid inclusions was analyzed as follows. Water evaporates from the hot side of the gas bubble in the brine and is transported to the cold side where it condenses. The condensed water is recycled to the hot side by backflow of the brine, which provides the mechanism for moving salt from the cold face of the inclusion to the hot face. The inclusion thus moves in the opposite direction from the salt flow. The object of the analysis is to determine the velocity of the two-phase fluid inclusion in the thermal gradient imposed on the solid salt medium by the presence of the localized heat source due to the nuclear waste canister. The calculation combines the heat and mass transport pnenomenon in the solid-liquid-vapor phase system. Water transport occurs by molecular diffusion in the inert carrier gas trapped in the bubble. Heat is transported across the bubble by conduction in the gas and by the latent heat stored in the diffusing water. The necessity of supplying the latent heat for the water evaporation/diffusion/ condensation process is considered to be the rate-controlling step.

Two sets of data on the velocities of migration of gas-liquid inclusions exist. One set, in $\mathrm{KCl}$ reported by Anthony and $\mathrm{Cl}$ ine, was accompanied by a crude theory that arrived at the right speed by erroneous reasoning. The other set of data, in $\mathrm{NaCl}$, was obtained in this laboratory. In our gasliquid inclusion model, an analytical expression for the inclusion velocity was obtained with the simplifications: (1) approximating the cubical cavity in the solid as a spherical hole containing a central gas bubble and an annular shell of liquid; (2) neglecting interface kinetics and assuming the process to be diffusion-controlled; and (3) disregarding fluid motion generated by surface tension gradients at the gas-liquid interface. 
The theory predicts a change in the migration direction at a critical volume fraction of gas in the cavity. For gas fractions greater than this critical value, the theory gives somewhat greater velocities of migration down the temperature gradient than the available experimental data indicate. The effect of changing the fill gas from air to helium or argon is predicted theoretically.

The theory of all-1iquid inclusion migration appears to be in good shape insofar as basic understanding of the mechanism is concerned. The solubility of salt in the brine inclusion increases with temperature. Consequently, in the presence of a temperature gradient across the inclusion, salt dissolves into the inclusion at the hot surface and crystallizes out at the cold surface. Thermal and molecular diffusion of salt within the liquid phase from hot to the cold faces causes the inclusions to move in the opposite direction. The lower temperature coefficient of solubility and the larger interfacial kinetic resistance to dissolution for $\mathrm{NaCl}$ compared to that for $\mathrm{KCl}$ are responsible for the observed differences in the values of the migration velocities.

Implementation of the theory in quantitative fashion, however, is difficult because a physical model of the all-important interface kinetic resistance is lacking. Project accomplishments in this area have clarified the nature of this resistance. Experiments have demonstrated that the inclusion speed is controlled principally by rate of solid dissolution at the hot face of the inclusion. This process, in turn, depends upon the presence of dislocations intersecting the surface to provide the imperfections needed to permit dissolution to occur at small undersaturation of the adjacent liquid. If the hot face of the inclusion were flat on an atomic scale, removal of solid atoms from the perfect surface would be so energetically 
unfavorable that very large undersaturation would be needed to produce the required dissolution rates. A dislocation which intersects the dissolving surface provides sites at which the atoms of the solid are less tightly bound than in a perfect atomic plane, and hence their removal to the liquid phase is correspondingty easier. The following experiments support this interpretation:

1. If a single inclusion is followed for a long period of time, variations of its velocity by a factor of 4 are observed. This is attributed to the loss and gain of dislocations at the hot face. In the low-dislocation-density synthetic crystals used in the experiments, each inclusion face is on the average intersected by fewer than 3 dislocations. Consequently, loss or gain of one dislocation (for example) can alter the velocity by a substantial fraction.

2. When the mechanical load on the crystal is increased, additional dislocations are created; these interact with the inclusions, causing them to speed up. The effect is not elastic, because the high migration speeds persist when the crystal is unloaded.

3. Selected inclusions were subjected to various temperature gradients, but the average temperature was not changed. In a liquid diffusion controlled process or one with linear interface kinetics (e.g., Anthony and Cline's model), the velocity should be proportional to the temperature gradient. However, we found that the velocity varied as the temperature gradient raised to a power $>2$. A theoretical model explaining this observation is Burton, Cabrerra, and Frank's theory of crystal growth, which, when taken in reverse (i.e., to be able to model dissolution), predicts a dependence of the velocity on the square of the temperature gradient. 
The nature of the dislocation-controlled migration process is consistent with the low observed values and the very large scatter of the measured velocities of small inclusions in crystals of high perfection. Larger inclusions in natural crystals are not limited by the number of dislocation intersections at the dissolving face, and these inclusions appear to move at the rate predicted by liquid diffusion control.

Most all-liquid inclusions are shaped like square platelets with their boundaries conforming to $\{100\}$ planes of the host single crystal. It was observed experimentally that certain inclusions showed interface instabilities during migration. Such an instability caused breakdown of an inclusion into two or more smaller but stable inclusions. A perturbation method was used to analyze interface instability of brine-filled inclusions in alkali halide single crystals. Using the calculated temperature distribution in the inclusion, an approximate theoretical model for the response of a planar solid/solution interface from an arbitrary perturbation is developed. These results were then applied to the interfaces of a migrating inclusion. 


\section{CHAPTER 1}

\section{INTRODUCTION}

The method of disposing of high-level nuclear wastes which is being actively considered around the world is that of construction of a nuclear waste repository. Under this plan, the nuclear waste canisters will be lowered and buried deep underground in a suitable geologic medium. The basic philosophy of geologic disposal is to isolate the nuclear waste from the biosphere. The integrity of the waste canisters must be guaranteed for as long as the wastes remain toxic and hazardous (typically 1000 years).

In addition to the high levels of radioactivity, the wastes generate decay heat. When such wastes are buried, they impose a temperature gradient on the surrounding geologic rock. The waste canisters must be designed to maintain their integrity under the conditions of stress, irradiation, temperature, and temperature gradient which will exist in a future nuclear repository. All significant physical and chemical interactions between the host rock and the waste packages must be considered.

The selection of the geologic medium depends on the seismicity and ground water occurrence. The host rock should exhibit low porosity, low plasticity and high thermal conductivity [1]. Bedded and domed natural salt deposits meet most of these requirements and are the prime candidates for future nuclear waste repository.

The salt deposits, however, contain brine inclusions distributed throughout the medium [2]. The inclusions were trapped when salt deposits originally crystallized from sea water some 200 million years 
ago. These inclusions will be mobilized by the thermal gradient generated by the decay heat of the nuclear wastes buried in a salt repository. There may be other mechanisms of brine mobility. However, this study concentrates on thermal-gradient-induced mobility including the effects of applied stresses on migration rates.

The inclusions are essentially pockets of brine trapped inside the solid rock salt. They are found in the size range of a few micrometers to several millimeters $[2,3]$. In one study [3] of samples of bedded salt from New Mexico, the average fluid content varied from 0.1 to 1.7 weight percent (roughly 0.2 to 3.0 volume percent). The fluid content in domed salt deposits is found to be generally lower than bedded salt deposits, usually in the range of 0.01 to 0.001 volume percent [4].

The composition of the brine in inclusions is found to vary from one salt deposit to the other. Most analyses show that the brines contain $\mathrm{Ca}^{++}$and $\mathrm{Mg}^{++}$ions in addition to varying amounts of $\mathrm{Na}^{+}, \mathrm{Cl}^{-}$, and $\mathrm{SO}_{4}^{--}[2]$. Samples of brine inclusions in the bedded salt at Hutchinson, Kansas were found to contain 2.1 molar $\mathrm{MgCl}_{2}$ and 1.9 molar $\mathrm{NaCl}$, with small amounts [5] of $\mathrm{Ca}^{++}, \mathrm{Br}^{-}, \mathrm{SO}_{4}^{--}$, and $\mathrm{K}^{+}$.

Most inclusions observed in natural salt are filled completely with brine (the all-liquid inclusions). Occasionally, however, a gas phase is also present within the brine. This may have resulted from the reappearance of dissolved gases upon cooling of the Earth's crust since the salt deposits originally formed. It is also speculated [6] that the gas phase may have appeared in the inclusions due to decomposition of mineral impurities such as carbonates in the rock salt. The gas in these inclusions is generally composed of water vapor, $\mathrm{CO}_{2}, \mathrm{CH}_{4}, \mathrm{~N}_{2}$, and $\mathrm{H}_{2} \mathrm{~S}$. 
Under an imposed thermal gradient, both the types of inclusions are set into motion within the host solid. While all-liquid inclusions move up the temperature gradient, the gas-liquid inclusions generally move down the gradient.

The motion of brine inclusions under a thermal gradient naturally raises concern about suitability of salt deposits for a nuclear waste repository. The all-1iquid inclusions distributed throughout the salt formation will migrate towards the waste canisters under the influence of the temperature gradient generated by the decay heat of the wastes. Resulting accumulation of brine near the canisters may cause corrosion and leaching of radionuclides. Since gas-liquid inclusions move down the temperature gradient, it is conceivable that they could act as a pathway for the leached nuclides to the biosphere. Therefore, it is important to consider the migration of each kind of inclusion to properly evaluate performance of future nuclear repository in salt.

Thermomigration of brine inclusions was studied in high-purity synthetic single crystals of $\mathrm{NaCl}$ and $\mathrm{KCl}$ as well as in natural salt. Gas-liquid inclusions with different gas phases were introduced into single crystals of $\mathrm{NaCl}$ and migration experiments were subsequently conducted on them.

The mechanism of migration of both types of inclusions is discussed in Chapter 2. The experimental techniques used in this work are described in Chapter 3. Chapter 4 contains the theory of thermomigration of al1-liquid inclusions. The interfacial stability of the migrating 
a)l-liquid inclusions is treated theoretically in Chapter 5. In Chapter 6 experimental results are discussed. Finally, in Chapter 7 the conclusions of this work are given. 
CHAPTER 2

THE MECHANISM OF THERMOMIGRATION

When an external potential gradient is applied to matter containing inclusions, a directed motion of these inclusions is to be expected. Such motion in a variety of potential gradients is of great academic interest and has many technological consequences. Under the influence of a temperature gradient, pores in ceramic nuclear fuels move up the gradient and affect the fuel element performance [7]. Inclusions in metals can be set into motion by the application of an external electric field [8]. Experimental evidence and theoretical treatments of the inclusion migration under other potential gradients such as accelerational fields and stress gradients are also summarized in reference [8].

A review of the mechanism of thermal gradient migration of allliquid and gas-liquid inclusions in single crystals of alkali halides such as $\mathrm{NaCl}$ and $\mathrm{KCl}$ is presented below.

\subsection{ALL-LIQUID INCLUSIONS}

An inclusions can be viewed as a negative crystal of the host solid. Since alkali halides such as $\mathrm{NaCl}$ and $\mathrm{KCl}$ have a cubic crystal structure, the inclusions originally exhibit cubic shape. However, when an external temperature gradient is applied to the host crystal, the inclusions undergo a shape change. Most all-liquid inclusions take up a square platelet shape by flattening out in the direction of the applied gradient. The shape change process is thermodynamically analysed by 01 ander and coworkers [9]. 
The mechanism responsible for migration of all-liquid inclusions is discussed in literature by Anthony and $\mathrm{Cl}$ ine [10] and Geguzin and coworkers [11]. Figure 2-1 shows an al1-1iquid inclusion of width $L$ in a salt crystal supporting a temperature gradient. Since the thermal conductivity of the solid is higher than that of liquid brine, the temperature gradient within the liquid, $\nabla T_{\ell}$, is different from the applied gradient to the solid, $\nabla T_{\infty}{ }^{\cdot}$. The solubility of salt in water increases with temperature; therefore, the brine adjacent to the hot face of the inclusion has a higher concentration of dissolved salt than the brine adjacent to the cold face (i.e., $c_{h}^{\text {sat }}>c_{c}^{\text {sat }}$ ).

All-liquid inclusions migrate by the diffusional transport of dissolved salt from the hot face of the cavity to the cold face. In a temperature gradient, salt dissolves at the hot face, diffuses through the brine by molecular and thermal diffusion, and crystallizes out at the cold face. Consequently, the inclusion moves up the temperature gradient.

It should be noted that the interfacial mass transfer (i.e., the processes of solid dissolution into brine at the hot face and crystallization from the brine at the cold face) occurs in series with the thermal and molecular diffusion in brine. The kinetics of interfacial mass transfer is an important factor which, in addition to the diffusional transport of salt in the cavity, determines the velocity of migration of an inclusion. This will be discussed further in Chapter 4. 


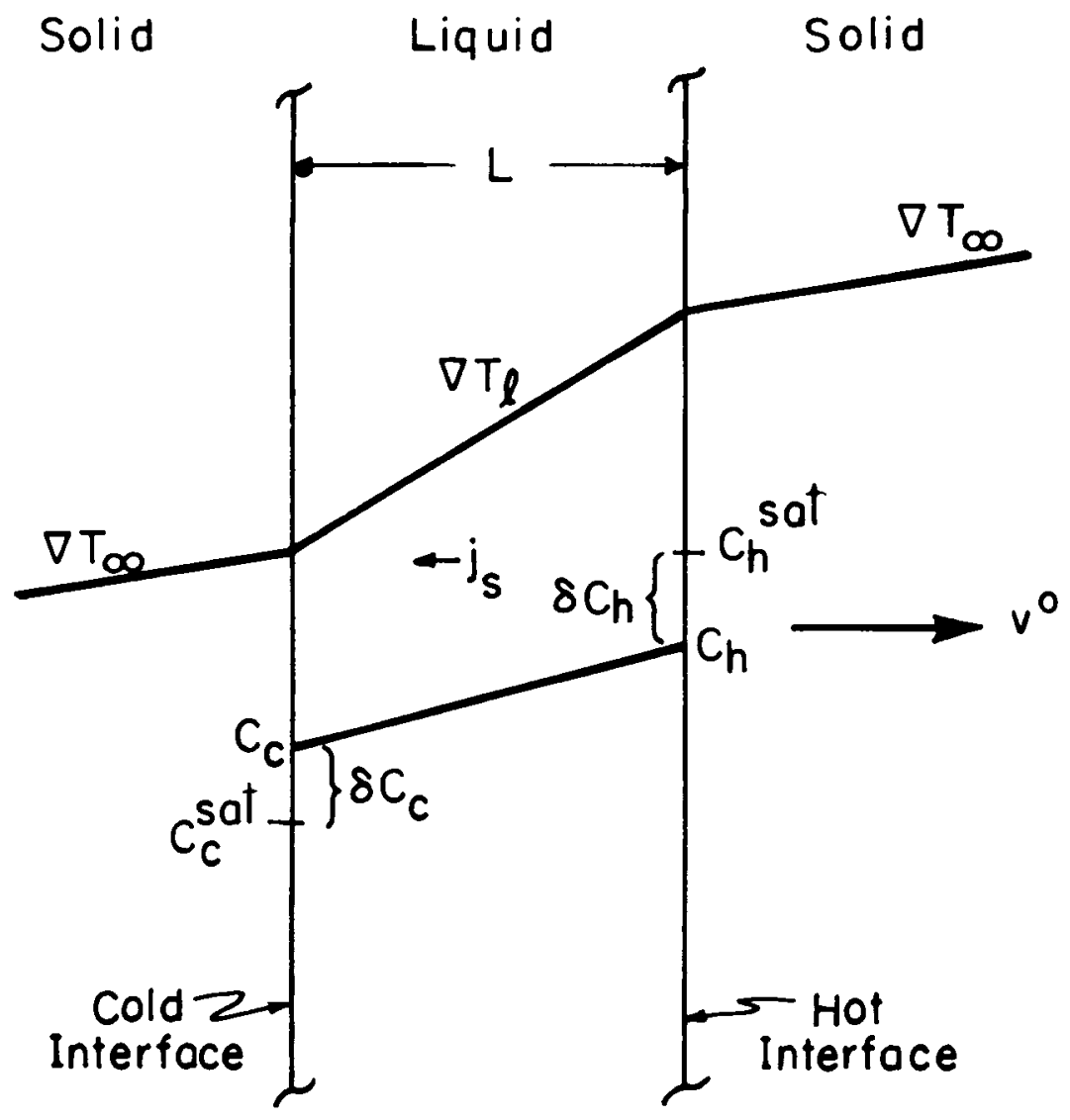

XBL 827-6057

Figure 2-1. Section of an all-1iquid inclusion in a solid supporting a temperature gradient. 


\subsection{GAS-LIQUID INCLUSIONS}

Gas-liquid inclusions are generally cubic in shape with the gas bubble with in the brine (Figure 2-2). However, gas-liquid inclusions of several different shapes were observed in the present work, and the bubble is generally not centrally located during migration.

The mechanism of thermomigration of these inclusions is reported by Anthony and Cline [12] and 01ander and coworkers [13]. Due to the increase in vapor pressure of water over brine with temperature, water evaporates from the hot side of the gas bubble and is transported to the cold side where it condenses. The condensed water is recycled to the hot side by backflow of brine which provides a means of moving dissolved salt from the cold face of the inclusion to the hot face. The change in temperature also causes a difference in the surface tension of the gas/brine interface. This results in a drag force on the brine in the annulus around the gas bubble.

of course, the physical phenomenon of increase in solubility of salt with temperature, which gives rise to a diffusional transport of the brine from the hot brine/solid interface to the cold brine/solid interface, also operates here and results in a dissolved salt flux in the direction opposite to the backflow. However, depending on the phase volume ratio, the backflow effect overwhelms the solubilitydriven salt flux and the net transport of dissolved salt is from the cold side of the cavity to the hot side. Consequently, for gas volume fractions $>0.1$, gas-liquid inclusions move down the temperature gradient -- from the hot regions of the host solid crystal to the cold regions. 


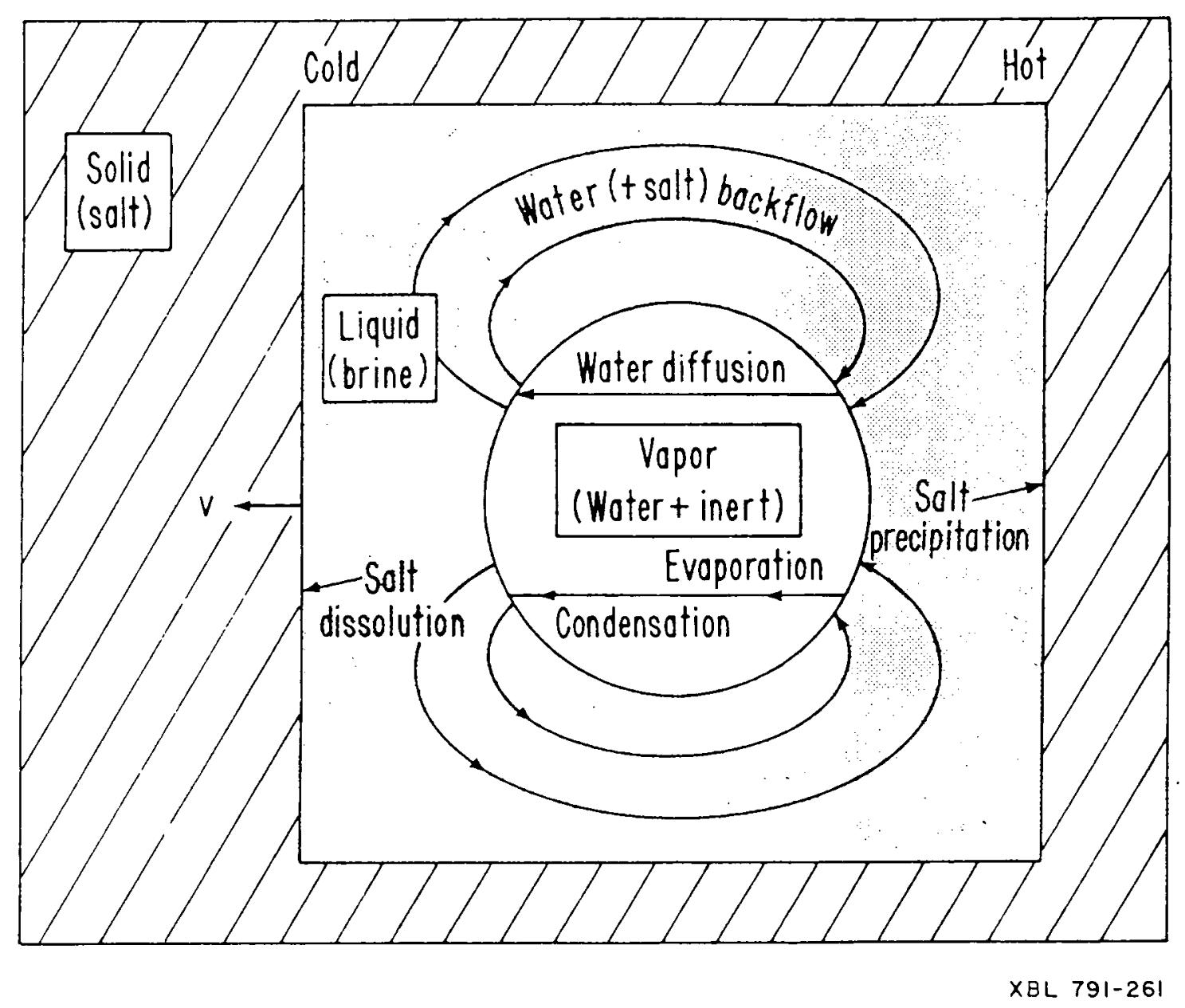

Figure 2-2. Schematic of the migration mechanisms of gas-1iquid inclusions in a temperature gradient. 
CHAPTER 3

\section{EXPERIMENTAL PROCEDURE}

\subsection{SAMPLE PREPARATION}

\subsubsection{Synthetic Crystals}

High purity crystals of $\mathrm{NaCl}$ and $\mathrm{KCl}$ of $15 \mathrm{~mm} \times 5 \mathrm{~mm} \times 5 \mathrm{~mm}$ size with $\langle 100\rangle,\langle 110\rangle$, and $\langle 111\rangle$ crystallographic orientation were obtained from the Harshaw Chemical Company.

All-liquid inclusions are produced by drilling a $0.3 \mathrm{~mm}$ diameter and $3 \mathrm{~mm}$ deep hole in an end face of the crystal. The hole is filled with deionized water (or mixed brine, as the case may be), and the crystal is sandwiched with a rubber sheet and placed between two copper blocks maintained at different temperatures. The rubber sheet prevents evaporation of the liquid in the hole. By applying a temperature gradient of about $10^{\circ}$ to $30^{\circ} \mathrm{C} / \mathrm{cm}$ for five to fifteen days, a 11-liquid inclusions with a size distribution ranging from 7 to $200 \mu \mathrm{m}$ can be produced. Because the inclusions conform to $\{100\}$ planes, they are parallelepipeds when a temperature gradient is applied along a $\langle 100\rangle$ direction. When the temperature gradient is applied in a different crystallographic direction, the shapes of the inclusions is more complex (chevron type), but the velocities are not significantly different from those in $\langle 100\rangle$ directions for the same temperature gradient.

Gas-liquid inclusions are produced by essentially the same method but the direction of the applied temperature gradient used to create micron-size inclusions from the liquid-filled hole is reversed. In 
other words, the end face of the crystal which is drilled and filled with deionized water is kept at a nigher temperature from the other end face. The water and air trapped inside the drilled hole spawn gas-liquid inclusions (with air as the gas phase) in about two weeks time.

Figure 3-1 shows several inclusions of both kinds. The all-liquid inclusions are transparent platelets whereas gas-liquid inclusions are of several different shapes with a bubble of gas trapped in brine within a roughly cubic cavity.

Fabricating gas-liquid inclusions with helium or argon as the gas phase was more complex. For this purpose, an air-tight glove box was constructed through which high purity gas (helium or argon) was flushed. The glove box was equipped with a hot stage capable of applying a temperature gradient to the crystal into which the inclusions were to be introduced. A vial of deionized water, the drilled crystal, several drill bits (of the same size as the hole) were also placed inside the glove box before the gas flushing began. Initially during the gas flushing, the drilled hole on the crystal end face was scraped several times with the drill bits at regular intervals to ensure removal of the air from the hole. Since the crystal was drilled outside the glove box, the hole is likely to have some trapped air.

After about two days, a drop of deionized water was pushed into the hole on the crystal end face. The hole was sealed to prevent evaporation of the water and placed in a temperature gradient using the hot stage. The crystal was then allowed to stand the temperature 


\section{ALL LIQUID $\longrightarrow$}

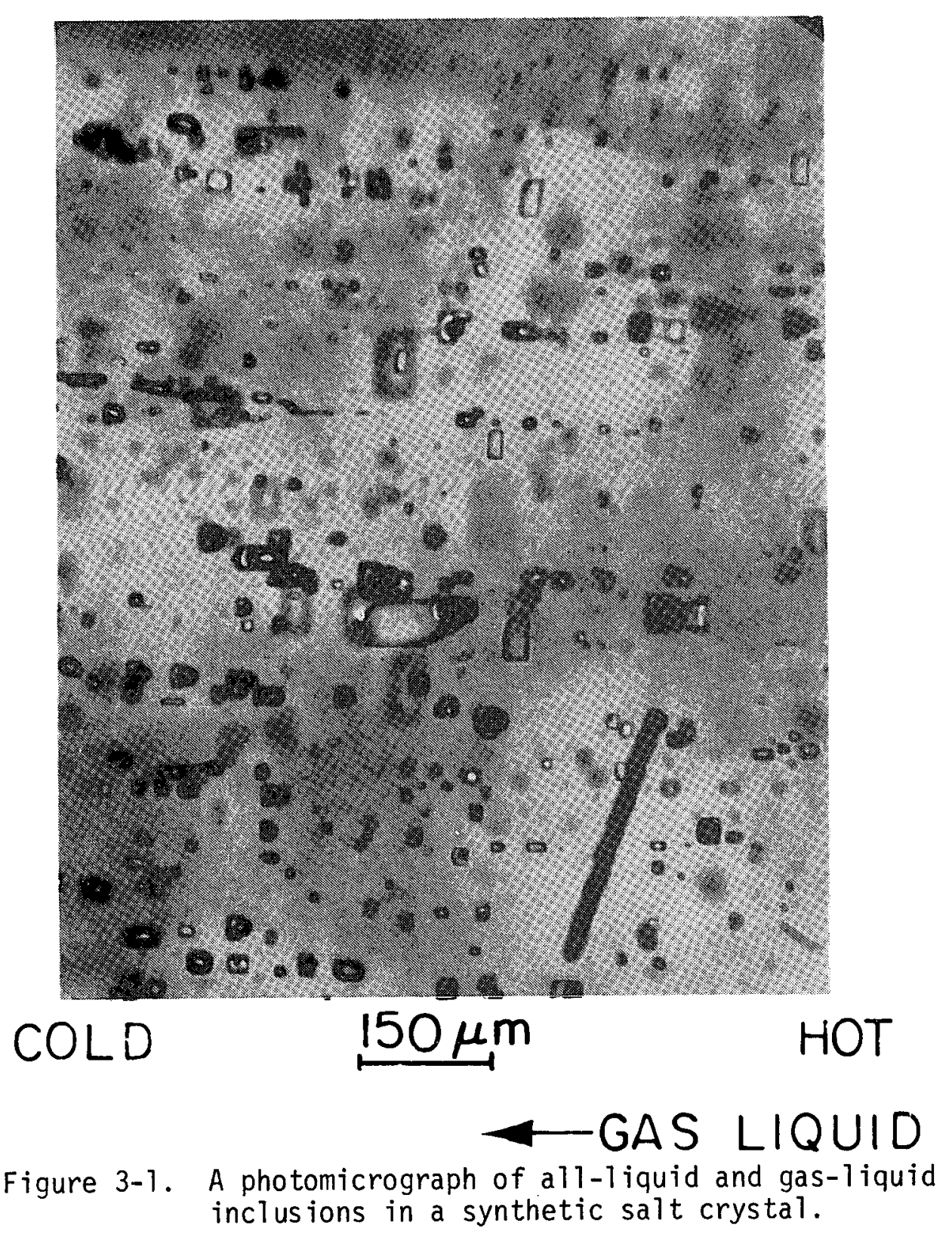


gradient with continuous flushing of the gas. As before, in about two weeks time, the crystal had several trapped gas-liquid inclusions.

\subsubsection{Natural Salt}

Several large semi-transparent specimens of natural salt, taken from a depth of 796 feet from the Richton Dome, were tested. Unlike metals, the grains of natural salt are weakly bound and the specimen could easily be broken into smaller pieces by shearing. Careful procedures had to be used to machine the specimens to the desired sample size $(15 \mathrm{~mm} \times 5 \mathrm{~mm} \times 5 \mathrm{~mm})$. To enhance transparency, the surfaces of the machined samples were cleaned with a mixture of distilled water and absolute ethyl alcohol using cotton swabs. Finally, allliquid inclusions were produced by the same method as described before. occasionally, naturally occurring brine inclusions were also found in these samples.

Natural salt samples so prepared were essentially single crystallites of rock salt (halite). These samples were expected to have far higher impurity levels than the synthetic single crystals. Due to the inherent weakness of the grain boundaries, it was difficult to machine a polycrystalline sample of natural salt. Also, typical grain size in the original salt specimen was about $1 \mathrm{~cm}$, almost comparable to the desired sample size. Only a limited number of such samples could be prepared, and these contained only one or two large-angle grain boundaries. 


\subsection{OPTICAL HOT STAGE}

\subsubsection{Description}

The experimental setup used to study the migration process of brine inclusions in salt crystals is shown in Figure 3-2. It consists of a transmitted light Nikon Optiphot microscope equipped with a hot stage attachment, a Tiyoda filar eyepiece with goniometer, and four objective lenses with magnifications of $40,100,200$, and 320 .

The hot-stage attachment consists of two rectangular copper blocks ( $A$ and $B$ ) fixed on insulator plate $C$. The entire assembly can be moved in three principal directions with respect to the objective lens/condenser system. The copper blocks are heated by clamshell electric heaters ( $D$ and $E$ ) and insulated with $1 / 4$ inch thick Rulon except for small portions at the ends. The salt crystal $F$ is held between the block end faces which have been polished and gold-plated to promote good thermal contact.

The hot-stage attachment maintains the temperature profile in the salt crystal while applying a constant uniaxial stress. The copper block temperatures, measured by Omega platinum resistance temperature detector elements, are held within $20.5^{\circ} \mathrm{C}$ of the preset value by regulating the power to the clamshell heaters by Barber Coleman process controllers. An independent check of the temperatures close to the crystal end faces is made by the means of the thermocouples T1 and T2 in Figure 3-2.

Block $B$ is actually a hollow shell with two sliding copper pieces $G$ and $H$, the movement of which are controlled by knob I. A Sensotec 


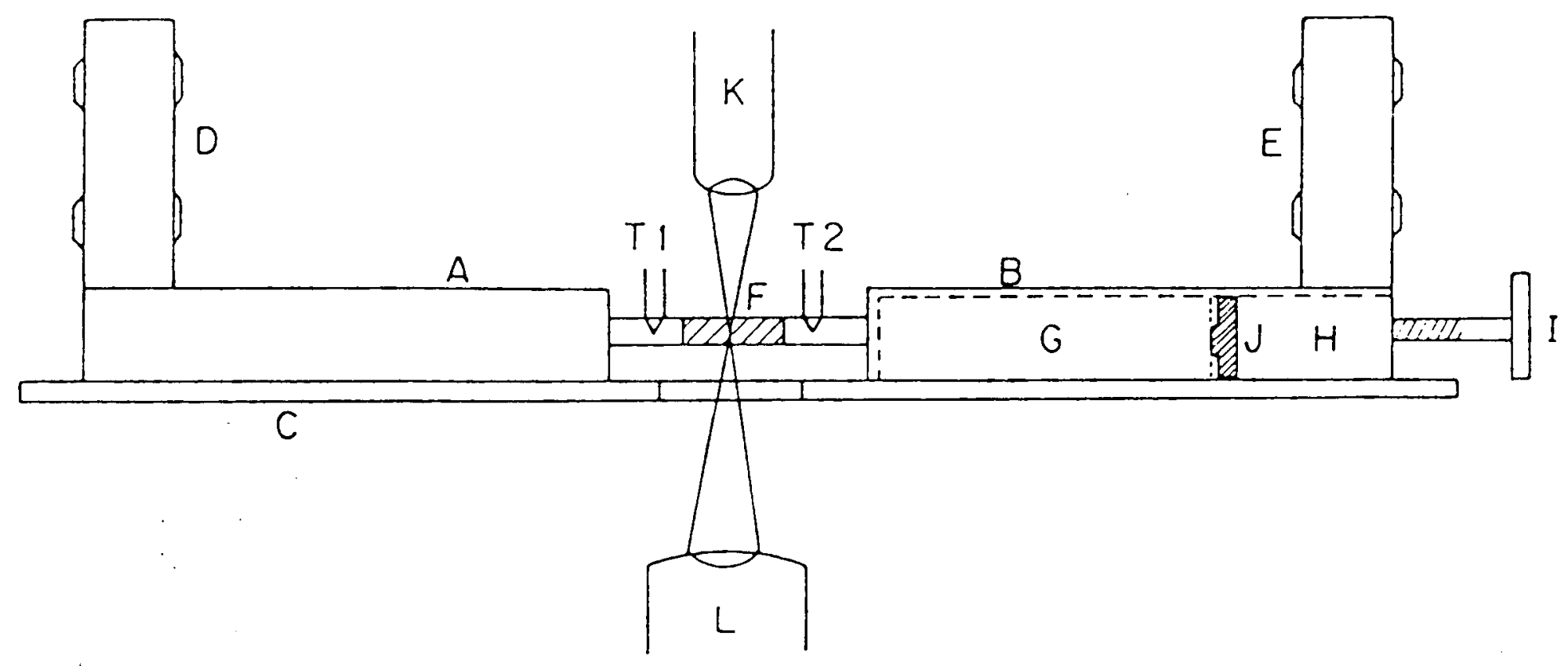

A, B Copper electrodes

$C$ Insulator.plate

$D, E$ Clam-shell heaters

F Crystal

G, H Inner copper blocks
I Knob to control lood

J Lood-cell

$K$ Microscope objective lens

$L$ Microscope condenser

T1, T2 Thermocouples

Figure 3-2. Microscopic hot-state attachment 
miniature load cell $\mathrm{J}$ is placed between $\mathrm{G}$ and $H$. The axial load on the crystal is measured by the load cell with its compatible Sensotec amplifier-transducer.

\subsubsection{Temperature Profile in the Crystal}

The controllers described in Section 3.2.1 control the temperatures at the tip of the copper blocks between which the crystal is held. Thermocouples $\mathrm{T} 1$ and $\mathrm{T} 2$ give an independent measure of these temperatures. However, the exact temperature profile in the crystal determines the thermal environment of the inclusions which are located at different positions in the crystal.

Figure 3-3 shows the result of computation of this profile for a $\mathrm{NaCl}$ crystal under various lateral face conditions when the end faces of the crystal are maintained at $35^{\circ} \mathrm{C}$ and $105^{\circ} \mathrm{C}$, respectively. The figure shows that the maximum difference between the linear profile 1 and profile 4 (where all lateral faces of the crystal are assumed to be cooled by ambient air and heat is also lost by radiation), is about $5^{\circ} \mathrm{C}$. This is a difference of about 7 percent at the temperature of $70^{\circ} \mathrm{C}$ at the center of the crystal. On the other hand, if the crystal is properly insulated from all sides (profile 2), the difference is about 3 percent.

This calculation was tested by measuring the profiles along a $\mathrm{NaCl}$ single crystal subjected to a temperature gradient. As shown in Figure 3-4, three holes were drilled in the crystal, and Chromel-Alumel thermocouples were inserted using conducting epoxy. The factory-made thermocouples were of fine size (AWG 30, wire diameter $0.025 \mathrm{~cm}$ ), and the 


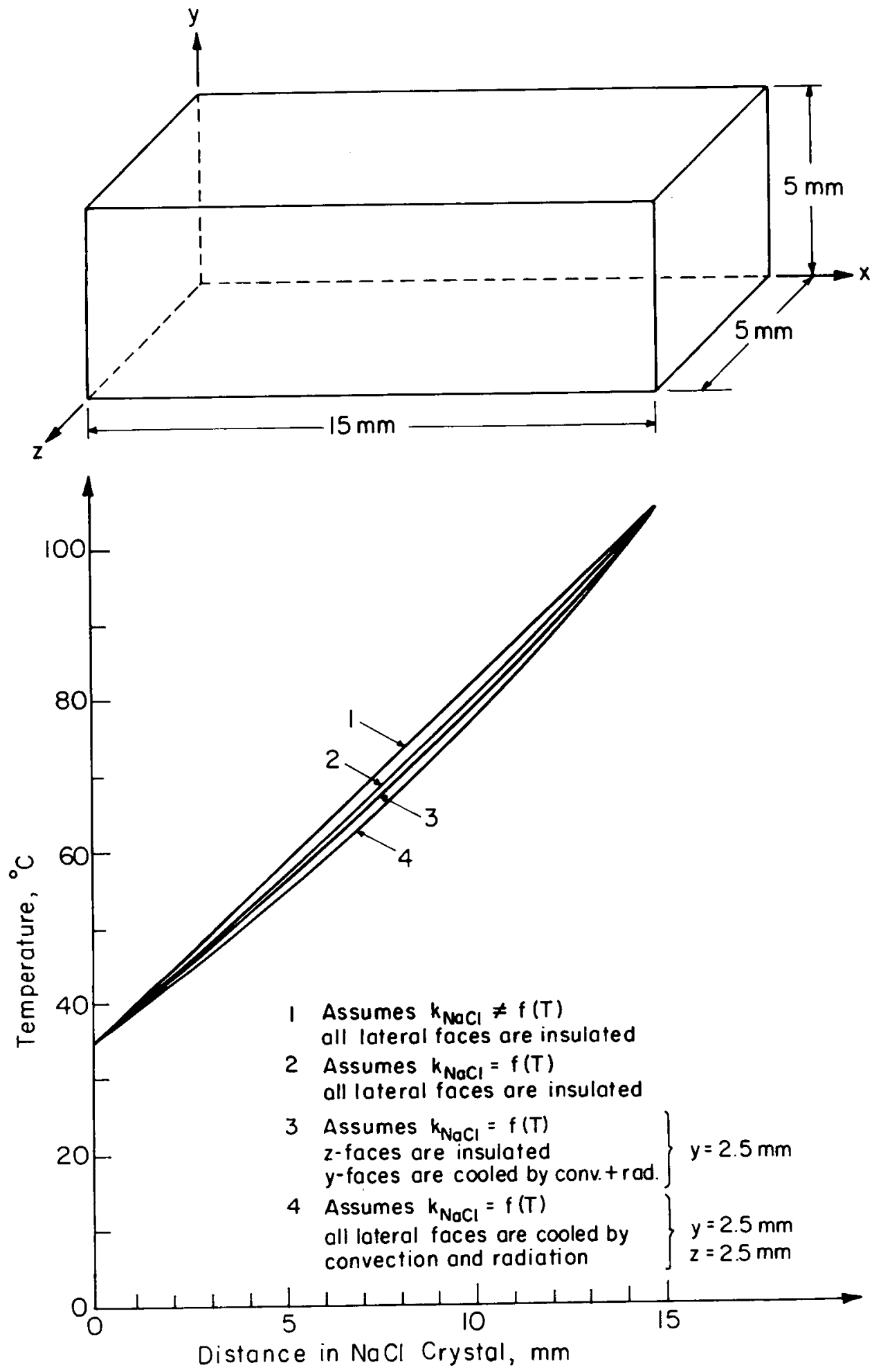

X8L $827-6058$

Figure 3-3. Temperature profiles in the salt crystal computed under different conditions. 

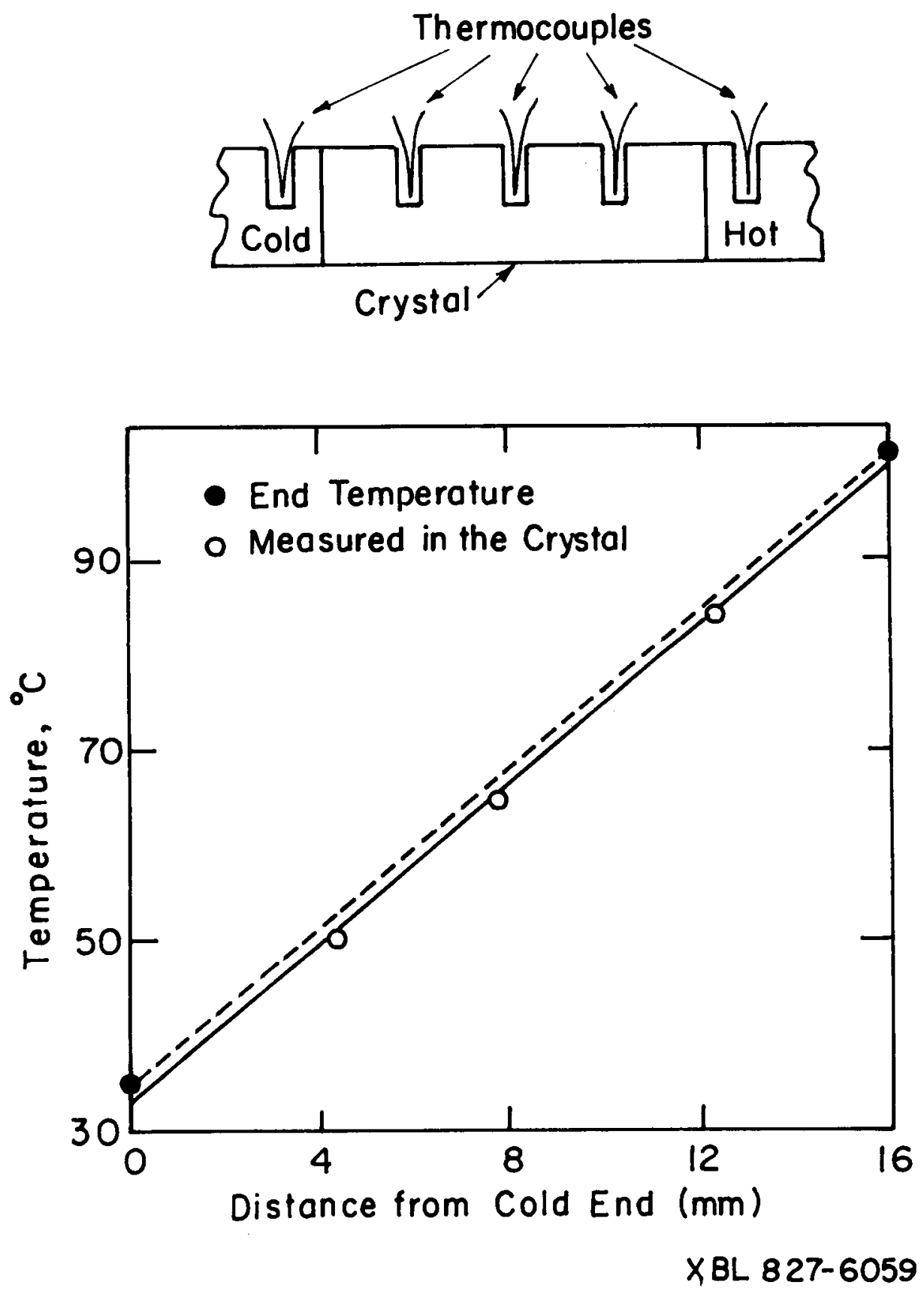

Figure 3-4. Temperature profile measurements in a $\mathrm{NaCl}$ single crystal. 
uniformity of the "bead" or junction assured precise temperature measurements. The measured temperature profile was found to be in excellent agreement with the expected profile 1 as shown in Figure 3-4. No change in the temperature profile was observed when the applied axial load on the crystal was varied over a large range.

Substantiated by the computation and the measurements, the temperature profile in the crystal was assumed to vary linearly along the crystal axis.

\subsubsection{Migration Velocity Measurements}

A typical observation consists of measuring the inclusion size (thickness $L$ in the direction of the temperature graduation and width $W$ in the transverse direction) and the distance travelled during the time between two successive observations, typically separated by several hours. With the microscopic attachment described previously, these quantities can be measured with an accuracy of $\pm 1 \mu \mathrm{m}$. All side faces of the crystal were kept insulated between measurements. The global temperature of an inclusion at a particular location was obtained by linear interpolation of the crystal end face temperatures.

\subsection{DISLOCATION DENSITY IN THE CRYSTAL}

The applied axial stress essentially alters the dislocation density in the crystal, which can alter the brine/solid interfacial resistance. Therefore, it was important to estimate this parameter.

There are several standard methods of determining dislocation density in alkali halide crystals. Due to its simplicity and speed, the method of developing etch pits on the surface of the crystal, described 
in Ref. [14], was adopted. This method involves treating the surface with selected chemicals etchants. The etched surface develops pits representing emerging dislocations. The etch pits so formed can be observed under an optical microscope. The etch pit technique consists of three basic steps, polishing, etching and rinsing. These are described in detail below.

\subsubsection{Polishing}

The crystal surface is polished chemically to remove scratches and spots present on the as received crystals to provide a smooth surface for etching. For $\mathrm{NaCl}$ and $\mathrm{KCl}$ crystals, a 50 percent mixture of deionized water and absolute ethyl alcohol gives good results. This mixture is gently applied to the surface using a cotton tip. The surface is dried in a stream of warm air.

\subsubsection{Etching}

The etchant contains a concentration of "poison" (usually an inorganic salt) dissolved in a solvent (usualiy organic). Precise control of poison concentration and etching time (which usually ranges from one second to a couple of minutes) is extremely important. The etchant is applied to the surface by cotton tips or by gently dipping the crystal in a small amount of etchant placed on a petri dish.

For $\mathrm{NaCl}\{100\}$ surfaces, the best results are obtained with a 4 $\mathrm{gm} / 1$ solution of $\mathrm{FeCl}_{3}$ in glacial acetic acid with etching time of 30 seconds [15]. For $K C l\{100\}$ surfaces, a 25 percent solution of $\mathrm{BaBr}_{2}$ in absolute ethyl alcohol gives good results with etching time of about 30 seconds [16]. 


\subsubsection{Rinsing}

The etching process is terminated by rinsing the surface with carbon tetrachloride or acetone. The rinsed surface is quickly dried in a stream of warm air.

Figure 3-5 shows etch pits on a $\mathrm{NaCl}(100)$ surface. Each square pit represents an emerging dislocation. The dislocation density is determined by counting the pits on a photomicrograph. A typical $\mathrm{NaCl}$ crystal used in this investigation contains about $10^{5}$ dislocations $/ \mathrm{cm}^{3}$.

The etch pit method is very sensitive to the parameters which are sometimes difficult to control (e.g., etching time of the order of a few seconds). Moreover, the dislocations are usually not uniformly distributed but tend to form clusters. Therefore, the results are not always quantitatively conclusive. 


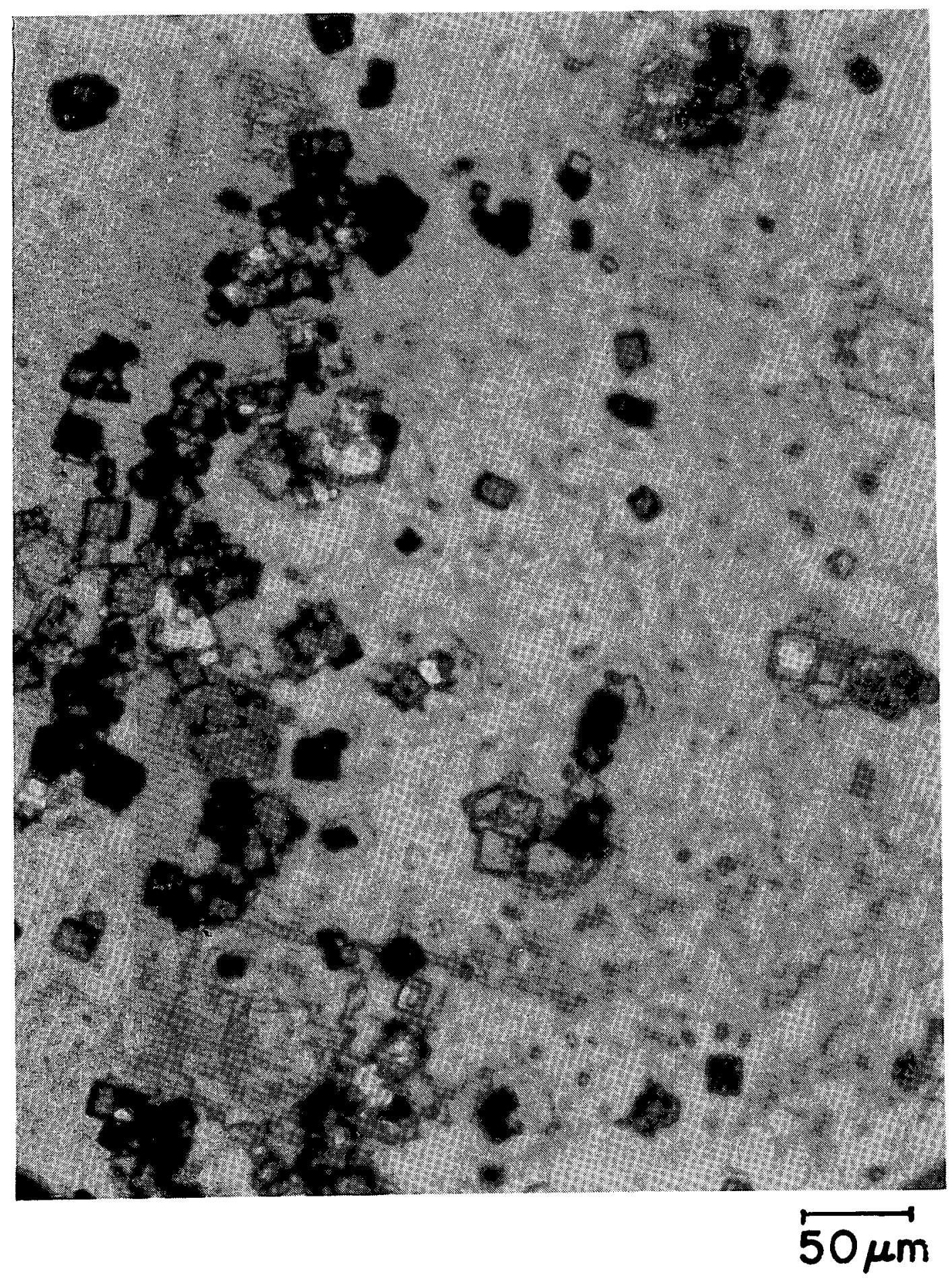

Figure 3-5. Dislocation etch pits on the $\mathrm{NaCl}(100)$ surface. 
CHAPTER 4

THEORY OF THERMOMIGRATION

\subsection{ALL-LIQUID INCLUSIONS}

\subsubsection{Inclusion Velocity}

In the section of an al1-liquid inclusion shown in Figure 2-1, the symbols $C_{h}^{\text {sat }}$ and $C_{C}^{\text {sat }}$ denote the equilibrium solubilities at the hot and the cold side of the inclusion respectively. Salt transport from the hot to the cold face of the inclusion proceeds through a three-step series mechansim: (1) dissolution at the hot face, (2) molecular and thermal diffusion through the liquid, and (3) crystallization at the cold face.

Supersaturation is required for crystallization to take place and undersaturation is required for dissolution. Both types of departures from interfacial equilibrium are present in a migrating all-liquid inclusion. In Figure 2-1, therefore, $c_{h}^{\text {sat }}>c_{h}$ and $c_{c}^{\text {sat }}<c_{c}$ where the subscripts $h$ and $c$ refer to the hot and the cold interfaces, respectively, and the superscript "sat" refers to saturation conditions. The difference $C_{h}-C_{C}$ within the liquid brine drives the diffusional transport step. Since the solid is a better conductor of heat than the brine, the temperature gradient across the inciusion $\nabla T_{\ell}$ is always larger than the applied temperature gradient to the solid, $\nabla T_{\infty}$. The temperature distribution in an a 11-liquid inclusion is derived in Appendix A.

Because the temperature difference across the inclusion is very small $\left(\sim 0.1^{\circ} \mathrm{C}\right)$, the difference in solubilities at the hot and the cold face can be approximated by 


$$
C_{h}^{\text {sat }}-C_{c}^{\text {sat }}=\frac{d C^{\text {sat }}}{d T} L^{2} T_{\ell}
$$

Let the salt flux in each of the three steps previously described be $j_{s}$, then the inclusion velocity $v$ is

$$
v=\frac{j_{s}}{p_{s}}
$$

where $\rho_{S}$ is the molar density of the solid.

The molecular and thermal diffusional transport in the liquid can be accurately represented by the following equation for the salt flux

$$
j_{s}=\frac{D_{\ell}}{L}\left(C_{h}-C_{C}\right)-\sigma D_{\ell} C^{s a t} T_{\ell}
$$

where $D_{\ell}$ is the diffusivity of the salt in water, $\sigma$ is the Soret coefficient, which is taken to be negative when solute moves towards the cold end (this is the case for $\mathrm{NaCl}$ and $\mathrm{KCl}$ ). The fractional undersaturation of the solution at the hot face is defined by

$$
\xi_{h}=\frac{c_{h}^{\text {sat }}-C_{h}}{c_{h}^{\text {sat }}}
$$

and the fractional supersaturation at the cold face is

$$
\xi_{c}=\frac{c_{c}-c_{c}^{s a t}}{c_{c}^{s a t}}
$$

Combining Eqs. (4-1), (4-3), and (4-4) yields

$$
j_{s}=D_{\ell} C^{s a t}\left[\left(\frac{1}{c a t} \frac{d c^{s a t}}{d T}-\sigma\right) \nabla T_{l}-\frac{\xi_{C}+\xi_{h}}{L}\right]
$$

The sum $\xi_{C}+\xi_{h}$ in Eq. (4-5) represents a reduction in the salt flux due to the kinetics of dissolution and crystallization. If interfacial processes do not pose any resistance (by way of requiring undersaturation or supersaturation), $\xi_{C}+\xi_{h} \simeq 0$, and combination 
of Eqs. (4-1) and (4-5) yields the purely diffusion-controlled inclusion speed

$$
v=\frac{D_{\ell} c^{\text {sat }}}{\rho_{S}}\left(\frac{1}{c^{\text {sat }}} \frac{d C^{\text {sat }}}{d T}-\sigma\right) \nabla T_{\ell}
$$

As first recognized by Anthony and Cline ([10], [17]), this limiting case is not applicable to a salt-water system. In their treatment $\operatorname{RT}\left(\xi_{C}+\xi_{h}\right)$ was called "kinetic potential". It was found by them to be dependent on inclusion speed, or equivalently, on the salt flux.

\subsubsection{Crystal Growth/Dissolution Principles}

As evident from Eq. (4-5), the interfacial kinetic processes can contribute substantially to the migration velocity of the inclusion. A brief review of the basic principles and theories of crystal growth/ dissolution is appropriate at this point.

Growth occurs when a solute crystal is placed in contact with its supersaturated solution. Conversely, for crystal dissolution to occur, the solid must be in contact with an undersaturated solution. Both the processes are essentially interfacial in nature and involve incorporation into or detachment from the solid of the molecules or atoms of the dissolved solute.

\subsubsection{Nucleation Growth Theory}

The simplest model of crystal growth is that of a perfectly flat solid surface in contact with a supersaturated solution. The solute molecules adsorb onto the crystal surface and tend to form clusters or nuclei of the solute. Thermodynamically, there exists a critical size below which the nuclei will simply redissolve into the solution. 
Occassionally, purely by chance, a nucleus of the critical size is formed, which instantly grows into a new layer of the solid. Successive layers are similarly formed and the crystal grows in the direction normal to the surface.

The radius of the critical sized nucleus, $r_{c}$, on a perfectly flat crystal surface is thermodynamically given by [18]

$$
r_{c}=\frac{r V_{m}}{k \ln (1+\xi)}
$$

where $\gamma$ is the interfacial energy, $V_{m}$ is the volume of a solid molecule, $k$ is the Boltzmann Constant, $T$ is the temperature and $\xi$ is the dimensionless supersaturation defined, in terms of actual solute concentration $C$ and saturation concentration $c^{\text {sat }}$, as follows

$$
\xi=\frac{c-c^{s a t}}{c^{s a t}}
$$

As evident from Eq. (4-7) the requirement of forming a criticalsized nucleus for growth is equivalent to requirement of a critical supersaturation below which no growth occurs. Similarly there should be a critical undersaturation for dissolution to begin.

\subsubsection{Surface Diffusion Growth Theory}

If crystal growth were to take place on a perfectly flat surface by nucleation of critical-sized nuclei, extremely small growth rates are predicted [19]. Calculations show that the nucleation rates in such a case are very small compared to experimentally observed growth rates [19]. The explanation for the discrepancy lies in the imperfect nature of crystal surface. The surface of a real crystal is far from being perfectly flat. As shown in Figure 4-1, it is populated by kinks 


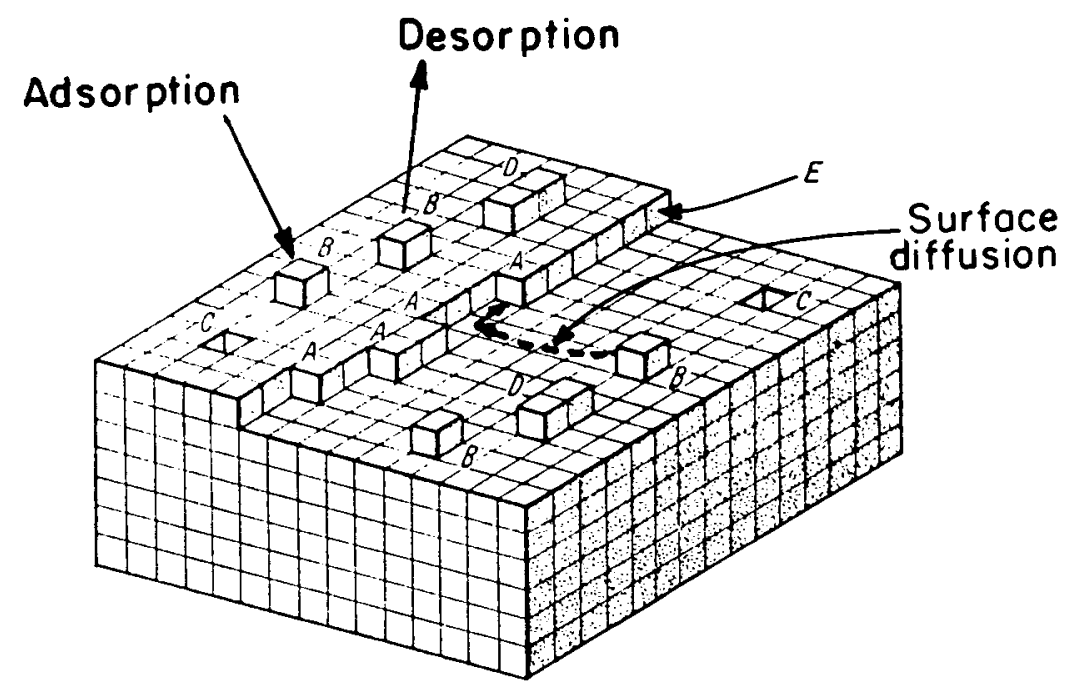

$X B L 827-6183$

Figure 4-1. (100) Surface of a crystal with single cubic lattice: $A$, kinks in the ledge; $B$, adsorbed molecule; $C$, vacancies; D, adjacent pair of adsorbed molecules; $E$, straight ledge (Ref. [19]). 
$(A)$, ledges or steps (E), vacancies (C), and adsorbed molecules ( $B$ and D). The solute molecules constantly adsorb on and desorb from the growing surface. Adsorbed molecules are not tightly bound to the crystal surface and tends to desorb rather quickly. However, kinks have three nearest neighbors and hence atoms attached here are tightiy bound to the crystal lattice. Thermodynamically, an extremely small population of kinks exists on the surface and it is a rare event for a solute molecule to hit a kink directly from the solution [19]. However, surface diffusion assists transport of adsorbed molecules to the kink sites where they are likely to get permanantly incorporated into the growing lattice. Frank [20] suggested that emerging screw dislocations on the crystal surface provide a perpetual source of ledges and kinks which act as binding sites (Figure 4-2). Therefore, it is likely that dislocations intersecting the inclusions determine the interfacial mass transfer rates.

The scenario of crystal growth from solution is, therefore, as follows. The solute molecules from supersaturated solution constantly adsorb on the crystal surface. Being weakly bound to the surface, adsorbed molecules diffuse on the surface to reach energetically favorable positions (kinks or the ledges or the ledges created by emerging dislocations.) Some adsorbed molecules will, undoubtedly, desorb before they reach the binding sites on these surface defects. However, those which get attached at kinks or ledges are very likely incorporated into the crystal lattice. The kinks are present on the ledges provided by emerging screw dislocations. By adding molecules to the kinks, the dislocation ledge "sweeps" the crystal surface in a 


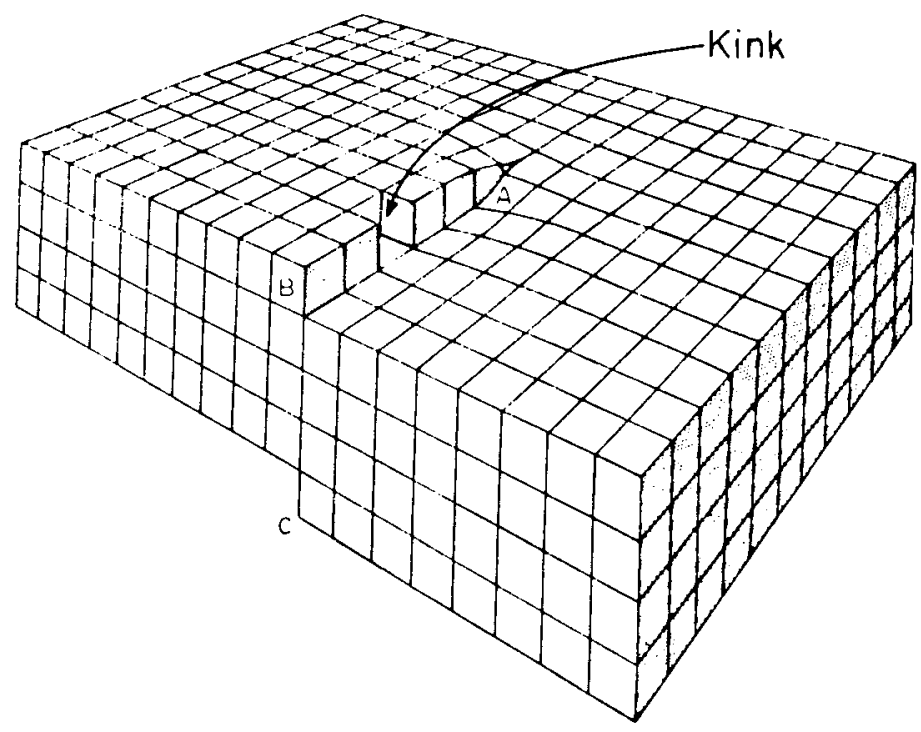

XBL 827-6060

Figure 4-2. A screw dislocation intersecting surface of a simple cubic crystal. The dislocation ledge $A B$ provides energetically favorable sites for crystal growth. 
circular motion and winds itself, layer by layer, in the direction normal to the surface. Thus, the crystal grows. For crystal dissolution, a similar scenario, in the reverse sense, takes place.

Burton, Cabrerra and Frank developed a surface diffusion crystal growth theory based on the scenario described above. The popularly known BCF Theory is reviewed and rederived in reference [18]. For the present purpose, it is sufficient to state two important results of the theory:

(i) The sweeping ledge motion on the crystal surface, caused by the addition of the solute molecules on the binding sites, depends on parameter $r_{C}$ as given by Eq. (4-7). The higher the value of $r_{C}$, the lower the lateral ledge velocity [18]. The ledge velocity on the crystal surface is directly related to the normal crystal growth rate.

(ii) The final result of this theory in terms of the crystal growth rate normal to surface can be equivalently stated in terms of the net solute flux $j_{s}$ to the surface as follows

$$
j_{s}=k_{1} \xi^{2} \tanh \left(\frac{k_{2}}{\xi}\right)
$$

where $K_{1}$ and $K_{2}$ are constants.

Constants $K_{1}$ and $K_{2}$ depend on temperature, solid density dislocation density in the solid, the surface diffusion coefficient of the adsorbed molecules, and the average time spent by an adsorbed molecule on the surface. These parameters are generally unknown and therefore only the mathematical form of the $\xi$-dependence in Eq. (4-9) is useful in a practical sense [18]. 
In particular, two interesting limiting cases of Eq. (4-9) have application to the theory of thermomigration. At low supersaturation, the values of $k_{2} / \xi$ is large, the tanh term is $\sim 1$, and the growth rate is proportional to $\xi^{2}$. On the other hand, at high supersaturations when $k_{2} / \xi$ is small, the tanh term reduces to its argument, or $j_{s}$ is proportional to $\xi$. These are known as non-linear and linear limits of the BCF growth $1 \mathrm{aw}$, respectively. It is noteworthy that unlike nucleation growth theory (Sect. 4.1.2.1), BCF theory does not predict the existence of critical super saturation below which no growth occurs.

\subsubsection{Impurity Effects}

Presence of foreign ions in solution or on the crystal surface can greatly alter crystal growth or dissolution rates. Of particular interest is work of Botsaris [21], who showed that small amounts of lead (i.e. in sub ppm levels) significantly affect the growth rate of the $\{100\}$ faces of $\mathrm{KCl}$ crystals. Usual ly impurities retard growth, possib]y for one of the following reasons [18]:

(i) Impurity adsorption may increase interfacial energy $\gamma$. If so, then the theories described earlier predict a growth retardation. As $\gamma$ increases, the size of the critical nucleus $r_{c}$ increases which mean a higher critical supersaturation for the growth to proceed according to the nucleation growth theory. For the surface diffusion growth theory, a larger value for $r_{c}$ means a lower lateral ledge velocity and hence smaller growth rate. 
(ii) Immobile impurities adsorbed on the surface hinder the smooth flow of ledges, which is the mechanism of growth. As shown in Figure 4-3, an advancing straight ledge is somehow forced to flow between immobile impurity atoms. The surface diffusion growth theory predicts that the lateral velocity of a curved ledge is lower than that of a straight ledge. In fact, if two impurity atoms are separated by a distance less than $2 r_{C}$, the local ledge curvature becomes so large that the ledge movement completely ceases [18].

Based on this second idea of immobile adsorbed impurities, it can be shown [18] that the presence of such impurities leads to a critical supersaturation below which no growth occurs.

\subsubsection{Interfacial Kinetics}

The principles of crystal growth/dissolution briefly summarized in the previous section will be used here to describe the interfacial kinetics of a migrating a11-liquid inclusion.

Because an inclusion is equivalent to a negative crystal, growth steps are automatically provided by the edges of side facets which border the cold face, so that crystallization should be relatively easy. However, steps for dissolution are difficult to form on the hot face [22]. Therefore, the rate limiting interfacial kinetic step is associated with dissolving the hot side of the inclusion [17]. This conclusion is substantiated by the following microscope observation of migrating inclusions; corners between lateral and cold (crystallizing) faces are rounded while the corners between the lateral and hot (dissolving) faces remain sharp. The same phenomenon is also evident from the work of Anthony and Cline [10]. The rounded corners at the cold 

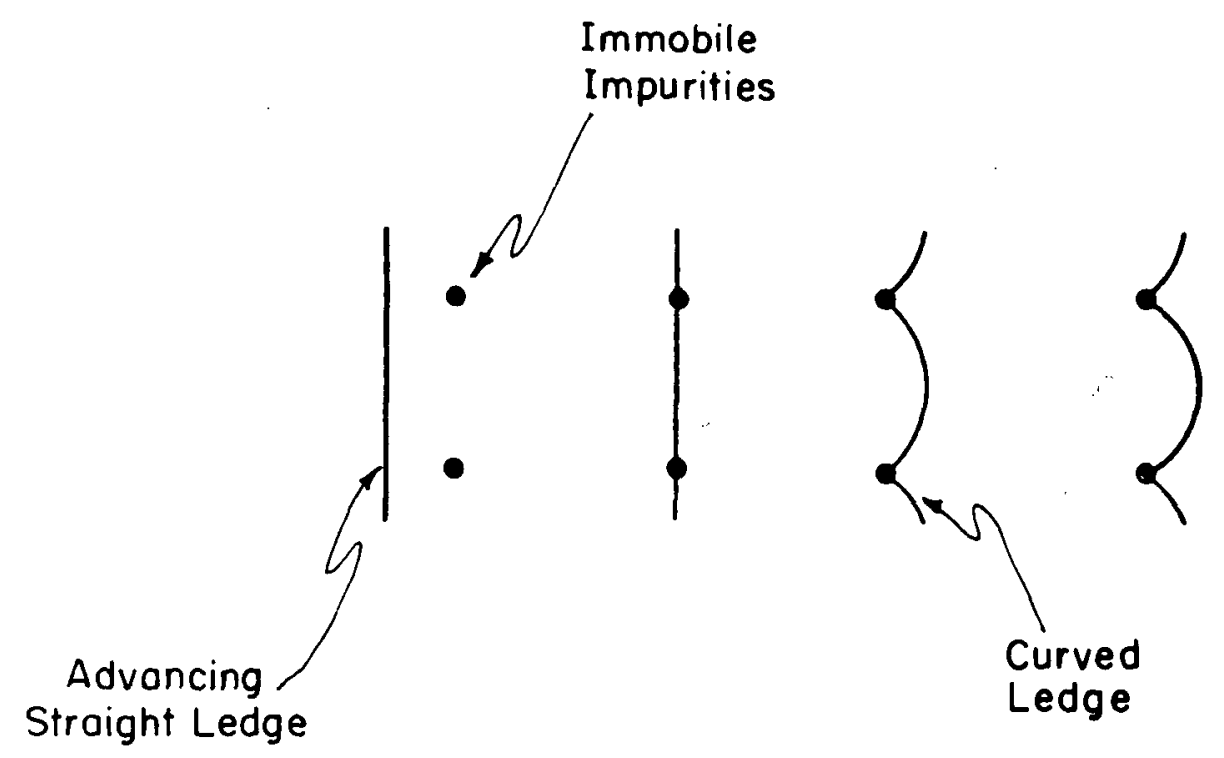

XBL827-6184

Figure 4-3. Effect of immobile adsorbed impurities on the lateral motion of ledges on the crystal surface. 
face of a migrating inclusion provide many ledges or steps for attachment of solute precipitating from solution. This in turn implies that the supersaturation required for crystallization on this face is small. Hence $\xi_{C}$ in Eq. (4-5) is set equal to zero in the subsequent application of the theory.

Dissolution of a crystal face can be viewed as the reverse of growth and the salt flux at dissolving interface is expressed as:

$$
j_{S}=k f\left(\xi_{h}\right) f^{\prime}\left(\xi_{h}, \xi^{\star}\right)
$$

where $k$ is an interfacial kinetic coefficient and $f\left(\xi_{h}\right)$ is a function of the fractional undersaturation of liquid in contact with the dissolving face. The product $k f\left(\xi_{h}\right)$ constitutes a phenomenological rate law describing the interfacial kinetics of dissolution of a pure crystal $\left[\right.$ e.g. Eq. 4-9)] . The function $f^{\prime}\left(\xi_{h}, \xi^{\star}\right)$ expresses the dependency of the dissolution rate on impurities in the crystal, which results in a critical fractional undersaturation, $\xi^{\star}$ below which no dissolution occurs.

The following functions have been chosen to describe $f\left(\xi_{h}\right)$ and $f^{\prime}\left(\xi_{h}, \xi^{\star}\right):$

$$
f\left(\xi_{h}\right)=\xi_{h}^{r}
$$

and

$$
f^{\prime}\left(\xi_{h}, \xi^{*}\right)=\left\{\begin{array}{lll}
1-\frac{\xi^{*}}{\xi_{h}} & \text { for } & \xi_{h}>\xi^{\star} \\
0 & \text { for } & \xi_{h}<\xi^{\star}
\end{array} .\right.
$$

Equation (4-11a) encompasses the BCF Theory [Eq. (4-9)], according to 
which the exponent $r$ approaches 2 at low undersaturation and tends towards unity at high undersaturation. Equation (4-11b) is justified based on the impurity effects described in Section 4.1.2.3.

Equation (4-10) and (4-11) can be combined and used in the migration velocity analysis with the additional specification $r=1$ (linear model) or $r=2$ (non-linear model) to conform with the high and low- $\xi$ limits of the BCF Theory.

\subsubsection{Linear Interface Kinetics}

For $r=1$, the salt flux at the dissolving interface is

$$
\begin{aligned}
& j_{s}=k\left(\xi_{h}-\xi^{*}\right) \quad \text { if } \quad \xi_{h}>\xi^{\star} \\
& =0 \quad \text { if } \quad \xi_{h}<\xi^{\star}
\end{aligned}
$$

Using Eq. (4-12) in Eq. (4-5) together with $\xi_{C}=0$ gives the migration velocity

$$
v=\frac{1}{\rho_{s}} \frac{D_{\ell} c^{s a t}}{1+C D}\left[\left(\frac{1}{c^{s a t}} \frac{d C^{s a t}}{d T}-\sigma\right) \nabla T_{\ell}-\frac{\xi}{L}\right]
$$

where

$$
\mathbb{D}=\frac{D_{e^{c}} c^{s a t}}{k L}
$$

is a dimensionless quantity reflecting relative importance of diffusion in the liquid and interfacial kinetics in the overall transport rate.

This approach is identical to the model formulated by Geguzin et a) [11] and equivalent to one proposed by Anthony and $\mathrm{Cl}$ ine [10], when $\xi_{c} \simeq 0$. If the kinetic potential $K$ utilized by the latter authors is, as they suggest, a linear function of inclusion speed 


$$
k=k_{0}+\alpha v,
$$

then coefficients $K_{0}$ and $\alpha$ can be identified with the parameters of the linear model as follows

$$
K_{0}=R T \xi^{*}
$$

and

$$
\alpha=R T \rho_{s} / k \text {. }
$$

Use of these formulae converts the velocity equation derived by Anthony and Cline [Eq. (10) of Ref. [10]) to Eq. (4-13). The parameters $K_{0}$ and $\alpha$ are equivalent to the critical departure from saturation and the interfacial transfer coefficient of the linear model.

\subsubsection{Nonlinear Interface Kinetics}

For $r=2$, the salt flux at the dissolving interface is

$$
\begin{aligned}
& j_{S}=k\left(\xi_{h}-\xi^{*}\right) \quad \text { if } \quad \xi_{h}>\xi^{*} \\
& =0 \quad \text { if } \xi_{h}<\xi^{\star} \text {. }
\end{aligned}
$$

Combining Eq. (4-15) with Eq. (4-5) with $\xi_{\mathrm{c}}=0$ yield

$v=\frac{D_{\ell} c^{s a t}}{4 L_{\rho_{s}}} d\left[\left\{\left[\left(1-\frac{\xi^{*}}{D}\right)^{2}+\frac{4 L \nabla T_{\ell}}{\Phi}\left(\frac{1}{c^{s a t}} \frac{d c^{s a t}}{d T}-\sigma\right)\right]^{1 / 2}-1\right\}^{2}-\left(\frac{\xi^{*}}{C D}\right)^{2}\right]$

with Ddefined by Eq. (4-14).

The limit of kinetic control is obtained for $\mathcal{D}$ sufficiently large and $\xi^{\star}$ small, as

$$
v=\frac{k}{\rho_{S}}\left(\frac{1}{c^{s a t}} \frac{d C^{s a t}}{d T}-\sigma\right)^{2}\left(L \nabla T_{l}\right)^{2}
$$


while the limit for diffusion control is obtained for small $\mathbb{D}$, in which case Eq. (4-16) reduces to Eq. (4-6). Both these limits are derived in Appendix B.

\subsubsection{Threshold Temperature Gradient for No Migration}

Equations (4-13) and (4-16) predict the migration velocity at a given temperature and inclusion size for the linear and non-linear interface kinetics. Pigford [23] predicted the existence of a threshold temperature gradient below which no migration takes place (i.e. the inclusion remains stationary). At the threshold temperature gradient, the temperature difference across the inclusion is just sufficient to meet the requirement of critical undersaturation for dissolution at the hot interface and critical supersaturation for growth at the cold interface.

Setting the right hand side of Eq. (4-13) and (4-16) equal to zero, the threshold temperature gradient for migration calculated from either of the equations results in

$$
\nabla T_{\min }=\frac{\xi^{\star}}{L\left(\frac{1}{c^{\text {sat }}} \frac{d C^{\text {sat }}}{d T}-\sigma\right)}
$$

which is equivalent to Eq. (29) of Ref. [23].

Similarly for a given temperature and $\nabla T_{\infty}$ (or $\nabla T_{\ell}$ ), there exists a minimum size below which the inclusion becomes immobile. Equation (4-18) can be rewritten to obtain an expression for this minimum size.

$$
L_{\min }=\frac{\xi^{*}}{\left(\frac{1}{c^{c a t}} \frac{d C^{c a t}}{d T}-\sigma\right) \nabla T_{\ell}} .
$$


Physically the existence of $L_{\text {min }}$ means that the inclusion size is so small that, the critical sized nuclei for growth and dissolution [as predicted by Eq. (4-7) for nucleation growth theory, for example] cannot be sustained.

Pigford [23] explained that the existence of the minimum size for migration is responsible for uniformly distributed small sized inclusions in natural salt deposits. During the 200 million-year age under the influence of geothermal gradient, the inclusions would have otherwise migrated towards the bottom of the salt deposits.

\subsection{GAS-LIQUID INCLUSIONS}

The mechanism of thermomigration of this type of inclusions was discussed in Chapter 2. Referring to Figure 2-2, the following processes must be considered in formulating the inclusion speed in this case:

(i) The diffusion of water vapor in the gas bubble under the driving force of vapor pressure difference between the hot and the cold sides of the bubble. The diffusional flux will depend on gas phase properties such as the diffusion coefficient of water vapor in a given inert gas (helium or air or argon), and the gas phase thermal conductivity.

(ii) The backflow of the liquid driven by the surface tension gradients. Since the surface tension is temperature dependent, a detailed knowledge of temperature distribution in the inclusion is necessary to calculate this backflow. The effect of heat of vaporization of water on the temperature distribution must be accounted for. 
(iii) The flux of the dissolved salt in the liquid around the gas bubble. This flux has both diffusional and convective components because salt concentration gradients as well as bulk liquid flow exist in the brine-filled region.

(iv) The interfacial kinetics of dissolution and growth at the cold and the hot brine/solid interfaces, respectively. In principle, these are identical to the interfacial processes at the brine/solid interfaces in all-liquid inclusions which were discussed in the previous section.

It is clear that theoretical modeling of the above processes will require detail calculations of fluid flow, heat, and mass transport in the inclusion. This can not be done analytically for the actual geometry of the inclusion, which is a gas bubble in a cubical brine cavity in an infinite medium of solid. 0lander and coworkers [13] have developed an approximate analytical model to determine the velocity of the two-phase fluid inclusions in an imposed thermal gradient. In their analysis, the actual shape of the cavity is approximated by a sphere of radius $b$ with a centrally placed spheroidal gas bubble of radius a (Figure $4-4)$.

Even with this idealized shape, numerical method is required to solve the concentration distribution of salt in the liquid shell. A further approximation consists of ignoring convective transport in the analysis of the salt-concentration distribution in the liquid shell. This leads to what is called the "approximate solution" [Eq. (115) of Ref. (13)], which provides an explicit and sufficiently accurate equation for the inclusion speed. 


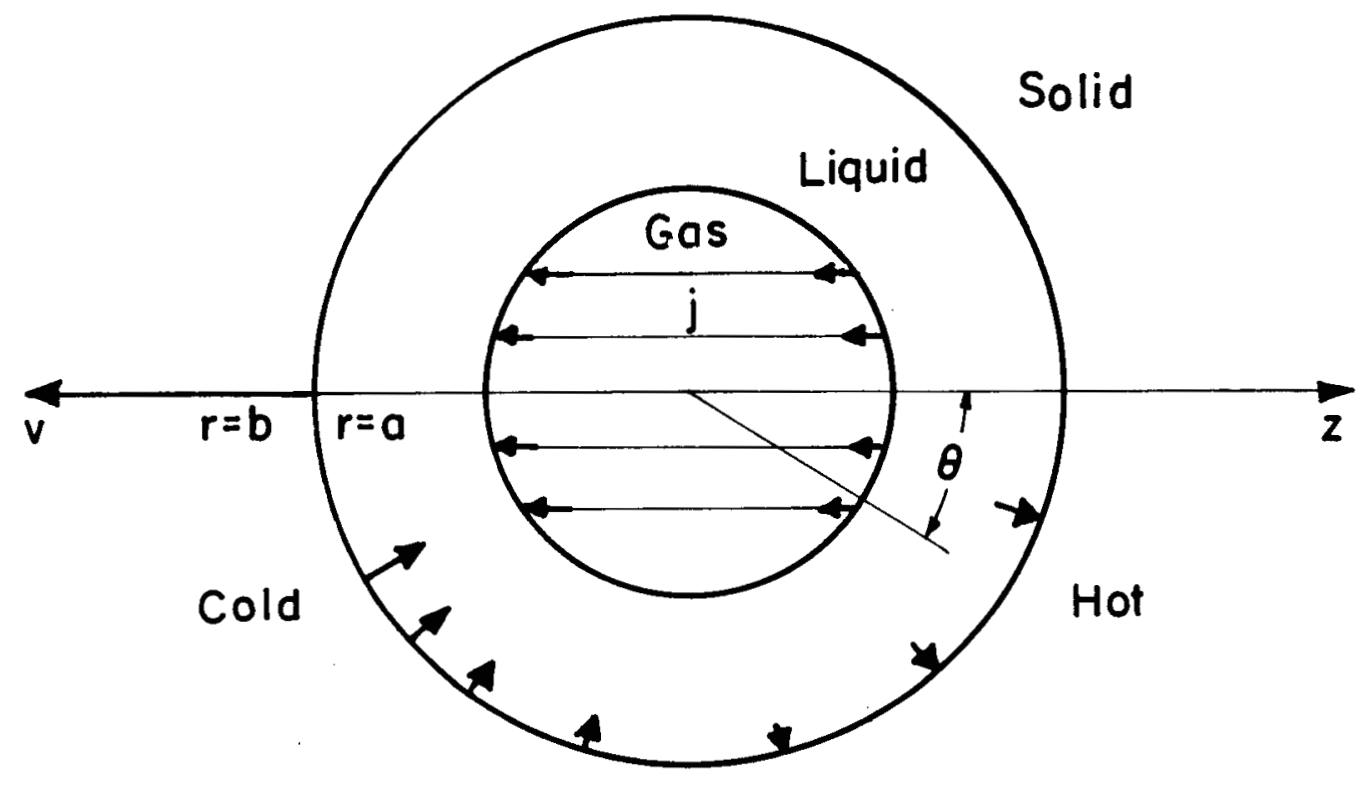

XBL 827-6061

Figure 4-4. Spherical model of a gas liquid inclusion showing the water flux crossing the bubble from hot to cold and the salt deposition or dissolution flux at the solid liquid boundary shown by arrows. (Ref. [13]). 
Without going into the details of the analys is of 01 ander and coworkers [13], it is sufficient here to state that the migration velocity, $v$, of the inclusion depends on the following parameters:

(1) Global temperature of the inclusion, $T_{\ell}$ at which all the physical property data are calculated.

(2) Applied temperature gradient in solid, $\nabla T_{\infty}$.

(3) The inclusion size, and the volume fraction of gas in the cavity.

(4) The inert gas phase in the bubble (helium or air or argon). A shorthand representation of Eq. (115) of Ref. [13] is

$$
v=f\left(T_{\ell}, \nabla T_{\infty}, a, b \text {, gas phase }\right) .
$$

The actual size of the whole cavity, and the contained gas phase are converted to equivalent spherical sizes given by $a$ and $b$. The ratio $a^{3} / b^{3}$ gives the volume fraction of gas. 
CHAPTER 5

INTERFACIAL STABILITY OF MIGRATING ALL-LIQUID INCLUSIONS

\subsection{INTRODUCTION}

Al1-liquid inclusions produced in the manner described in Chapter 3 are shaped like square platelets (Figure 3-1) with the ir boundaries conforming to $\{100\} \mathrm{planes}$ of the host single crystal. If $L$ is the thickness of the inclusion and $W$ is the width of one of its square sides, the aspect radio $L / W$ is much less than unity. The thickness $L$ is between 10 and $20 \mathrm{~mm}$, the exact value depending on the temperature and temperature gradient, and the width $W$ is fixed by the volume of liquid contained in by the inclusion.

In the present work, it was observed experimentally that certain inclusions showed interface instabilities during migration. Such an instability caused breakdown of an inclusion into two or more smaller but stable inclusions. Anthony and $\mathrm{Cl}$ ine have also reported [24] similar instabilities of brine inclusions in $\mathrm{KCl}$ single crystals. However, no rigorous quantitative explanation of such a behavior is available in the literature.

In this chapter a perturbation method is used to analyze interface instabilities of brine-filled inclusions in alkali halide single crystals. Using the temperature distribution in the inclusion derived in Appendix A, an approximate theoretical model for the response of a planar solid/solution interface from an arbitrary perturbation is developed. These results are then applied to the interfaces of a migrating inclusion. 
According to the analysis of Appendix $A$ the ratio $\nabla T_{\ell} / \nabla T_{\infty}$ decreases from its highest value at the center to unity at the periphery of the inclusion. Because the solubility of salt is temperature dependent, the concentration gradient across the inclusion (which is the driving force for the migration) is also largest at the center. Since the flux of dissolved salt across the inclusion, $j_{s}$, depends on the concentration gradient, it should also vary from a maximum value at the center to smaller values at off-axis locations. Alternatively, the flux $j_{s}$ can be made constant at each point on the inclusion face if the inclusion thickness is highest at the center with continuously decreasing values at off-axis location. This would mean that the inclusion would be roughly spherical in shape. But stable inclusions undoubtedly are square-platelet-shaped with $\{100\}$ facets. There are two principal reasons for the observed shape:

(i) The interfacial energy $\gamma$ is the lowest for $\{100\}$ planes in $\mathrm{KCl}$ and $\mathrm{NaCl}$. Any departure from $\{100\}$ is energetically unfavorable.

(ii) The interfacial kinetics (discussed in Chapter 4) favors layer by layer growth and dissolution.

Therefore, despite the local variations in concentrations, the stabilizing effects discussed above maintain an inclusion stable with $\{100\}$ facets and prevent the inclusion from assuming a spherical form. However, these stabilizing effects are not strong enough for inclusions of all sizes. Then the ratio $\mathrm{W} / \mathrm{L}$ is very large (i.e. for slender inclusions), the gradient amplification factor $\nabla T_{\ell} / \nabla T_{\infty}$ approaches $k_{s} / k_{\ell}$ (which is roughly 7 for $\mathrm{NaCl}$ and 10 for $\mathrm{KCl}$ ). In this limit the 
large "gradient effect" overwhelms the stabilizing effects of interfacial kinetics and interfacial energy. As a result, the inclusion breaks down as shown in Figure $5-1$.

Figure 5-2 shows schematically a typical sequence of events during migration which lead to breakdown of an unstable inclusion. The instabilities begin at the corners of the inclusions, where trailing veils first appear. These veils always appear at the interface towards the cold side. The veils lag behind the migrating inclusion for several hours, remaining physically attached to the inclusion. Eventually the veils detach, leaving behind two or more smaller but stable inclusions.

\subsection{PERTURBATION METHOD FOR STABILITY ANALYSIS}

The application of perturbation method to a growing interface for stability analysis is not a novel subject; the stability of crystal growing from a melt in various geometries (spherical, planar, cylindrical) under mass and heat flows have been analyzed by perturbation methods [25], [26], [27], [28], [29]. The subject is adequately reviewed by Sekerka [30] and Delves [31].

A similar perturbation method is used here for a planar crystal growth from solution. There are basic differences between the solidification and solution growth. The former theory has been worked out for temperature gradient zone melting, which refers to the process of solidification at the interface. The solute and solvent are considered to be present on the ejther side of the interface with a known distribution coefficient. In the case of solution growth, the solid phase is pure solute (no solvent is present in the solid). Other differences 


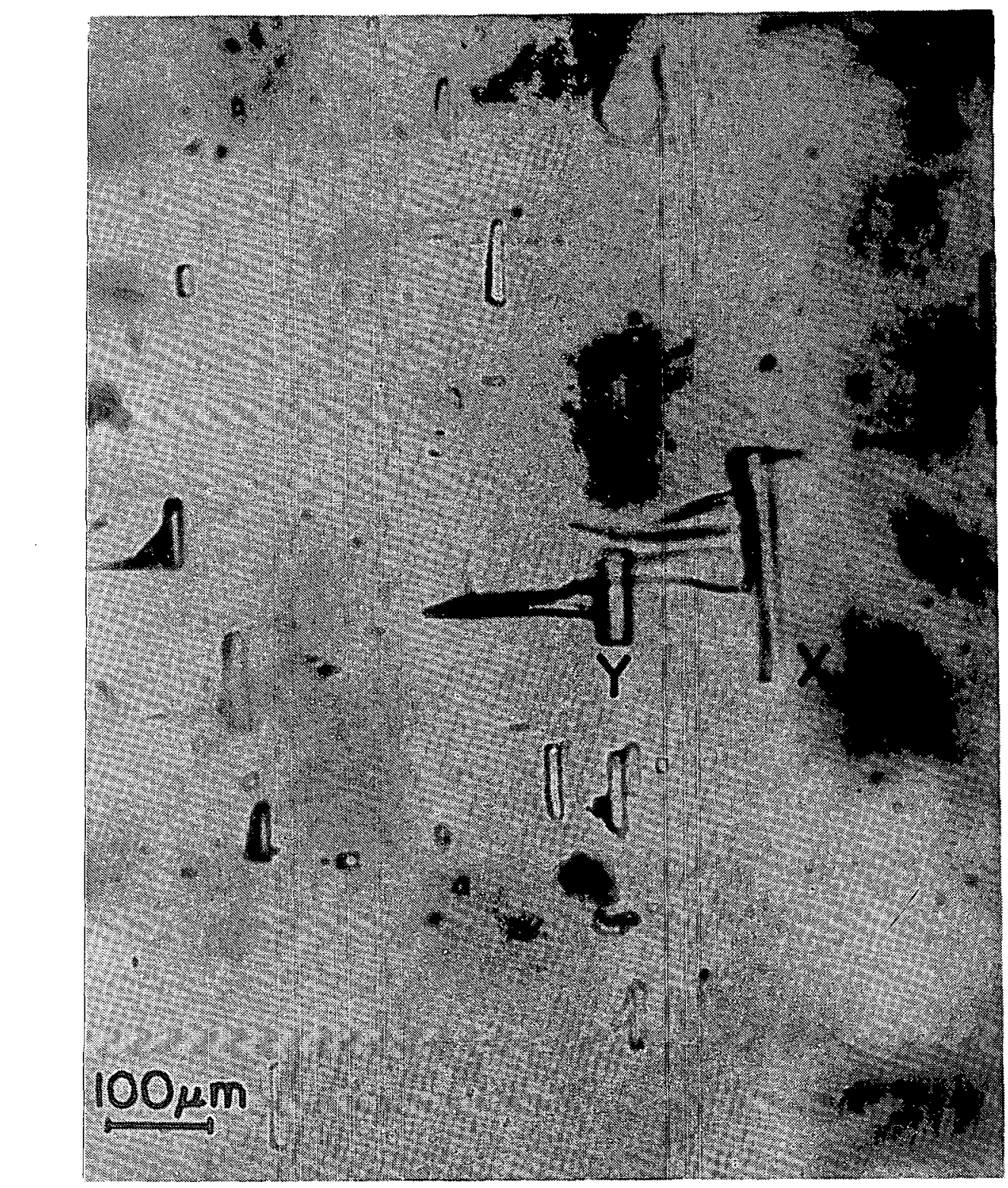

COLD

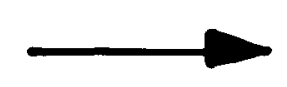

\section{[010] $\longrightarrow[100]$}

Figure 5-1. Photomicrograph of inclusions showing interfacial instabilities in an applied temperature gradient of $40^{\circ} \mathrm{C} / \mathrm{cm}$ and compressive axial load of $\sim 4 \mathrm{MPa}$. The small sized inclusions are stable with sharp boundaries whereas the inclusions with large $W / L$ ratios have begun to show instabilities at the interface. 

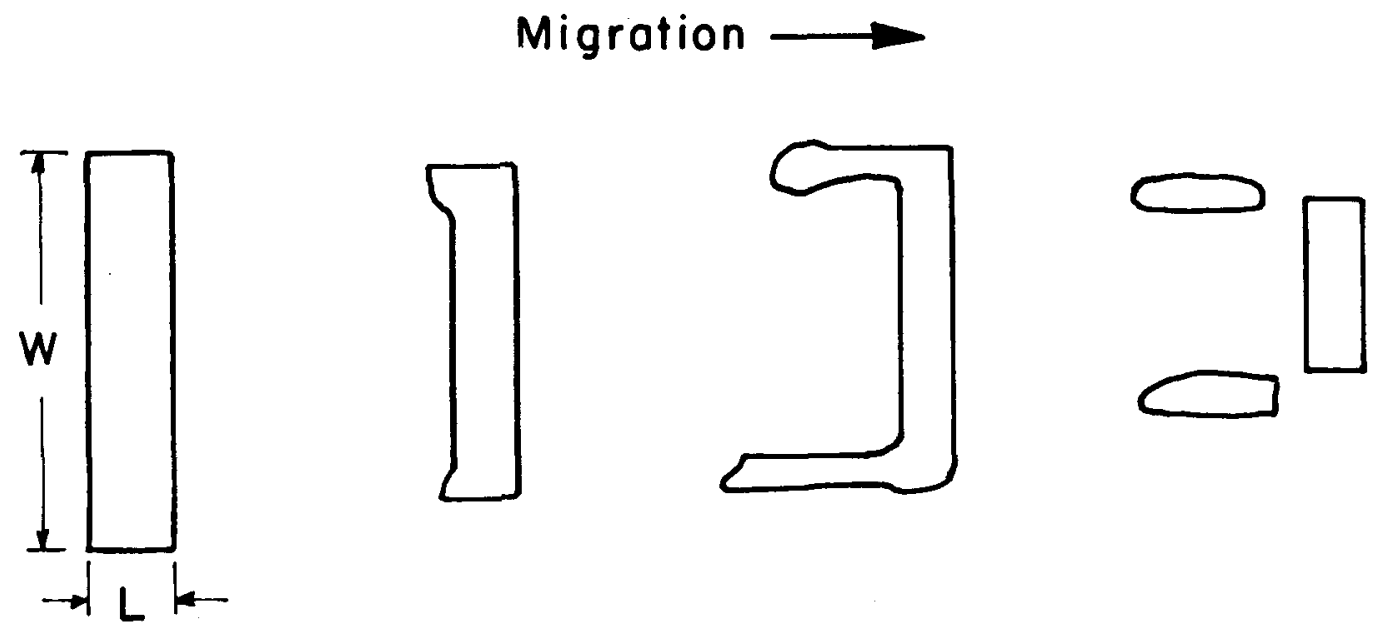

Increasing Time $\longrightarrow$

XBL 827-6062

Figure 5-2. A typical sequence of events leading to breakdown of an inclusion. 
between the prior studies and the present situation are in the boundary conditions at the interface. Also in the case of solidification, the interfacial velocity is dependent on the latent heat of freezing, whereas the heat of crystallization can be neglected in treating solution growth. (This can be justified by computing appropriate dimensionless numbers for $\mathrm{NaCl} / \mathrm{brine}$ and $\mathrm{KCl} /$ brine cases.) The density difference between solid and liquid are considered here whereas no density change is assumed at the interface in the previous studies.

\subsubsection{Temperature and Concentration Fields}

Since the migration velocities of the inclusions under consideration are very small (typically $5 \times 10^{-8} \mathrm{~cm} / \mathrm{s}$ ), the velocity terms are neglected in the heat and mass balance equations i.e., the transport equations are assumed to be identical in a fixed frame of reference and in a frame of reference moving with the interface. This assumption results in linear temperature and concentration profiles, which keep the mathematical analysis simple without loss of generality of the conclusions.

\subsubsection{The Unperturbed Case (superscript "o")}

Shown in Figure $5-3$ is a flat unperturbed planar interface growing from solution. The solid is pure solute crystal with molar density $\rho_{s} \cdot$

The temperature and concentration fields in the liquid and the solid are given by: 

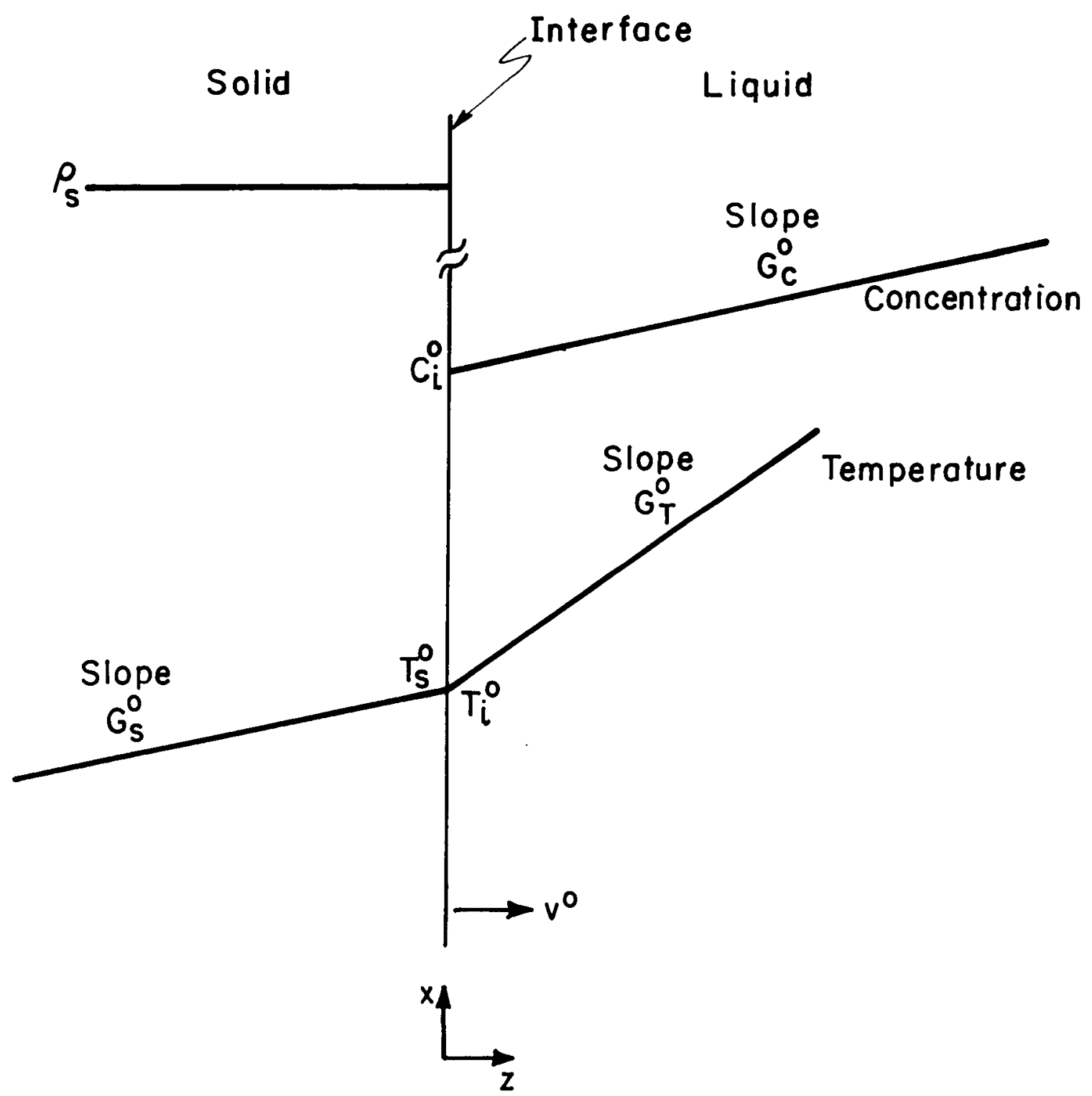

$X B L 827-6063$

Figure 5-3. Temperature and concentration fields at an unperturbed planar interface under growth conditions. The interface velocity $v^{\circ}$ is small. 
Liquid $(z>0)$

$$
\begin{aligned}
& C^{0}(z)=C_{i}^{0}+G_{C}^{0} z \\
& T^{0}(z)=T_{i}^{0}+G_{T}^{0} z
\end{aligned}
$$

where $C$ and $T$ represent concentration and temperature respectively, subscript $i$ refers to interfacial values, and superscript o refers to the unperturbed interface. $G_{C}^{O}$ and $G_{T}^{0}$ are concentration and temperature gradients in the liquid.

Solid $(z<0)$

$$
\begin{aligned}
& C_{s}^{0}(z)=\rho_{s} \quad \text { (constant) } \\
& T_{s}^{0}(z)=T_{i}^{0}+G_{s}^{0} z
\end{aligned}
$$

where subscript $s$ refers to the solid and $G_{S}^{0}$ is the temperature gradient in the solid. At the interface $z=0$, continuity of temperature, heat flux, and mass flux gives:

$$
\begin{aligned}
& T^{0}(z)=T_{s}^{0}(z) \\
& k_{\ell} G_{T}^{0}=k_{s} G_{s}^{0} \\
& D_{\ell} G_{C}^{0}=v^{0}\left(\rho_{s}-C_{j}^{0}\right) \simeq v^{0} \rho_{s} .
\end{aligned}
$$

where $D_{\ell}$ is the diffusivity of the solute in the liquid.

\subsubsection{The Perturbed Case}

An arbitrary time dependent sinusoidal perturbation with wavelength $\lambda=(2 \pi / \omega)$ is given at the interface:

$$
z=\phi(x, t)=\varepsilon(\omega, t) \sin \omega x .
$$

The amplitude of perturbation $\varepsilon(\omega, t)$ is very small. By solving the heat and mass transport equations in this perturbed case with appropriate boundary conditions, we can find $\dot{\varepsilon} / \varepsilon$, where $\dot{\varepsilon}$ is the time rate of change of amplitude $\varepsilon$. If $\dot{\varepsilon} / \varepsilon$ is negative, the perturbation will decay with time and the interface will be stable. If, on the 
other hand, $\dot{\varepsilon} / \varepsilon$ is positive, the perturbations will grow with time and the interface is said to be unstable.

The conservation equations for the concentration and temperature fields $C(z, x, t), T(z, x, t)$ and $T_{s}(z, x, t)$ in this case are:

$$
\begin{array}{ll}
\frac{\partial C}{\partial t}=D\left[\frac{\partial^{2} C}{\partial x^{2}}+\frac{\partial^{2} C}{\partial z^{2}}\right] & (\text { for } z \geqslant 0) \\
\frac{\partial T}{\partial t}=D_{t h}\left[\frac{\partial^{2} T}{\partial x^{2}}+\frac{\partial^{2} T}{\partial z^{2}}\right] & (\text { for } z \geqslant 0) \\
\frac{\partial T S}{\partial t}=D_{t h}^{S}\left[\frac{\partial^{2} T_{s}}{\partial x^{2}}+\frac{\partial^{2} T_{s}}{\partial z^{2}}\right] & (\text { for } z \leqslant 0)
\end{array}
$$

Note that the convective terms are neglected due to the assumed slow interface velocity. $D_{\text {th }}^{S}$ and $D_{\text {th }}$ are thermal diffusivities of the solid and the solution.

In the stability analysis one is interested in the sign of $\dot{\varepsilon} / \varepsilon$. At $\dot{\varepsilon} / \varepsilon$ nearly equal to zero, the interface changes shape slowly with time. Hence the time dependent left hand side of Eq. (5-5) can be neglected without loss of generality [31]. The resulting quasistationary conservation equation must meet the following conditions:

(i) The solution must reduce to that of the unperturbed case far from the interface. That is,

$$
\begin{array}{ll}
C(z, x) \rightarrow C^{0}(z) & \text { for } z \rightarrow \infty \\
T(z, x) \rightarrow T^{0}(z) & \text { for } z \rightarrow \infty \\
T_{S}(z, x) \rightarrow T_{S}^{0} & \text { for } z \rightarrow-\infty
\end{array}
$$

(ii) The interface shape is described by the periodic function $z=\phi(x)$, at which position 


$$
\begin{aligned}
c_{i} & =C_{i}^{0}+a \varepsilon \sin (\omega, x) \\
T_{i} & =T_{i}^{0}+b \varepsilon \sin (\omega, x) \\
T_{s_{i}} & =T_{i}^{0}+b \varepsilon \sin (\omega, x)
\end{aligned}
$$

where $a$ and $b$ are functions of system properties and remain to be determined.

The solutions to the quasi-stationary forms of Eqs. (5-5) with conditions (5-6) and (5-7) are:

$$
\begin{aligned}
& C(z, x)=C^{0}(z)+\varepsilon\left(a-G_{C}^{0}\right) \exp (-\omega z) \sin (\omega x) \\
& T(z, x)=T^{0}(z)+\varepsilon\left(b-G_{T}^{0}\right) \exp (-\omega z) \sin (\omega x) \\
& T_{S}(z, x)=T_{S}^{0}(z)+\varepsilon\left(b-G_{S}^{0}\right) \exp (+\omega x) \sin (\omega x)
\end{aligned}
$$

\subsubsection{Determination of the Parameters $a$ and $b$}

The parameters in Eqs. (5-7) are determined by two independent methods. The first is continuity of heat flux and mass flux at the perturbed interface. The second method is based on considerations of interfacial energy and interfacial kinetics.

\subsubsection{METHOD 1}

Mass Flux

$$
D_{\ell}\left[\frac{\partial C(z, x)}{\partial z}\right]_{z=\phi}=v\left(\rho_{s}-C_{i}\right) \simeq v_{\rho}
$$

Since $\rho_{s}$ is much larger than $C_{i}$ or $C_{j}^{0}$, both $C_{i}$ and $C_{i}$ can be neglected. From Eqs. (5-8a) and (5-9), with $\exp (-\omega \phi) \simeq 1$, for sma11 perturbations

$$
D_{\ell} G_{C}^{0}-D_{\ell} \omega \varepsilon\left(a-G_{C}^{0}\right) \sin \omega x=v \rho_{S} .
$$

Therefore, since $D_{\ell} G_{C}^{0}=\rho_{S} v^{0}$ from Eq. (5-3c),

$$
-D_{\ell} \omega \varepsilon\left(a-G_{c}^{0}\right) \sin \omega x=\rho_{s}\left(v-v^{0}\right) \text {. }
$$


But perturbed interface velocity $\vee$ can be expressed in terms of the unperturbed interface velocity $v^{0}$ as

$$
v=v^{0}+d \phi / d t=v^{0}+\dot{\varepsilon} \sin \omega x \text {. }
$$

Substituting Eq. (5-12) into Eq. (5-11)

$$
a=G_{C}^{0}-\frac{\rho_{S}}{D_{\ell} \omega} \frac{\dot{\varepsilon}}{\varepsilon}
$$

Heat Flux

$$
k_{\ell}\left[\frac{\partial T(z, x)}{\partial z}\right] z=\phi=k_{s}\left[\frac{\partial T_{S}(z, x)}{\partial z}\right] z=\phi .
$$

Using Eqs. (5-8b) and $(5-8 c)$, this yields:

$$
\begin{aligned}
& k_{\ell}\left[G_{T}^{0}-\omega \varepsilon\left(b-G_{T}^{0}\right) \exp (-\omega z) \sin \omega x\right]_{z}=\emptyset \\
= & k_{S}\left[G_{S}^{0}+\omega \varepsilon\left(b-G_{S}^{0}\right) \exp (+\omega z) \sin \omega x\right]_{z}=\phi
\end{aligned}
$$

Since $k_{\ell} G_{T}^{0}=k_{S} G_{S}^{0}$ and $\exp (-\omega \phi) \simeq \exp (+\omega \phi) \simeq 1$ for small perturbations, we obtain

$$
b=\frac{\left[k_{s} G_{s}^{0}+k_{\ell} G_{T}^{0}\right]}{\left[k_{s}+k_{\ell}\right]}
$$

\subsubsection{METHOD 2}

The second method of finding a relation between $a$ and $b$ is similar to that used by Seidensticker [32]. The difference is that Seidensticker considers an interfacial temperature which is different from the "equilibrium" temperature, whereas here it is the interfacial concentration $C_{i}$ which is different from the saturation concentration $c_{i}^{s a t}$. This difference is brought about by the interfacial kinetics and interfacial energy (the Gibos-Thompson Effect). Each of these effects will now be considered separately. 


\subsubsection{Interfacial Kinetics}

According to the theory of crystallization, supersaturation is necessary to initiate crystal growth. Similarly undersaturation is necessary to begin dissolution. As discussed in Chapter 4, according to the nucleation growth theory, this can be attributed to the free energy barrier to form a critical-sized nucleus before growth or dissolution becomes energetically favorable. Whatever the exact mode of interfacial crystallization or dissolution, the difference between the actual and saturation concentrations at the interface (which is the driving force) is related to the interfacial growth or dissolution by an interfacial kinetic law for which a general form is

$$
c_{i}-c_{i}^{s a t}=g(v)
$$

where $g(v)$ is the function representing the kinetics of the interface attachment or detachment processes. For the unperturbed interface. the kinetic law takes the following form

$$
c_{i}^{0}-c_{i}^{\text {osat }}=g\left(v^{0}\right)
$$

Because $v$ is close to $v^{0}, g(v)$ can be approximated by a two-term Taylor Series

$$
g(v)=g\left(v^{0}\right)+a\left(v-v^{0}\right)
$$

where

$$
\alpha=\left[\frac{d g}{d v}\right]_{v^{0}}
$$

Substituting Eqs. (5-16) and (5-17) into (5-18) and then using Eq. (5-12), one obtains

$$
\begin{aligned}
& c_{i}-c_{i}^{s a t}=c_{i}^{0}-c_{i}^{\text {osat }}+\alpha \dot{\varepsilon} \sin \omega x \\
& \text { or, } \quad C_{i}-C_{i}^{0}=c_{i}^{\text {sat }}-C_{i}^{\text {osat }}+\alpha \dot{\varepsilon} \sin \omega x
\end{aligned}
$$


The concentrations are not continuous at the interface as considered by previous workers. However, the saturation concentration is related to the interfacial temperature. Assuming a linear relation from the phase diagram (which is a good approximation for the $\mathrm{NaCl} / \mathrm{wa}-$ ter and $\mathrm{KCl} /$ water systems).

and

$$
\begin{array}{ll}
T_{i}^{0}=m C_{i}^{\text {osat }}+\tau & \text { (unperturbed) } \\
T_{i}=m C_{i}^{s a t}+{ }^{\text {sat }} & \text { (perturbed) }
\end{array}
$$

where $m$ and $\tau$ are respectively the slope and the intercept on the phase diagram line. Thus, using Eq. (5-7b)

$$
c_{i}^{\text {sat }}-c_{i}^{\text {osat }}=\frac{\left[T_{i}-T_{i}^{O}\right]}{m}=\frac{b \varepsilon \sin \omega x}{m} .
$$

And, using Eq. (5-19)

$$
\left(C_{i}-c_{i}^{0}\right)_{i n t-k i n}=\frac{b \varepsilon \sin \omega x}{m}+\alpha \dot{\varepsilon} \sin \omega x
$$

\subsubsection{Interfacial Energy}

Equation (5-21) gives the difference $\left(C_{i}-C_{j}^{0}\right)$ which is attributable to the interfacial kinetic resistance. Now the difference $\left(c_{i}-c_{i}^{0}\right)$ due to the interfacial energy will be computed. Since the perturbed interface is curved, capillarity effects must be considered.

Consider a small section of the interface with curvature nearly constant (Figure 5-4). Let $P_{S}$ and $P_{L}$ be the pressures at the curved interface in solid and liquid, respectively. Similar quantities for the flat unperturbed interface are $P_{S}^{0}$ and $P_{L}^{0}$. Since

$$
P_{S}^{0}=P_{L}^{0} \text {. }
$$

For the perturbed interface

$$
P_{S}-P_{L}=r\left(\frac{1}{r_{x}}+\frac{1}{r_{y}}\right)
$$



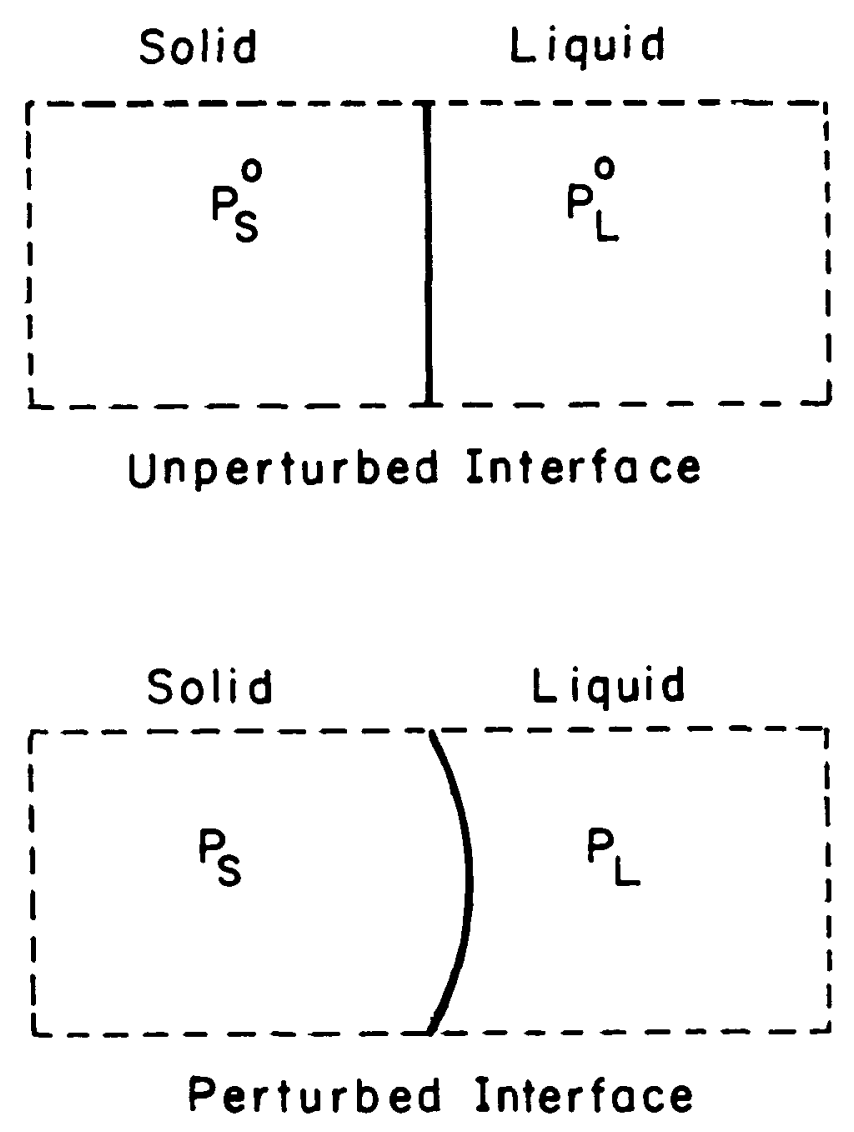

XBL $827-6064$

Figure 5-4. Small sections of unperturbed and perturbed interfaces to compute the effect of interfacial energy on the boundary conditions. 
where $r_{x}$ and $r_{y}$ are two principal radii of curvatures and $\gamma$ is the surface energy.

But $\quad \frac{1}{r_{y}}=0$

and $\frac{1}{r_{x}} \simeq \frac{\partial^{2} \phi}{\partial x^{2}} \simeq \varepsilon \omega^{2} \sin \omega x$.

Therefore, from Eq. (5-22)

$$
P_{S}-P_{L}=\gamma \varepsilon \omega^{2} \sin \omega x
$$

Assuming $P_{L}=P_{L}^{0}$, since the liquid is semi-infinite, yields

$$
\Delta P_{S}=P_{S}-P_{S}^{O}=\gamma \varepsilon \omega^{2} \sin \omega x
$$

Let $\Delta \mu_{s}$ and $\Delta \mu_{\ell}$ be the changes in the chemical potential of solute in solid and liquid due to the process of perturbing the interface. There

$$
\Delta \mu_{S}=\Delta \mu_{\ell}
$$

But

$$
\begin{aligned}
& \Delta \mu_{l}=k T \ln \frac{C_{i}}{C_{i}^{0}} \simeq k T \frac{C_{i}-C_{i}^{0}}{C_{i}^{0}} \\
& \Delta \mu_{s}=\Omega \Delta P_{S}-s \Delta T_{S}
\end{aligned}
$$

where $\Omega$ is the atomic volume of the solid and $s$ is the entropy. At constant temperature $\Delta T_{S}=0$. So from Eqs. (5-23) and $(5-26)$

$$
\Delta \mu_{S}=\operatorname{si\Delta } P_{S}=\Omega \gamma \varepsilon \omega^{2} \sin \omega x
$$

From Eqs. $(5-24),(5-25)$ and (5-27)

$$
k T \frac{C_{i}-C_{i}^{0}}{C_{i}^{0}}=\Omega \gamma \varepsilon \omega^{2} \sin \omega x
$$

or

$$
\left(C_{i}-C_{i}^{0}\right)_{\text {int-enrg }}=\frac{\gamma C_{i}^{0}}{k T} \Omega \in \omega^{2} \sin \omega x
$$


Adding Eqs. (5-21) and (5-28), the total departure from interfacial equilibrium is given by:

$$
\begin{aligned}
C_{i}-C_{i}^{0}=a \varepsilon \sin \omega x=\frac{b \varepsilon \sin \omega x}{m}+a \dot{\varepsilon} \sin \omega x+\frac{\Omega \gamma C_{i}^{0}}{k T} \varepsilon \omega^{2} \sin \omega x \\
\text { or, } \quad a=\frac{b}{m}+a \frac{\dot{\varepsilon}}{\varepsilon}+\frac{\Omega \gamma C_{i}^{0}}{k T} \omega^{2}
\end{aligned}
$$

Substituting a and $b$ from (5-13) Eqs. (5-13) and (5-15) solving for $\frac{\dot{\varepsilon}}{\varepsilon}$, one obtains:

$$
\frac{\dot{\varepsilon}}{\varepsilon}=\frac{G_{C}^{0}-\frac{k_{S} G_{S}^{0}+k_{\ell} G_{T}^{0}}{m\left(k_{s}+k_{L}\right)}-\frac{\delta_{\gamma} C_{i}^{0}}{k T} \omega^{2}}{\alpha+\frac{\rho_{s}}{D_{\ell} \omega}}
$$

The denominator of the right hand side of Eq. (5-30) is always positive, therefore, the sign of $\dot{\varepsilon} / \varepsilon$ is determined by the numerator $S$, where

$$
S=G_{C}^{0}-\frac{k_{s} G_{s}^{0}+k_{\ell} G_{T}^{0}}{m\left(k_{s}+k_{\ell}\right)}-\frac{\delta_{\gamma} C_{i}^{0}}{k T} \omega^{2}
$$

Equation (5-31) is applicable to any solid/solution interface with nonuniform temperature distributions in both phases and a solute concentration gradient in the solution adjacent to the boundary. In the following section, this stability criterion is specialized for the case of an al1-liquid inclusion in salt crystals.

\subsection{APPLICATION TO MIGRATING INCLUSIONS}

With reference to Figure 2-1 which shows the temperature and concentration profiles in a section of an all-liquid inclusion: 


$$
\frac{C_{h}-C_{c}}{L}=\frac{\left(C_{h}^{\text {sat }}-\delta C_{h}\right)-\left(C_{c}^{\text {sat }}+\delta C_{c}\right)}{L}=\frac{C_{h}^{\text {sat }}-C_{c}^{s a t}}{L}-\frac{\delta C_{h}+\delta C_{c}}{L}
$$

For the cold interface of the inclusion where crystal growth takes place, $\frac{C_{h}-C_{C}}{L}$ is approximately equal to the concentration gradient $G_{C}^{0}$ used in the previous section. Thus

$$
G_{C}^{0}=\frac{C_{h}-C_{C}}{L} \text {. }
$$

Similarly the temperature gradient within the liquid $\nabla T_{1}$ is approximately equal to $\frac{T_{h}-T_{c}}{L}$, where $T_{c}$ is temperature of a given point on the cold interface and $T_{h}$ is the temperature of exactly opposite point on the hot interface. Both $T_{h}$ and $T_{c}$ are related to the saturation concentrations in adjacent liquid. From phase diagram relation given by Eq. $(5-20)$, therefore

$$
\frac{C_{h}^{\text {sat }}-C_{C}^{\text {sat }}}{L}=\frac{T_{h}-T_{C}}{m L} \simeq \frac{\nabla T_{\ell}}{m} .
$$

Substituting Eqs. (5-34) and (5-33) into Eq. (5-32) yields

$$
G_{C}^{0}=\frac{\nabla T_{\ell}}{m}-\frac{\delta C_{h}+\delta C_{C}}{L} .
$$

Substituting Eq. (5-35) into Eq. (5-31) yields

$$
S=\frac{\nabla T_{\ell}}{m}-\frac{k_{s} G_{s}^{0}+k G_{T}^{0}}{m\left(k_{s}+k_{\ell}\right)}-\frac{\delta C_{h}+\delta C_{C}}{L}-\left[\frac{\delta \gamma C_{i}^{0}}{k T}\right] \omega^{2} .
$$

The last term in Eq. (5-36) contains $w$, the frequency of the sinusoidal perturbation, which is given in terms of the wave length $\lambda$ by $\omega=\frac{2 \pi}{\lambda}$. Because most inclusions begin to break down at corners [24], 
a good estimate is $\lambda=W$. With additional assumptions of $G_{S}^{0} \simeq$ $\nabla T_{\infty}$ and $G_{T}^{0} \simeq \nabla T_{\ell}, E q .(5-36)$ takes the following form

$$
S=\frac{\nabla T_{\ell}}{m}-\frac{k_{s} \nabla T_{\infty}+k_{\ell} \nabla T_{l}}{m\left(k_{s}+k_{l}\right)}-\frac{\delta C_{h}+\delta C_{c}}{L}-\frac{\delta \gamma C_{i}^{0}}{k T}\left(\frac{2 \pi}{W}\right)^{2}
$$

Using the temperature gradient amplification factor $A=\nabla T_{\ell} / \nabla T_{\infty}$ at the axis of the inclusion as an approximation in Eq. (5-37), one obtains

$$
S=\frac{(A-1) k_{s}}{m\left(k_{s}+k_{\ell}\right)} \nabla T_{\infty}-\frac{\delta C_{h}+\delta C_{c}}{L}-\frac{\delta \gamma C_{i}^{0}}{k T} \frac{4 \pi^{2}}{w^{2}}
$$

The first term on the right hand side of Eq. $(5-38)$ is called the "gradient term". The second and third terms are respectively the "interfacial kinetic term" and "interfacial energy term". Since $A>1$ (see Appendix $A$ ), the gradient term has a positive effect on $S$ and hence is unstabilizing. The interfacial kinetic and energy terms both have negative contributions to $S$ and hence are stabilizing. The same conclusion was previously obtained on qualitative grounds in section 5.1. The condition for stability is $S \leq 0$.

\subsection{DISCUSSION}

\subsubsection{Special Cases}

We consider some limiting cases of Eq. (5.38).

\section{Case 1: No Temperature gradient}

With the applied gradient $\nabla T_{\infty}=0$, Eq. $(5-38)$ indicates that $S$ will always be negative. As intuitively expected, the theory indicates that inclusions of all sizes are stable in absence of a thermal gradient. 
Case 2: Migration Controlled by Interfacial Kinetics

When migration is entirely controlled by the kinetic resistance at the interface, large supersaturation $\left(\delta C_{C}\right)$ and undersaturation $\left(\delta C_{h}\right)$ are needed for the interfacial crystallization and dissolution. In such a case the interfacial kinetic term in Eq. (5-38) is large and negative, and the inclusion will be stable.

Case 3: Purely Diffusion-Controlled Migration

This situation is just the opposite of case 2. Neglecting the interfacial kinetic term in Eq. (5-38) results in the following conditions for stability

$$
s=\frac{(A-1) k_{s}}{m\left(k_{s}+k_{\ell}\right)} \nabla T_{\infty}-\frac{\Omega \gamma C_{i}^{0}}{k T} \quad \frac{4 \pi^{2}}{w^{2}} \leqslant 0
$$

Table 5-1 lists the physical property data in Eq. (5-39) obtained from reference [33]. Substituting values from Table 5-1 in Eq. (5-39) for $\mathrm{NaCl} / \mathrm{b}$ rine at $50^{\circ} \mathrm{C}$, the condition for stability in the pure diffusion case reduces to

$$
\nabla T_{\infty} \leqslant \frac{8.76 \times 10^{-3}}{(A-1) w^{2}} .
$$

For a typical inclusion with thickness $L$ of $10 \mu \mathrm{m}$ and width $W$ of $100 \mu \mathrm{m}$, the temperature gradient amplification factor $A$ is approximately 4 , hence the condition for stability reduces to $\nabla T_{\infty} \leqslant 30^{\circ} \mathrm{C} / \mathrm{cm}$.

In the range of applied temperature gradients between 0 and $30^{\circ} \mathrm{c} / \mathrm{cm}$, a typical inclusion of above mentioned size will be stable if its migration is controlled purely by diffusion. However, most inclusions show interfacial-resistance-controlled migration [9] and hence fall under case 2. 
Table 5-1. Physical property data

\begin{tabular}{|c|c|c|c|}
\hline Property & Units & $\begin{array}{l}\mathrm{NaCl} / \mathrm{Br} \text { ine } \\
\text { at } 50^{\circ} \mathrm{C}\end{array}$ & $\begin{array}{l}\mathrm{KCl} / \mathrm{Br} \text { ine } \\
\text { at } \mathrm{T}=40\end{array}$ \\
\hline$k_{s}$ & $\frac{W}{c m-K}$ & $5.01 \times 10^{-2}$ & $5.99 \times 10^{-2}$ \\
\hline $\mathrm{k}_{\ell}$ & $\frac{W}{c m-K}$ & $6.11 \times 10^{-3}$ & $5.81 \times 10^{-3}$ \\
\hline$\frac{1}{m}=\frac{d C^{S a t}}{d T}$ & $\frac{\text { moles }}{\mathrm{cm}^{3} \mathrm{~K}}$ & $2.1 \times 10^{-6}$ & $2.54 \times 10^{-5}$ \\
\hline$c_{i}^{0} \simeq c^{s a t}$ & $\frac{\text { moles }}{\mathrm{cm}^{3}}$ & $5.45 \times 10^{-3}$ & $4.53 \times 10^{-3}$ \\
\hline$D_{\ell}$ & $\frac{\mathrm{cm}^{2}}{\mathrm{~s}}$ & $2.6 \times 10^{-5}$ & $3.12 \times 10^{-5}$ \\
\hline$\sigma$ & $\left({ }^{\circ} \mathrm{C}\right)^{-1}$ & $-2 \times 10^{-3}$ & $-1.8 \times 10^{-3}$ \\
\hline$\gamma$ & $\frac{\text { ergs }}{\mathrm{cm}^{2}}$ & 75.65 & 75.65 \\
\hline$\rho_{s}$ & $\frac{\text { moles }}{\mathrm{cm}^{3}}$ & $3.68 \times 10^{-2}$ & $2.66 \times 10^{-2}$ \\
\hline$V_{m}$ & $\frac{\mathrm{cm}^{3}}{\text { motecute }}$ & $4.5 \times 10^{-23}$ & $6.24 \times 10^{-23}$ \\
\hline$k T$ & $\frac{\text { ergs }}{\text { molecule }}$ & $4.46 \times 10^{-14}$ & $4.32 \times 10^{-14}$ \\
\hline
\end{tabular}




\subsubsection{General Case}

In general, inclusions migrate under the combined influence of diffusion and interfacial kinetics. A general condition for stability relating the migration velocity $v^{0}$ and the applied temperature gradient can be derived as follows:

The flux of dissolved salt as given by Eq. $(4-5)$ can be rewritten as

$$
j_{s}=v^{0} \rho_{s}=D_{\ell}\left[\left(\frac{d C^{s a t}}{d t}-\sigma C^{s a t}\right) \nabla T_{\ell}-\frac{\delta C_{C}+\delta C_{h}}{L}\right]
$$

Substituting Eq. (5-41) into Eq. (5-38) with $\nabla T_{L}=\mathcal{A} \nabla T_{\infty}$ and $\frac{1}{m}=\frac{d C^{\text {sat }}}{d T}$ yields

$$
\begin{aligned}
& s=\frac{v^{0} \rho_{s}}{D_{\ell}}+\frac{(\mathcal{A}-1) k_{s}}{m\left(k_{s}+\dot{k}_{\ell}\right)} \nabla T_{\infty}-\left(\frac{1}{m}-\sigma c^{s a t}\right) A_{\nabla T}-\left[\frac{\Omega \gamma C_{j}^{0}}{k T}\right] \frac{4 \pi}{W^{2}} \\
& \text { Since } c_{i}^{0} \simeq t^{s a t} \text {, the above equation reduces to. }
\end{aligned}
$$

$s=\frac{v^{0} \rho_{s}}{D_{l}}-A \nabla T_{\infty}\left[\frac{\frac{k_{s}}{A}+k_{l}}{m\left(k_{s}+k_{\ell}\right)}-\sigma c^{s a t}\right]-\left[\frac{\Omega r c^{s a t}}{k T}\right] \frac{4 \pi^{2}}{w^{2}}$

Note that the second and the third terms in the right hand side Eq. (5-43) are always negative ( $\sigma$ is negative for $\mathrm{NaCl} / \mathrm{brine}$ and $\mathrm{KCl} / \mathrm{brine}$ ). The first term with $v^{0}$ is positive for the growing cold interface. The condition of stability at the cold interface is obtained by setting $S \leqslant 0$ in Eq. (5-43), yielding

$$
\frac{v^{0} \rho_{s}}{D_{l}} \leqslant A \nabla T_{\infty}\left[\frac{\frac{k_{s}}{d}+k_{l}}{m\left(k_{s}+k_{l}\right)}-\sigma c^{s a t}\right]+\left[\frac{\Omega \gamma c^{s a t}}{k T}\right] \frac{4 \pi^{2}}{w^{2}}
$$


The speed of a migrating inclusion of a given size and aspect ratio in a known gradient must satisfy Eq. (5-44) for stability. If the migration speed is not small enough to meet this condition, the inclusion will break down at the cold interface.

Equation (5-44) was derived for a planar interface growing from solution. At the hot interface of the migrating inclusion, dissolution instead of growth takes $p l a c e$ hence $v^{0}$ is negative. However, the applied gradient $\nabla T_{\infty}$ is also negative when viewed from a coordinate system with its origin at the dissolving surface.

From Eq. (5-44), therefore, the stability condition for the hot interface of the inclusion is:

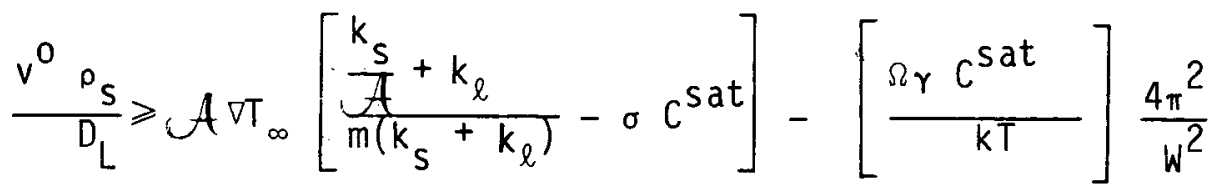

Let $\quad A=A\left[\frac{\frac{k}{A^{+}}+k}{m\left(k_{s}+k_{l}\right)}-\sigma c^{s a t}\right] \cdot \frac{D_{l}}{\rho_{s}}$

and $B=\left[\frac{\Omega \gamma C^{s a t}}{k T}\right]\left(\frac{4 \pi^{2}}{w^{2}}\right) \cdot \frac{D_{l}}{\rho_{s}}$

Then Eq. (5-44) and (5-45) give the following conditions for stabi ity

at the cold Interface:

$$
v^{0} \leqslant A \nabla T_{\infty}+B
$$

at the Hot Interface

$$
v^{0} \geqslant A \nabla T_{\infty}-B
$$

Equations (5-48) are general stability conditions for an al1-liquid inclusion in a crystal supporting an external temperature gradient. 


\subsubsection{Comparison with Experimental Data}

Figure 5-5 schematically shows a sketch of Eqs. (5-48) with the regions of stability for an inclusion with specific values of $L$ and $W$. The stability region bound by straight 1 ines in Figure $5-5$ is valid only for constant values of $L$ and $W$. In practice, however, a given inclusion flattens in the direction of applied temperature gradient as the gradient is increased (i.e. with an increase in $\nabla T_{\infty}, L$ decreases and $W$ increases keeping the inclusion volume $W^{2} L$ constant). Since parameters $A$ and $B$ defined in Eqs. (5-46) and (5-47) depend on $L$ and $W$, the slope and the intercept of the stability lines on figure 5-5 should actually vary with $\nabla T_{\infty}$. Therefore the stability region is, in fact, determined by the complex inter-relation between $v^{0}, \nabla \nabla_{\infty}^{\top}, L$, and $W$ for a given inclusion.

Table 5-2 summarizes the values of parameters $A$ and $B$ at a specified temperature for $\mathrm{NaCl}$ and $\mathrm{KCl}$ as the inclusion width $\mathrm{W}$ is varied keeping the thickness $L$ constant at $10 \mu \mathrm{m}$. The physical property data of Table 5-1 are used to compute $A$ and $B$. For an inclusion migrating with a velocity $v^{0}$ under the combined influence of diffusion and interfacial kinetics in a crystal supporting a temperature gradient $\nabla T_{\infty}$, the experimental values of $L$ and $W$, together with the physical property data at the temperature of the inclusion, determine whether or not the condition stated in Eqs. (5-48) are met.

A simpler stability criterion exists for inclusion migrating under purely diffusion control. For the cold interface of the inclusion, this condition is given by Eq. (5-39), which can be rewritten as 


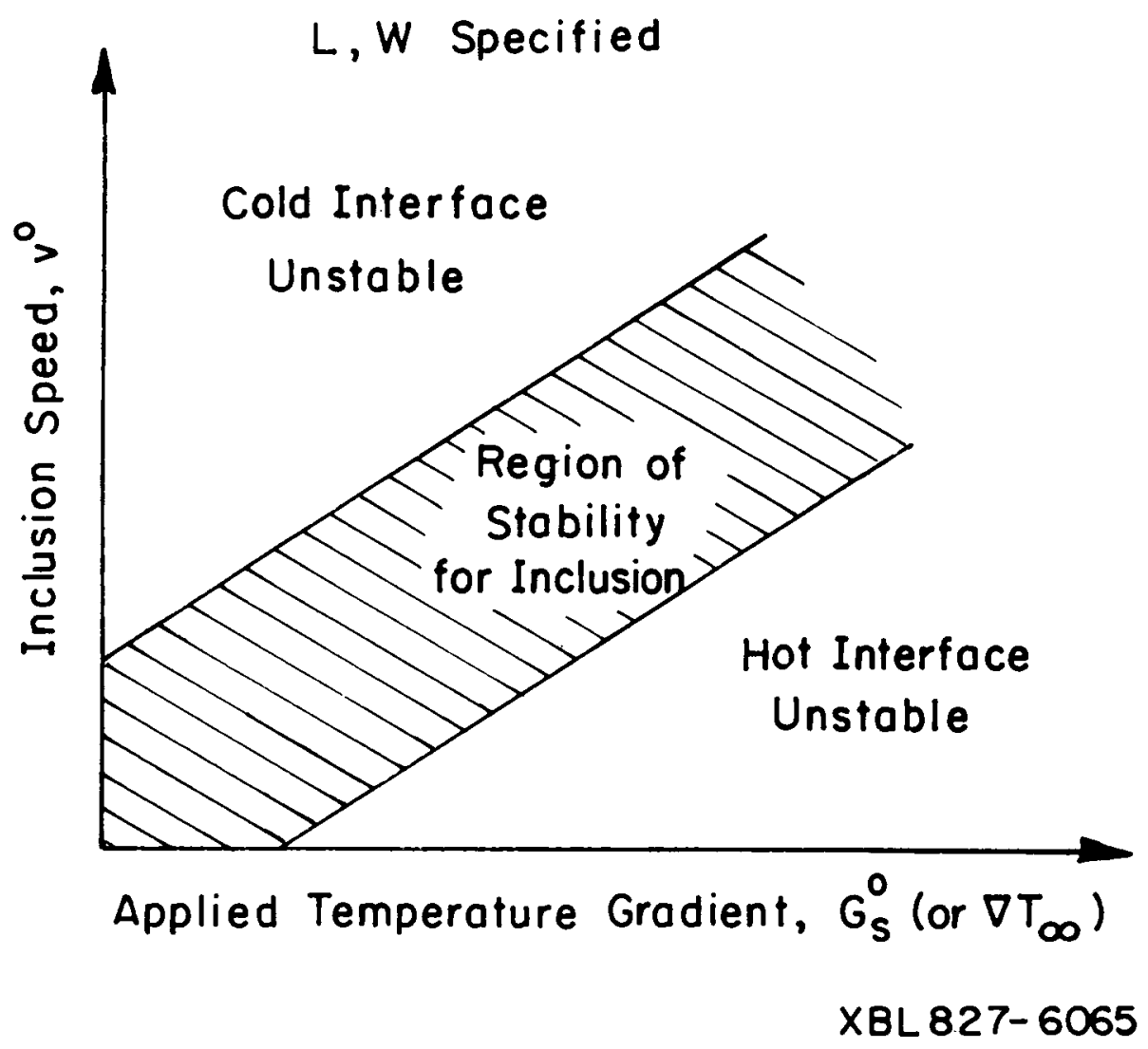

Figure 5-5. Schematic representation of the region of stability for an inclusion with specific values of $L$ and $W$ migrating under the combined influence of diffusion and interfacial kinetics. 
Table 5-2. Stability parameters for inclusions in $\mathrm{NaCl}$ and $\mathrm{KCl}$ (Inclusion thickness $L=10 \mu \mathrm{m}$ )

\begin{tabular}{|c|c|c|c|c|}
\hline \multirow{2}{*}{$\begin{array}{l}\text { Inclusion } \\
\text { Width, } W \\
\mu \mathrm{m}\end{array}$} & \multicolumn{2}{|c|}{$\begin{array}{c}\mathrm{NaCl} \\
T=50^{\circ} \mathrm{C}\end{array}$} & \multicolumn{2}{|c|}{$\begin{array}{l}\mathrm{KCT} \\
\mathrm{T}=40^{\circ} \mathrm{C}\end{array}$} \\
\hline & $\begin{array}{l}\mathrm{A}[\mathrm{Eq} \cdot(5-46)] \\
\left(10^{8} \mathrm{~cm}^{2} /^{\circ} \mathrm{C}-\mathrm{s}\right)\end{array}$ & $\begin{array}{c}\mathrm{B}[\mathrm{Eq} \cdot(5-47)] \\
\left(10^{8} \mathrm{~cm} / \mathrm{s}\right)\end{array}$ & $\begin{array}{l}A[\mathrm{Eq} \cdot(5-46)] \\
\left(10^{8} \mathrm{~cm}^{2} /^{\circ} \mathrm{C}-\mathrm{s}\right)\end{array}$ & $\begin{aligned} \mathrm{B} & {[\mathrm{Eq} .(5-47)] } \\
& \left(10^{8} \mathrm{~cm} / \mathrm{s}\right)\end{aligned}$ \\
\hline 10 & 1.23 & 1160.0 & 4.44 & 23600.0 \\
\hline 25 & 1.70 & 186.0 & 5.20 & 3770.0 \\
\hline 50 & 2.42 & 46.4 & 6.47 & 944.0 \\
\hline 100 & 3.32 & 11.6 & 8.16 & 236.0 \\
\hline 500 & 5.40 & 0.5 & 12.42 & 9.4 \\
\hline 1000 & 5.88 & 0.1 & 1.3 .67 & 2.3 \\
\hline$\infty$ & 6.52 & 0.0 & 15.25 & 0.0 \\
\hline
\end{tabular}




$$
\nabla T_{\infty} \leqslant\left(\frac{\Omega_{\gamma} C^{S a t}}{k T}\right)\left(\frac{4 \pi^{2\left(k_{s}+k_{\ell}\right)}}{k_{s}(1 / m)}\right)\left(\frac{1}{(\mathcal{A}-1) w^{2}}\right)
$$

Experimentally, inclusions can be forced to migrate with up to 80 percent of the theoretically calculated diffusion controlled velocities by increasing the axial load on the solid crystal (see Section 3.3). To test the condition in Eq. (5-40), four inclusions ( $F, G, H, I)$ with sharp boundaries were followed in a KCl crystal supporting an external temperature gradient and axial load of $4 \mathrm{MPa}$. As the temperature gradient $\nabla T_{\infty}$ was varied, the inclusion size ( $L$ and $W$ ) was carefully noted at regular intervals. The results are shown in Figure 5-6. Most experimental points are well within the stable region.

The inclusions shown in Figure 5-1 are migrating in a $\mathrm{KCl}$ single crystal to which an external temperature gradient of $40^{\circ} \mathrm{C} / \mathrm{cm}$ and axial compressive load of $\sim 4 \mathrm{MPa}$ is imposed. These inclusions are expected to migrate with up to 80 percent of the theoretical diffusion-controlled velocities. The inclusions marked $X$ and $Y$ on Figure 5-1 are clearly unstable by virtue of having long trailing veils of liquid which are separating away from the cold interface. Some other inclusions also show similar veils of instability. Such inclusions are within the unstable region of Figure $5-6$.

On the other hand, some inclusions of approximately same size as that of $X$ and $Y$ (which will also fall in the unstable region of Figure 5-6) do not show the trailing veils of instability. These apparently stable inclusions may in fact be unstable inclusions whose veils may not have grown sufficiently long, since the onset of the instability, to be clearly visible at the magnification used in the photomicrograph 


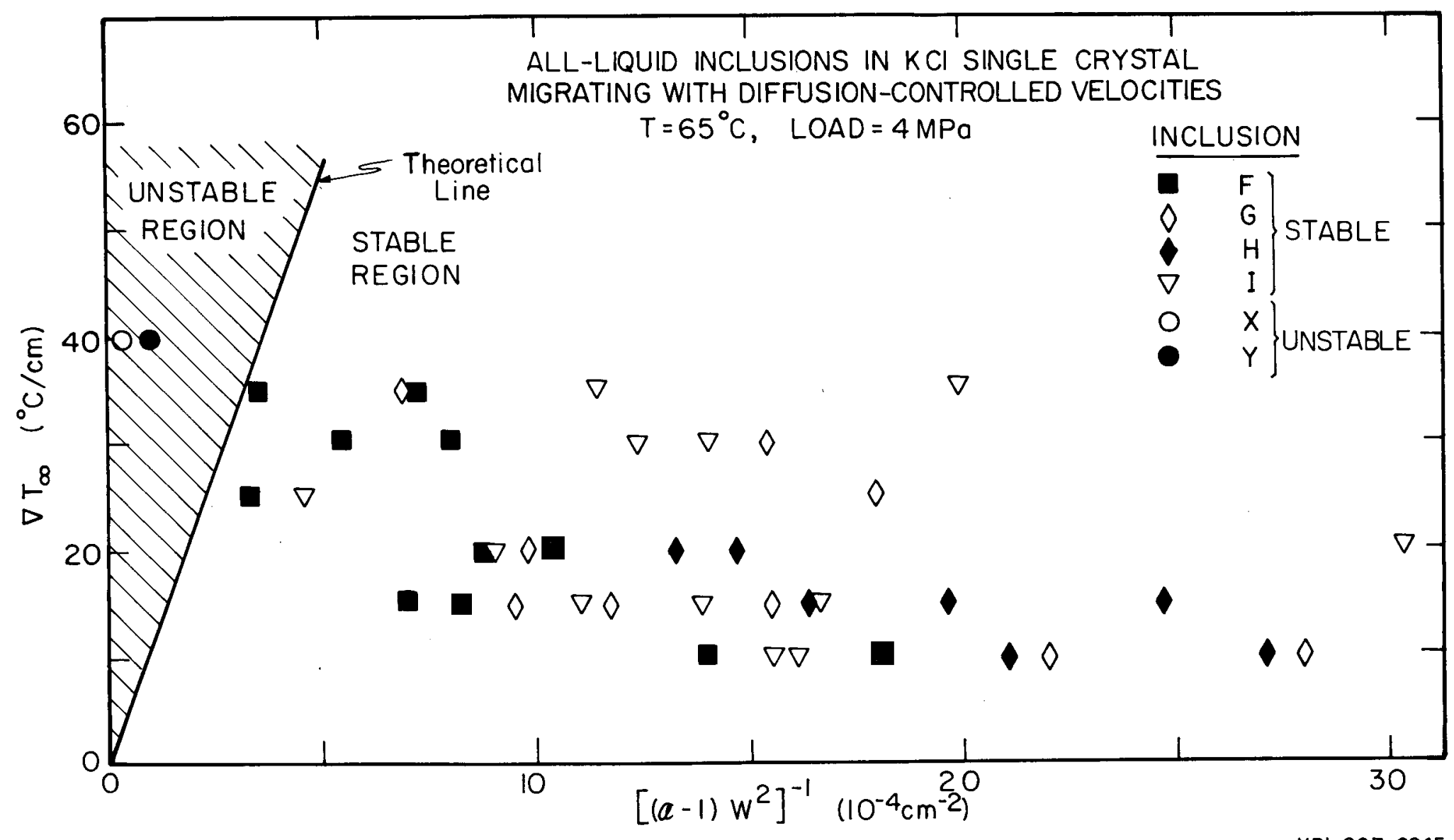

Figure 5-6. Experimental data for several stable and unstable inclusions migrating with diffusion-controlled velocities in a $\mathrm{KCl}$ single crystal. 
of Figure 5-1. In other words, the presence of trailing veils of liquid is a sufficient but not a necessary condition of interfacial instability.

The theoretical 1 ine in Figure $5-6$ is computed for an extreme limit of purely diffusion-controlled migration. In practice, however, most inclusions exhibit certain interfacial mass transfer resistance even when high axial compressive loads are applied to the crystal. It will be further elaborated in Chapter 6 that two inclusions of the same size under otherwise identical conditions often have different values of interfacial parameters (and hence different stability criteria) due to stochastic nature of interaction between dislocations and migrating inclusions.

\subsubsection{Comparison with the Work of Anthony and Cline}

The approach used in the present work is more accurate compared to the stability condition previously proposed by Anthony and Cline [24]. Based on experimental data, Anthony and Cline [24] proposed a maximum

value of $9.4 \times 10^{-8} \mathrm{~cm}^{2} / \mathrm{sec}^{\circ} \mathrm{C}$ for the ratio $\mathrm{v} / \nabla \mathrm{T}_{\infty}$, above which $\mathrm{a} 11$ inclusions become unstable. In their data, temperature does not appear to be held constant for different inclusions. Their data obtained for several inclusions in a $\mathrm{KCl}$ single crystal in a temperature gradient inherently imply that the inclusions were at different temperatures by virtue of being at different locations in the crystal. Moreover, the inclusion size and shape is unaccounted for in their work.

It is clear from Eqs. (5-48) that both temperature and inclusion shape and size are very important parameters in stability analyses. 
Although Anthony and $\mathrm{Cl}$ ine data [24] are abundant, it is not possible to make any meaningful comparison of their data to the present work.

\subsection{SUMMARY}

An approximate analytical approach is used to explain the interfacial instability of all-liquid inclusions in alkali halide single crystals supporting an external temperature gradient. It is clear that the interfacial kinetics is a strong stabilizing force and that inclusions migrating with interfacial kinetic control are always stable. For a diffusion controlled migration, the inclusions are unstable above a temperature gradient which is inversely proportional to the square of the inclusion width $W$. For a mixed diffusion-interfacial kinetics controlled migration, stability conditions are separately derived for the cold and the hot interfaces of the inclusion. 
CHAPTER 6

\section{RESULTS AND DISCUSSIONS}

\subsection{ALL-LIQUID INCLUSIONS}

\subsubsection{Potassium Chloride Single Crystals}

\subsubsection{Solid Unstressed}

According to the BCF theory discussed in Chapter 4 , the rate of removal of solid from the hot face of an inclusion depends on the presence of dislocations intersecting this surface. Dissolution steps are provided by screw dislocation ledges on the surface. Assuming a dislocation density of $10^{5} \mathrm{~cm}^{-2}$, as estimated by the etching method described in chapter 3 , and an inclusion $50 \mu \mathrm{m}$ wide, the average number of dislocations intersecting the dissolving face is 2.5. Therefore, substantial differences in the coefficient k of Eq. (4-10) can be expected from one inclusion to another due solely to the statistical variations of this number. Changes in crystal growth rate with size (size-dependent growth) and variations of growth rate for a given size (growth dispersion) are well-documented phenomena [34] which support the above argument.

In addition, the dissolution rate will in general be different for two inclusions which are intersected by the same number of dislocations on the hot face. The temperature gradient, and hence the temperature, vary considerably over the face perpendicular to the thermal gradient (see Appendix $A$ ). Hence, a dislocation near the axis will be a more prolific source of dissolution steps than one near the edge of the inclusion. 
Thus, the number and the location of the dislocations intersecting the hot face of the inclusions are believed to be responsible for the average velocity under specified conditions as well as the dispersion about this average value. The additional experimental results described below support this general interpretation of inclusion migration.

Figure 6-1 shows the migration velocity of a single inclusion in $\mathrm{KCl}$ which was followed for $72 \mathrm{~h}$. Periodic measurements of the position of the inclusion allowed the average speed between successive observations to be determined. These average velocities are shown as the horizontal line segments on Figure $6-1$. The long segments indicate a large interval between measurements; they do not imply that the inclusion velocity was constant over this interval. The velocity of the inclusion followed in this test changed by a factor of four, from a minimum value of $\sim 8 \mu \mathrm{m} / \mathrm{h}$ to a maximum of $\sim 32 \mu \mathrm{m} / \mathrm{h}$. The change was fairly smooth--the velocity tended to increase or decrease continuously for long periods of time. This behavior is most easily interpreted in terms of the dynamic interaction between the inclusion and dislocations in the crystal.

The dislocations in the crystal are modeled as lines which intersect the hot face of the inclusion at random of $f$-axis locations with random angles from the normal to the surface. The interfacial kinetic coefficient depends on the number of dislocations which intersect the hot side of the inclusion as well as their off-axis locations, which determine the application $\nabla T_{\ell}$ (see Figure $A-1$ in Appendix $A$ ). Since $\nabla T_{\ell}$ is greatest at the center of the inclusion and $\nabla T_{\infty}=\nabla T_{\ell}$ at the 


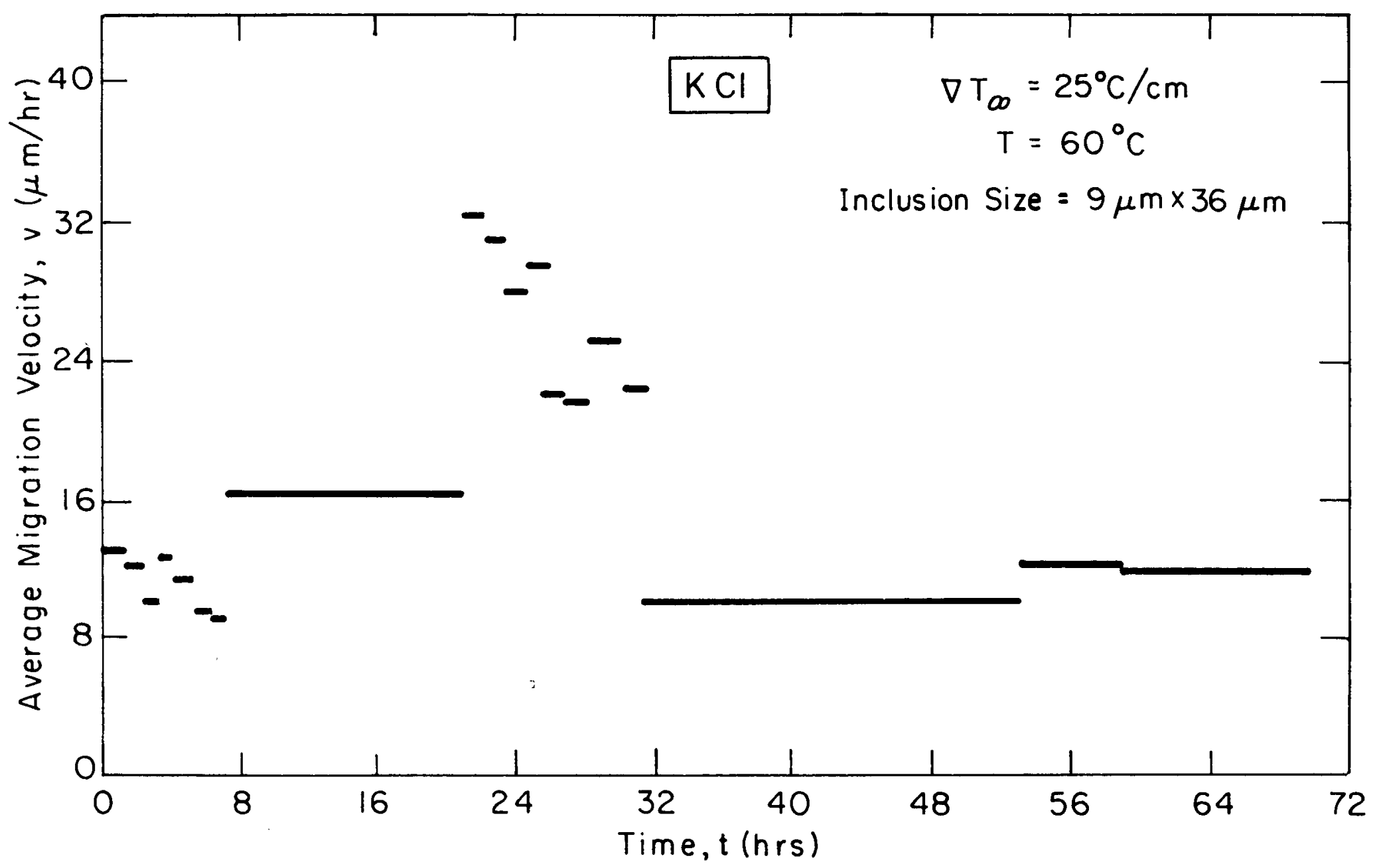

Figure 6-1. Migration velocity of an inclusion in $\mathrm{KCl}$ as a function of time. 
inclusion boundary (Appendix $A$ ), there is no fixed value of $\nabla T_{\ell}$ for a given inclusion which may encounter a dislocation intersection whose position on the hot face continuously varies as it migrates.

In general, a dislocation does not intersect the hot face at $90^{\circ}$, so that as the inclusion moves, the lateral position of the intersection changes. This causes the inclusion to speed up (if the intersection approaches the axis) or to slow down (if the intersection moves towards the edges). In addition, the inclusion can pick up or lose dislocations as it moves, which would result in abrupt velocity changes. This type of intersection is consistent with the sizable variations of the speed of a single inclusion (Figure 6-1). The model also provides an explanation for the large scatter in the velocities of different inclusions measured under the same nominal conditions.

The pattern shown in Figure 6-1 can be rationalized in the manner shown schematically in Figure 6-2. At time zero, imagine that the hot face of the inclusion is intersected by a single dislocation (No. 1) close to the center of the face. In general, the dislocation does not intersect the surface at $90^{\circ}$, so that as the inclusion moves, the intersection point moves further off axis. At off-axis positions, $\nabla T_{\ell}$ is less than it is close to the axis, and hence inclusion slows down. Somewhere between 8 and 20 hours the inclusion picks up another dislocation designated as No. 2 in Figure 6-2. The three dislocation intersections with the desolving face result in a several-fold increase in the inclusion velocity. As the intersection of No. 2 dislocation with the hot face in off-axis, the inclusion begins to slow down. The inclusion followed in Figure 6-1 seems to be capable of sustaining a minimum 

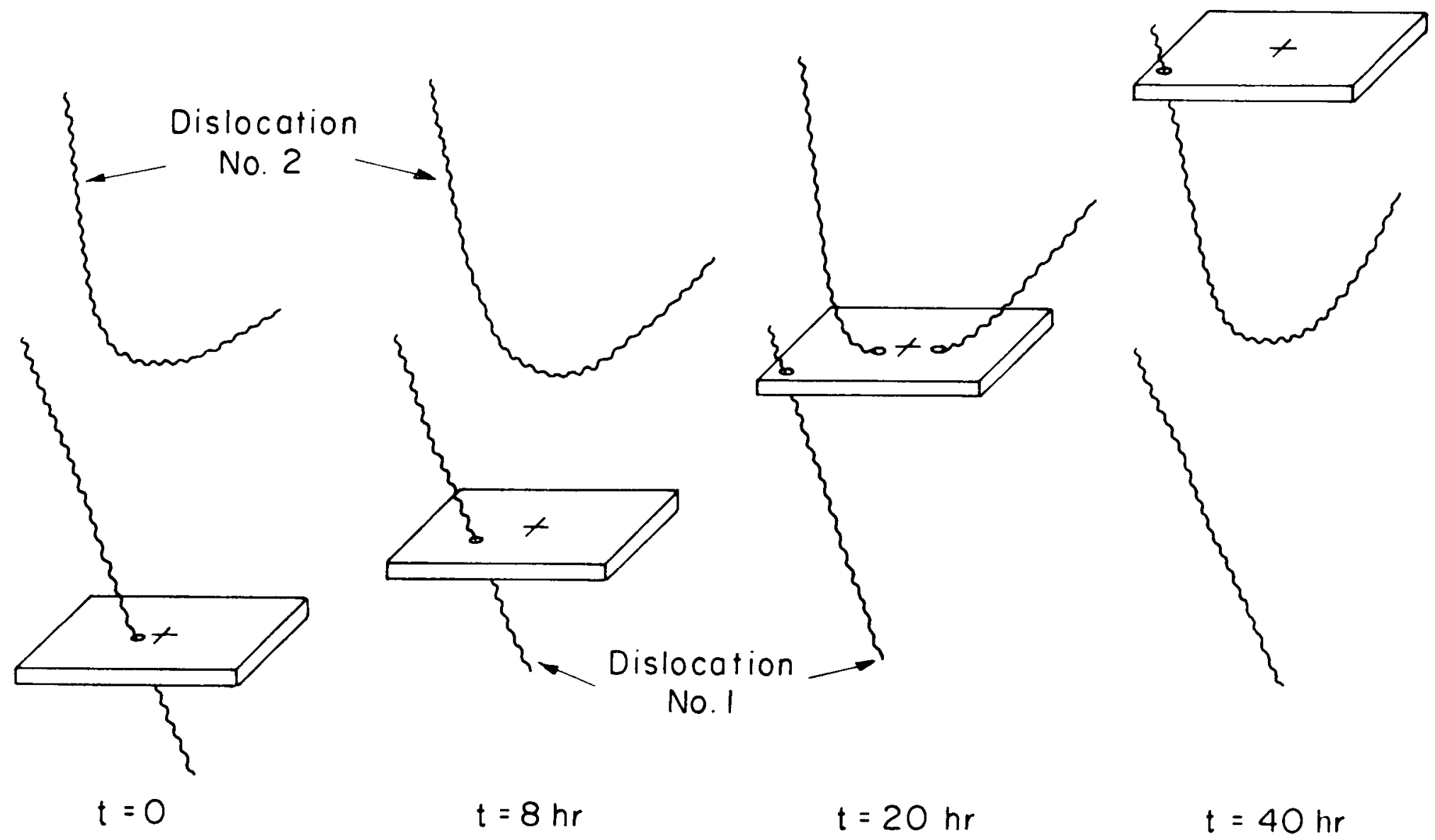

$t=40 \mathrm{hr}$

XBL $8010-6068$

Figure 6-2. Schematic sketch of dislocations in the crystal as they encounter migrating inclusions. 
speed of $\sim 8 \mu \mathrm{m} / \mathrm{hr}$, which may represent the velocity in absence of any dislocation intersection with dissolving face.

Although the scenario described above is only illustrative, it is clear that the dislocation hypothesis is quite consistent with the stochastic nature of the measured inclusion speeds seen in Figure 6-1. Essentially the same ideas were also used by Lemaire and Bowen [35] to explain pore migration in $\mathrm{KCl}$ due to a temperature gradient.

Tests were made to distinguish between control of the migration velocity by liquid diffusion and by interfacial kinetics. In these tests, several inclusions were selected and the applied temperature gradient $\nabla T_{\ell}$ was varied while keeping the temperature in the vicinity of the inclusions constant. Each time $\nabla T_{\ell}$ was changed, the inclusions changed shape. In general, large gradients $\nabla T_{\ell}$ are associated with small inclusion thickness $L$. This shape change, and the reverse process of shape relaxation, have been analyzed by 01 ander and coworkers [9]. Figure 6-3 shows the variation in inclusion size with applied temperature gradient according to Eq. (A12) of Ref. [9].

For interface kinetic control, Eqs. (4-15) and (4-17) indicate that the velocity should depend upon the product $L \nabla T_{\ell}$ raised to some power other than one. For each $\nabla \mathrm{T}_{\ell}$ and inclusion shape, the centerline $\nabla T_{\ell}$ was calculated by the method described in Appendix A. Figure 6-4 shows the velocities of five inclusions plotted in this manner. The slopes on the $\log -\log$ plots range from 2.0 to 3.4 . Figure $6-4$ also shows the diffusion-controlled limits calculated from Eq. (4-6) for the two temp- 


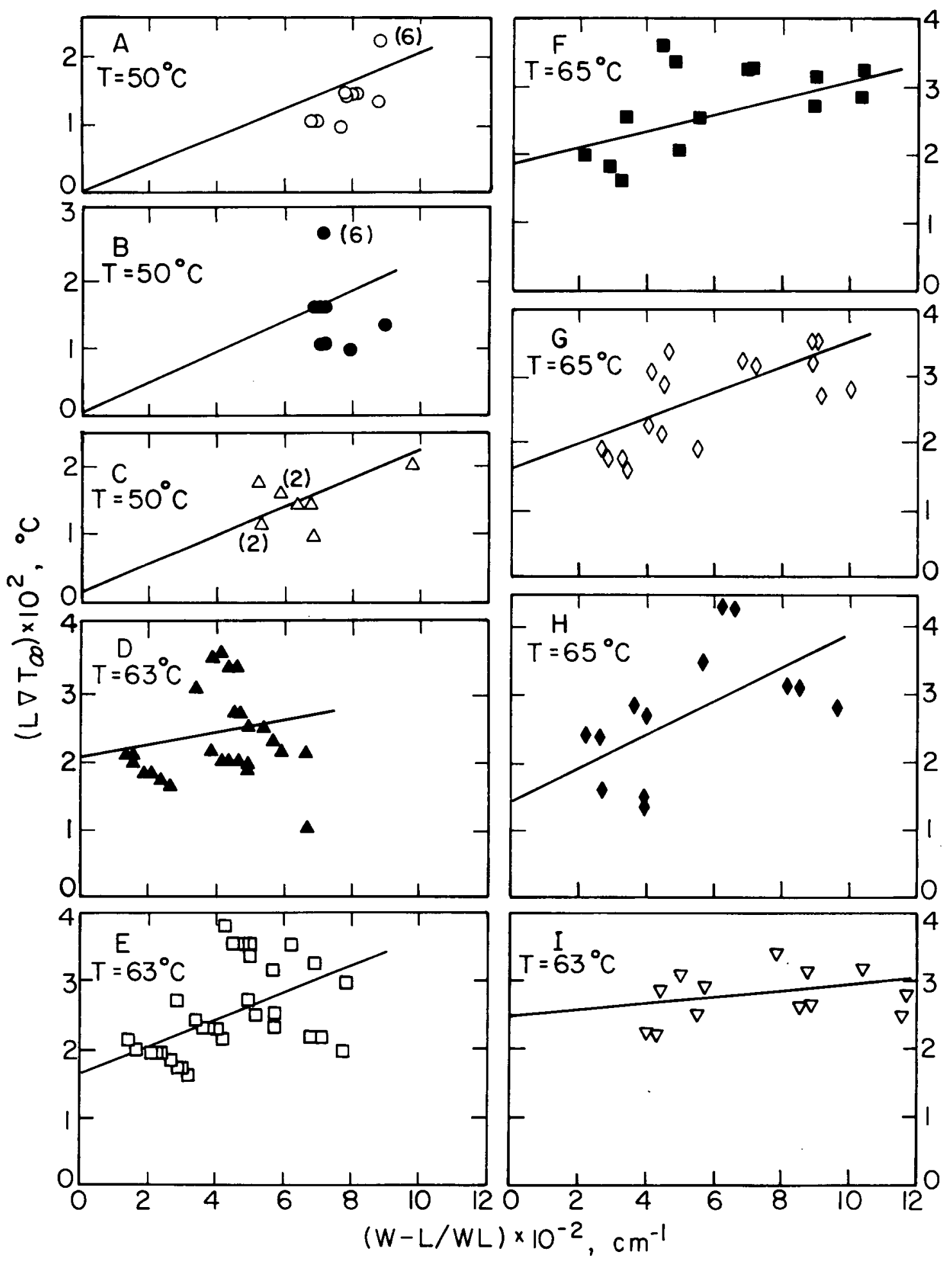

XBL 81 8-6237

Figure 6-3. The variation in inclusion size with applied temperature gradient fitted to Eq. (A12) of Ref. [9]. The inclusion volume is $W_{0}^{3}=W^{2} L$. 


\section{8}

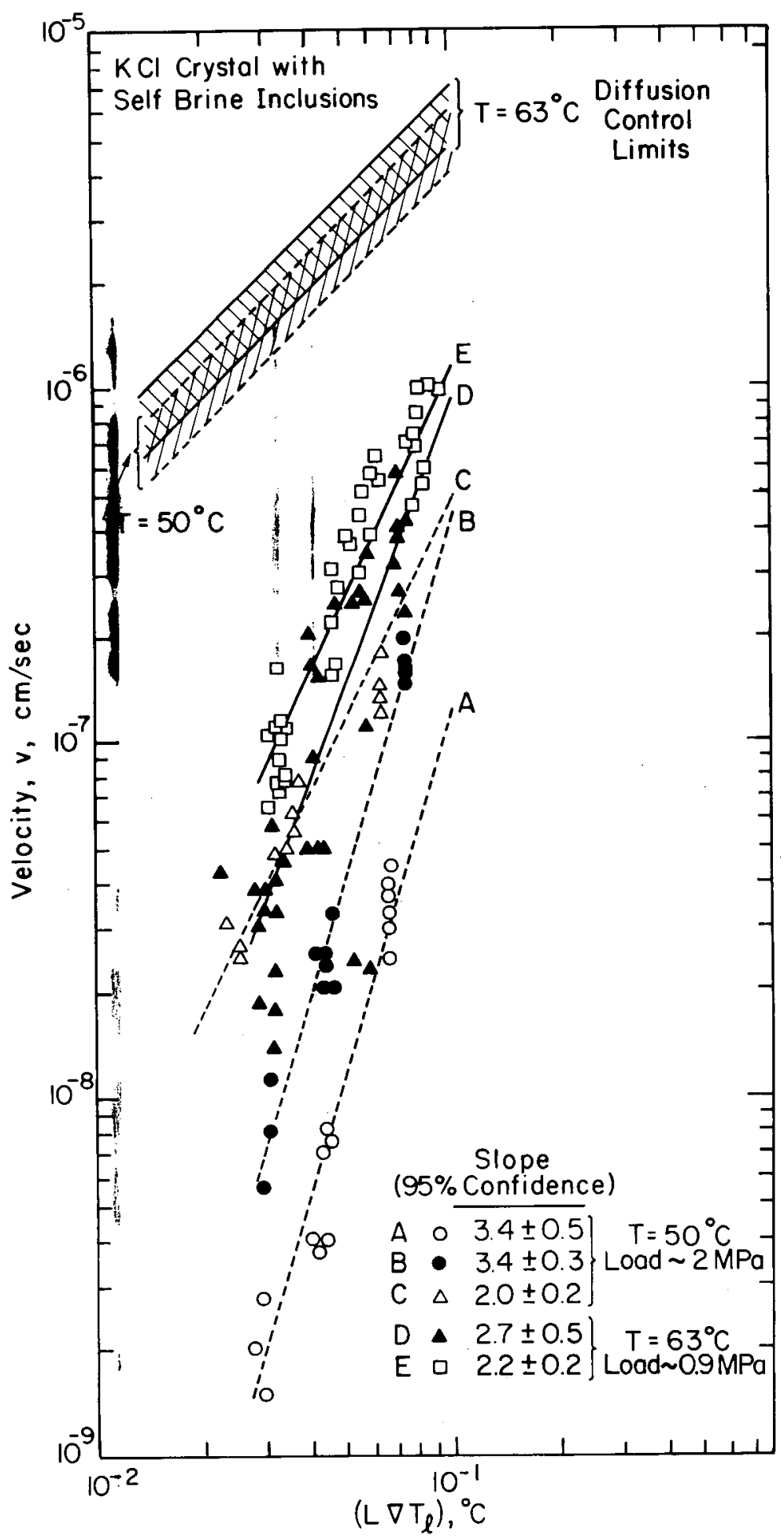

$X B L$ 8 $\mid 8-6238$

Figure 6-4. Variation of migration velocity of five inclusions in $\mathrm{KCl}$ with the applied temperature gradients. The lines represent best fit curve from the theory [Eq. (4-16)]. 
eratures with the required physical property data taken from Ref. [33]. The upper and lower limits correspond to the lowest and highest values of inclusion thickness $(\sim 9 \mu \mathrm{m} \leq \mathrm{L} \leq \sim 13 \mu \mathrm{m})$ observed experimentally as the temperature gradient was varied. The observed velocities for all five inclusions are one to three orders of magnitude lower than the diffusion-controlled limits, indicating that interfacial kinetics is rate-limiting. The slopes close to 2.0 are in accord with the low- $\xi$ limit of the BCF model (Eq. [4-17]). The higher values of exponents are attributed to the impurity effects which, as discussed earlier, is manifest as the critical undersaturation parameters $\xi^{\star}$. As $\xi^{\star}$ increases, Eq. (4-16) predicts that $v$ should increase with $L \nabla T_{\ell}$ more rapidly than $\left(L \nabla T_{\ell}\right)^{2}$. This is proved mathematically in Appendix $B$. Velocity calculations require specification of the temperature gradient $\nabla T_{\ell}$. Previous work of Anthony and Cline [10], and Geguzin et a1 [11] as well as the analysis needed for preparation of Figure 6-4, utilized the temperature gradient along the inclusion axis, which may be several times larger than the local $\nabla \mathrm{T}_{\ell}$. When the inclusion velocity is controlled by interface kinetics, this choice is valid only if the defect responsible for solid dissolution is located at the center of the dissolving face. However, the dislocation intersections are randomly distributed over the hot face of the inclusion, and for each intersection, the local $\nabla T_{\ell}$ is the appropriate one. No theory of inclusion migration provides guidance on the choice of $\nabla T_{\ell}$. Yet because the inclusion retains $\{100\}$ faces perpendicular to the applied temperature gradient, it is evident that only a single value of $\nabla T_{\ell}$ controls the 
migration speed. If the kinetics of dissolution, diffusion, and crystallization followed the local value of $\nabla T_{\ell}$, the inclusion would adopt a spherical shape, as discussed in Chapter 5. Obviously the great stability of the $\{100\}$ faces prevents such deformation. As the reverse of crystal growth, dissolution proceeds by removal of molecules from surface steps which as a result move across the surface to the inclusion edges [36]. This process retains a flat dissolving surface except for pyramidal depressions centered on each dislocation intersection. The use of the center-line $\nabla T_{\ell}$ in data analysis is arbitrary, but a choice is unavoidable.

\subsubsection{Effect of stress}

Figure 6-5 shows the effect of increasing the axial load on the crystal by several fold during the migration process. At the time of the stress increase, the migration velocities of the two inclusions being followed jumped abruptly and continued to increase with time under the higher load. This behavior is attributed to the activation of dislocation sources in the crystal by the increase in load and their continued movement by creep at the high load. As a result of the increased dislocation motion, more dislocation intersections with the inclusions occurred, thereby decreasing the resistance to dissolution of the hot face for the prevailing undersaturation and increasing the inclusion speeds. The velocities do not return to their initial values upon removal of the load, so the effect is not elastic.

To observe the effect of axial load on the migration speed, another set of experiments was performed. First, the velocities of four 


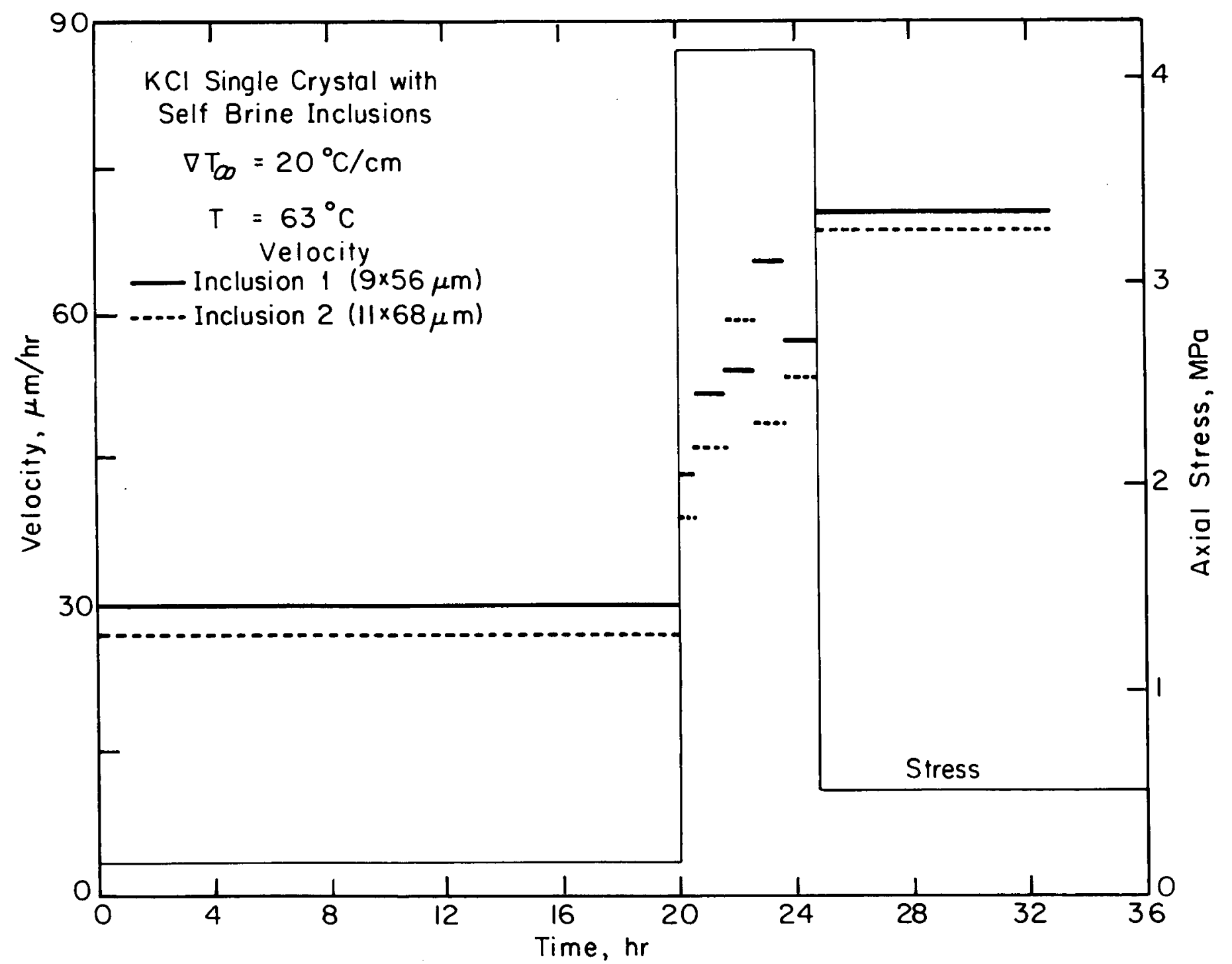

Figure 6-5. Effect of increasing the mechanical load on a salt crystal containing inclusions migrating in a temperature gradient. 
inclusions ( $F, G, H$, and I) were followed as the applied temperature gradient was varied at constant temperature and low axial load. The same four inclusions were then monitored at axial loads of about $4 \mathrm{MPa}$. The results are plotted in Figure 6-6 for both conditions. As expected from the dislocation arguments presented here, the velocities are higher at the higher load, attaining from 60 percent to 80 percent of the diffusion-controlled limits. In addition, the velocities are proportional to $\left(L \nabla T_{\ell}\right)$ at high axial load and to $\left(L \nabla T_{\ell}\right)^{2}$ at low axial load. This load response of the inclusion velocities is in excellent agreement with the model. At low loads the dislocation density in crystal is small and there are few dislocation intersections with the dissolving face of the inclusions. At high loads the dislocation density is increased by deformation and more dislocations intersect the inclusion, making dissolution of the hot face easier. As a result of the reduced interfacial kinetic resistance, the inclusions move at nearly the liquid diffusion-controlled rate.

\subsubsection{Evaluation of Interfacial Kinetic Parameters}

The experimental aspect ratio data fitted to Eq. (A12) of Ref. [9] are shown in Figure 6-3 for nine inclusions (A-I). The interfacial energy $\gamma$ and the critical undersaturation $\xi^{*}$ obtained from the fitting are listed in Table 6-1. Similarly by fitting the migration speed data in Figures 6-4 and 6-6 to Eq. (4-16), the value obtained for interfacial kinetic coefficient $k$ and critical undersaturation $\xi^{*}$ are also listed in Table 6-1. The interfacial energy $\gamma$ is the same orders of magnitude as the values reported by Anthony and $\mathrm{Cl}$ ine [10], and Geguzin et al [11]. 


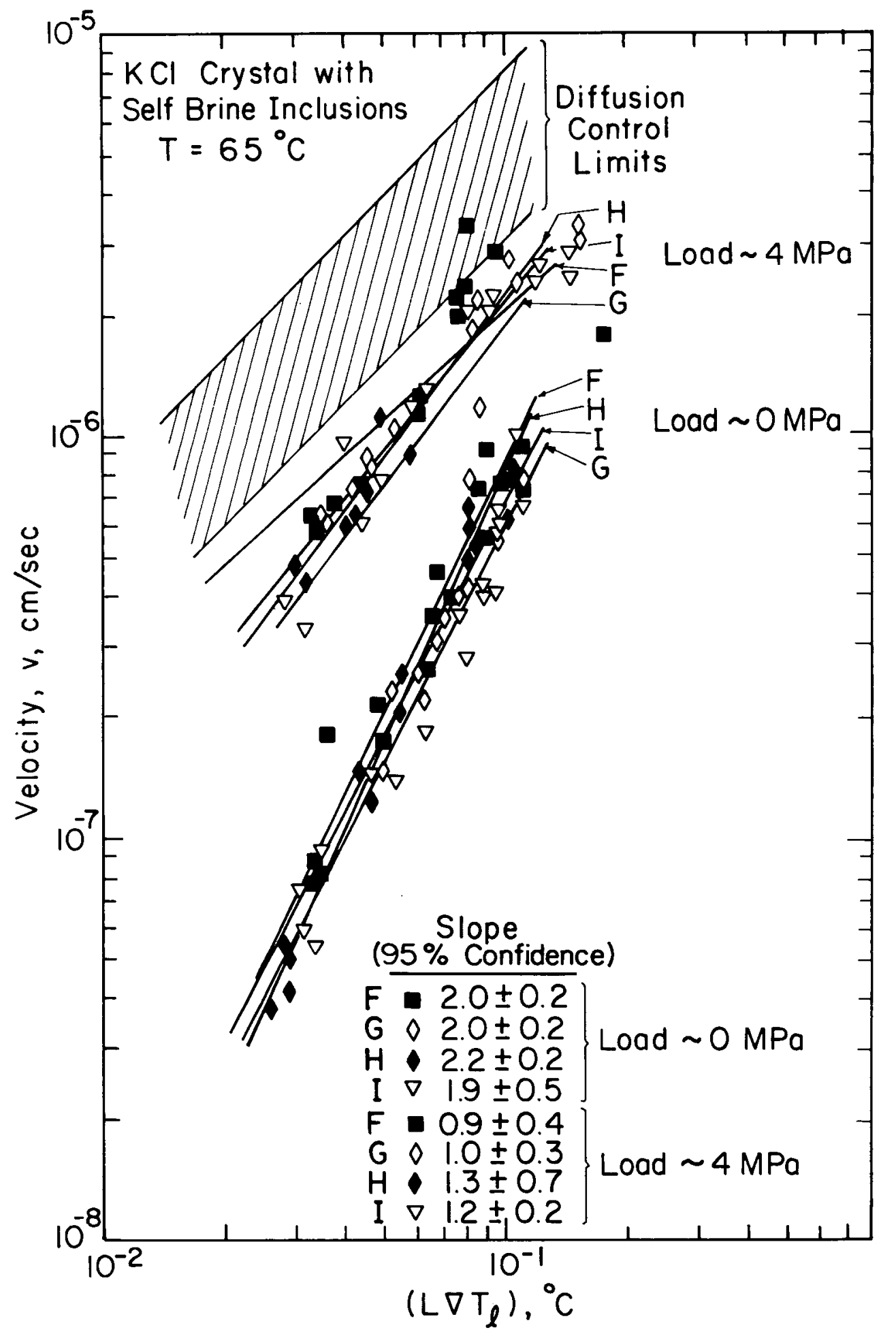

XBL818-6239

Figure 6-6. Effect of applied axial load on the inclusion migration speeds. The lines represent best fit curves from the theory [Eq. (4-16)]. 
Table 6-1. Interfacial parameters of KCl (self brine).

\begin{tabular}{|c|c|c|c|c|c|}
\hline $\begin{array}{l}\text { Inclusion } \\
\text { No. }\end{array}$ & $\begin{array}{l}\text { Temp. } \\
{ }^{\circ} \mathrm{C}\end{array}$ & $\begin{array}{l}\text { (100) Surface } \\
\text { energy, ergs } / \mathrm{cm}^{2} \\
\text { from Eq. }(\mathrm{A} 12) \\
\text { of Ref. [9] }\end{array}$ & $\begin{array}{l}\text { Critical Undersaturation, } \\
\text { From Eq. (A12) }\end{array}$ & $\begin{array}{l}\xi^{\star} \times 10^{5} \\
\text { From Eq. }(4-16)\end{array}$ & $\begin{array}{l}\text { Kinetic Coefficient } k \\
\text { (mol/cm } 2-s) \times 10^{2} \\
\text { From Eq. }(4-16)^{b}\end{array}$ \\
\hline $\begin{array}{l}A \\
B \\
C \\
D \\
E \\
F \\
G \\
H \\
I\end{array}$ & $\begin{array}{l}50 \\
50 \\
50 \\
63 \\
63 \\
65 \\
65 \\
65 \\
65\end{array}$ & $\begin{array}{r}38 \\
49 \\
39 \\
15 \\
30 \\
20 \\
28 \\
36 \\
6\end{array}$ & $\begin{array}{l}0 \\
0.4 \\
0.7 \\
9 \\
7 \\
7 \\
7 \\
6 \\
10\end{array}$ & $\begin{array}{r}21 \\
22 \\
1 \\
10 \\
9 \\
8 \\
\sim 0 \\
3 \\
\sim 0\end{array}$ & $\begin{array}{c}1 \\
3 \\
3 \\
9 \\
18 \\
7(370)^{a} \\
6(270) \\
8(100) \\
6(72)\end{array}$ \\
\hline
\end{tabular}

avalues in parentheses refer to crystals stressed to $4 \mathrm{MPa}$; all others refer to low-load experiments.

$b_{\nabla T_{1}}$ taken to be the centerline value. 
The critical undersaturation ranges from $10^{-5}$ to $10^{-4}$, but there are some inconsistencies between the values deduced from inclusion aspect ratios using Eq. (A12) of Ref. [9] and from the velocity measurements by Eq. (4-16). The interfacial kinetic coefficient with no load on the crystal are between $10^{-2}$ and $10^{-1} \mathrm{~mol} / \mathrm{cm}^{2} \mathrm{~s}$. The substantial variability of these results is a reflection of the stochastic nature of the dislocation intersection with the dissolving face of the inclusion as discussed earlier.

The numbers in the parenthes is in the last column of Table 6-1 show the best fit values of $k$ for inclusions F-I after the load on the crystal had been increased to $\sim 4 \mathrm{MPa}$. The very large interfacial coefficients imply diffusion control of the migration process.

\subsubsection{Sodium Chloride Single Crystal}

\subsubsection{Self Brine Inclusions}

Balooch and 0lander [37] noted that the data of Anthony and Cline [10], and Geguzin et al [11] are in single crystals of $\mathrm{KCl}$, whereas from the point of view of applications in salt repository, it is more appropriate to obtain data in $\mathrm{NaCl}$ single crystals. Their data suggest a rapid increase in migration speed with increase in inclusion size $W$. Assuming interfacial kinetic control, the increase in migration speed with width $W$ can arise from a larger temperature gradient amplification factor $\mathcal{A}$ (Figure $A-1$ ) and from the fact that the large inclusions should intersect more dislocations than smaller ones, which in turn, increase the dissolution rate.

In Figure 6-7 data of Anthony and $\mathrm{Cl}$ ine [10], and Geguzin et al [11] in $\mathrm{KCl}$ are compared with those of Balooch and 0lander [37] in $\mathrm{NaCl}$. 


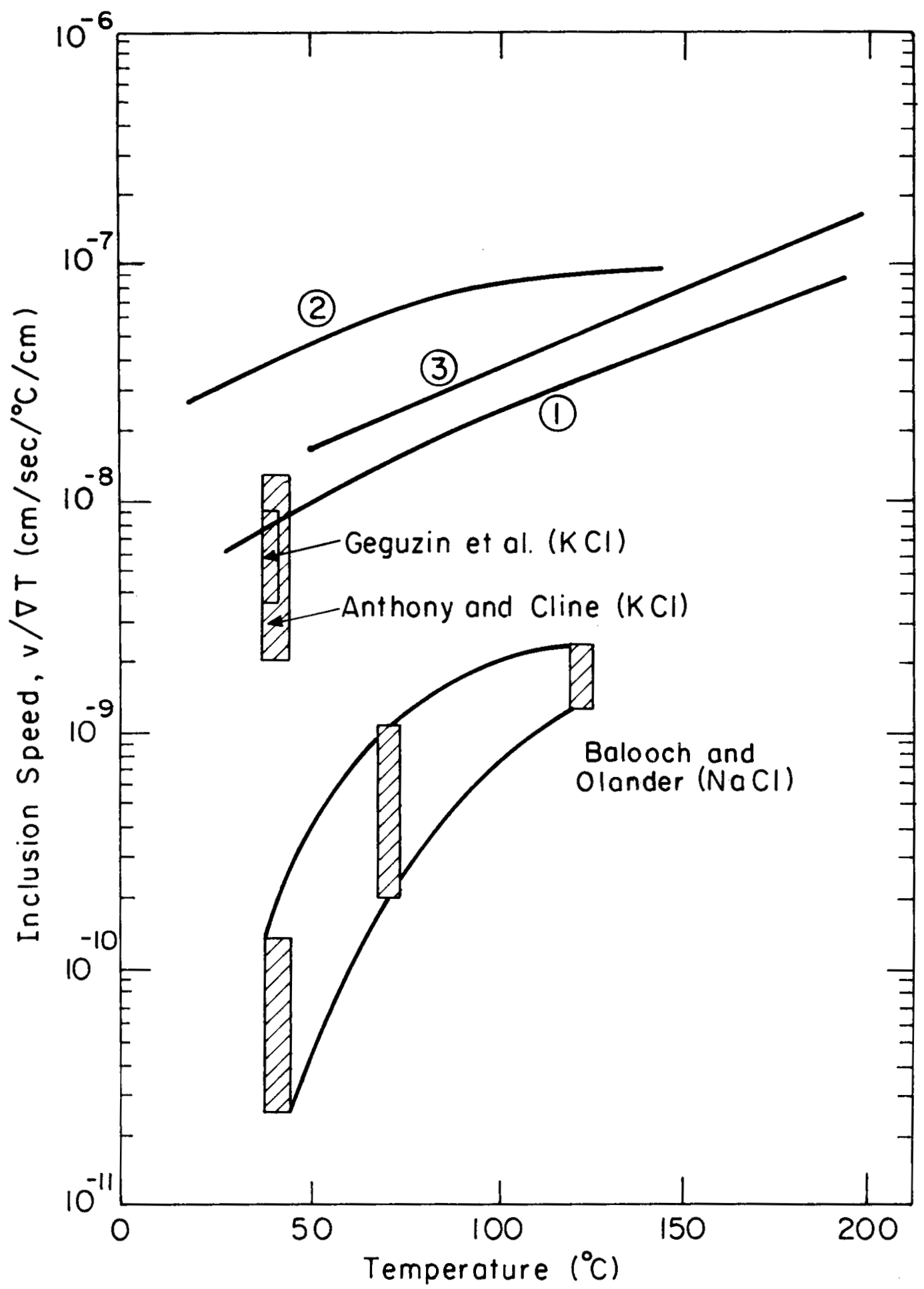

Figure 6-7. Migration velocities of all-liquid inclusion in $\mathrm{NaCl}$ and KCl single crystals as reported by Anthony and Cline, Geguzin et al, and Balooch and 01 ander. The theoretical diffusion curves and Jenks Equation are also plotted for comparison. 
Curves 1 and 2 on Figure 6-7 are diffusion limited calculations based on Eq. (4-6) for $\mathrm{NaCl}$ and $\mathrm{KCl}$ respectively. Curve 3 represents empirical formula proposed by Jenks [38]. Jenks obtained a conservative fit of the data of Bradshaw and Sanchez [39] in the form of the so-called Jenks Equation:

$$
\log \frac{v}{\nabla T_{\infty}}=0.00656 T-0.6036
$$

This equation is plotted as curve 3 on Figure 6-7.

Since Jenks' curve is based on Bradshaw and Sanchez's [39] data and the theoretical curves are for purely diffusion-limited migration, it follows that the inclusions onserved by Bradshaw and Sanchez were in fact moving at this limiting speed. The inclusions studied by Bradshaw and Sanchez were large (typical dimensions of $1 \mathrm{~mm}$ ) in natural crystals. Even if this material has a dislocation density as low as that of the synthetic single crystals $\left(10^{5} \mathrm{~cm}^{-2}\right)$, the faces of each inclusion would have been intersected by $\sim 10^{3}$ dislocations. Diffusion control is therefore expected for the large inclusions, which are intersected by enough dislocations to reduce the kinetic resistance to salt dissolution to negligible values.

Figure 6-8 shows results from the present work in $\mathrm{NaCl}$ single crystal. Four inclusions $(J, K, L, M)$ were followed at low load. Like the inclusions in $\mathrm{KCl}$ single crystals, these inclusions too migrated at velocities far lower than the diffusion control limits. Figure 6-8 clearly shows a non-linear dependence between $v$ and $L \nabla T$, as expected. To avoid overlapping of different 1 ines in Figure 6-8, a single 1 ine is fitted to velocity data from all four inclusions. 
88

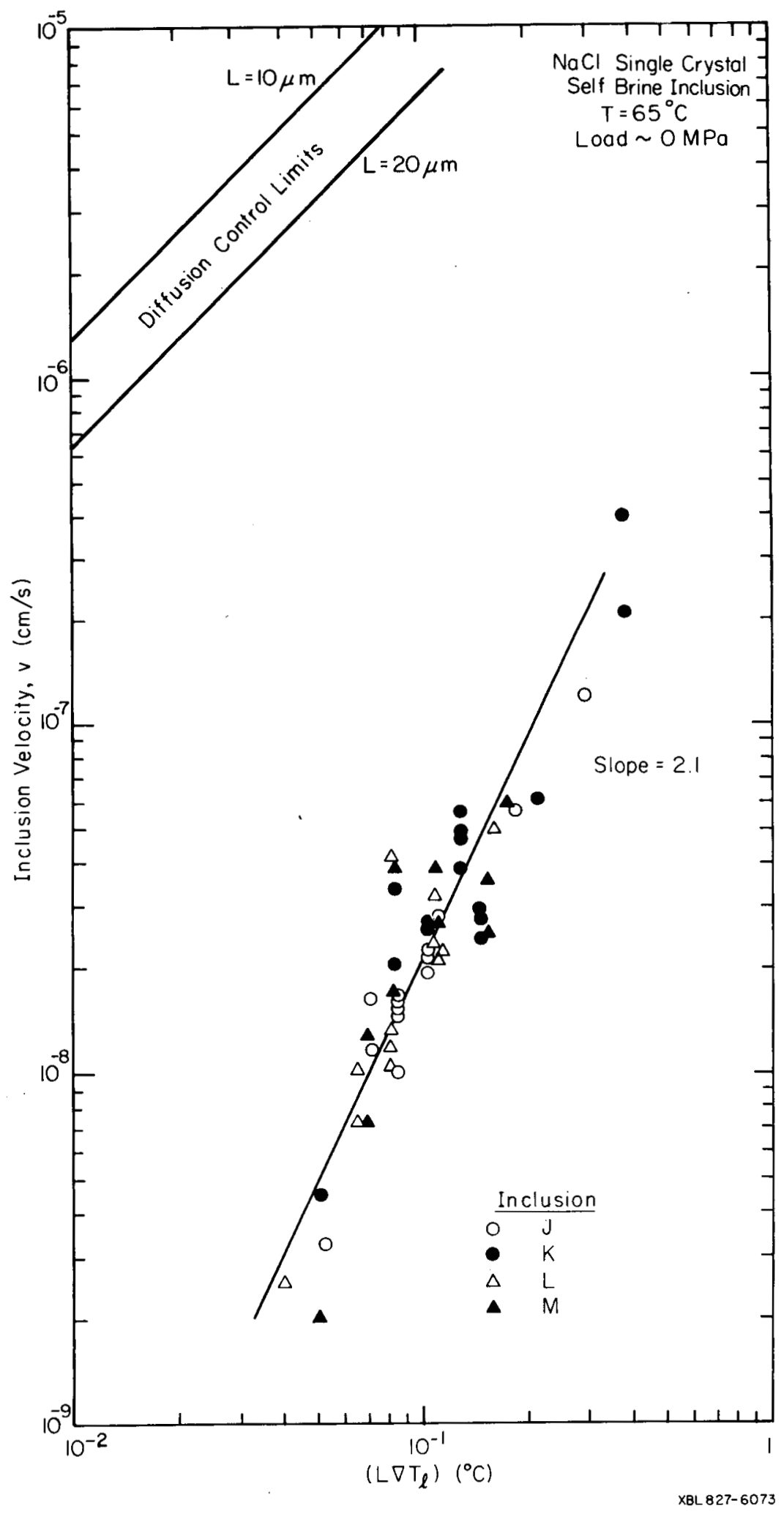

Figure 6-8. Variation of the migration velocity of four inclusions in $\mathrm{NaCl}$ with applied temperature gradient. A single line is fitted to Eq. (4-16) for all four inclusions. 
The major difference between the single crystal data (both $\mathrm{KCl}$ and $\mathrm{NaCl}$ ) of this work and those of Anthony and $\mathrm{Cl}$ ine [10], Geguzin et al [11], and Balooch and 0lander [37] is that the present work specifically addressed the question of evaluating interfacial kinetics, which needed careful experimental planning. This was accomplished by following only a few selected inclusions at constant temperature while the gradient $\nabla T_{\infty}$ was changed. Shape and size of the inclusions were carefully noted at each experimental observation. Between successive changes of the applied gradient $\nabla T_{\infty}$, the inclusions were allowed to return to their original position by changing the direction of $\nabla T_{\infty}$. When the inclusions returned to their original location, forward migration was resumed with a new $\nabla T_{\infty}$. In this manner all inclusions followed the same "track." Keeping the global temperature of inclusions fixed, and allowing inclusions to follow the same "track," assured that the parameters on which the interfacial kinetic coefficient depends were controlled as best as they could be.

\subsubsection{Mixed Brine Inclusions}

Since inclusions in natural salt contain mixed brines, migration experiments were also done with mixed brine inclusions in $\mathrm{NaCl}$ single crystals. For this purpose, inclusions were introduced in two separate samples using $2.1 \mathrm{M} \mathrm{MgCl}_{2}$ and $1 \mathrm{M} \mathrm{SrCl}_{2}$ solutions, respectively. The solutions will obviously be saturated by $\mathrm{NaCl}$ once inside the crystal in the form of inclusions. 
Mixed brine inclusions showed the same behavior as the self-brine in $\mathrm{NaCl}$. The migration speeds were far lower than the diffusion control limits as before. The inherent scatter in velocity data was also observed. The magnitude of migration speeds were about the same as those of self-brine inclusions. The two types of mixed brines (i.e., $\mathrm{MgCl}_{2}$ and $\left.\mathrm{SrCl}_{2}\right)$ showed no difference when compared with one another.

\subsubsection{Natural Salt Single Crystals}

Fabricated all-liquid inclusions in single crystal samples of natural salt from the Richton Dome behaved much the same way as they did in synthetic $\mathrm{NaCl}$ and $\mathrm{KCl}$ single crystals.

Figure $6 I$ shows migration speed data for four inclusions (1-4) at different values of applied gradient $\nabla T_{\infty}$ and compares them with the Jenks Equation [Eq. (6-1)]. As expected, Jenks Equation predicts about 2 orders of magnitude higher velocities compared to the experimental data. Also, no observable migration occurred at $\nabla T_{\infty} \leq 10^{\circ} \mathrm{C} / \mathrm{cm}$ even for about a week. This was unlike the case with synthetic single crystals where small but measurable migration took place at $\nabla T_{\infty}=10^{\circ} \mathrm{C} / \mathrm{cm}$. This can be attributed to nigher impurity levels in natural salt compared to the synthetic materials, which is manifest as a minimum gradient for migration or equivalently requires a critical undersaturation for dissolution.

Equation (4-16) was fitted to the data on Figure 6-9 and the results appear as a plot of velocity $v$ vs $L \nabla T_{\ell}$ in Figure 6-10. All four inclusions show non-linear kinetics. Inclusions 3 and 4 show a large degree of uncertainty in the slope of the fitted curves. This may be due to the fact that inclusion 3 has only four data points and inclusion 4 


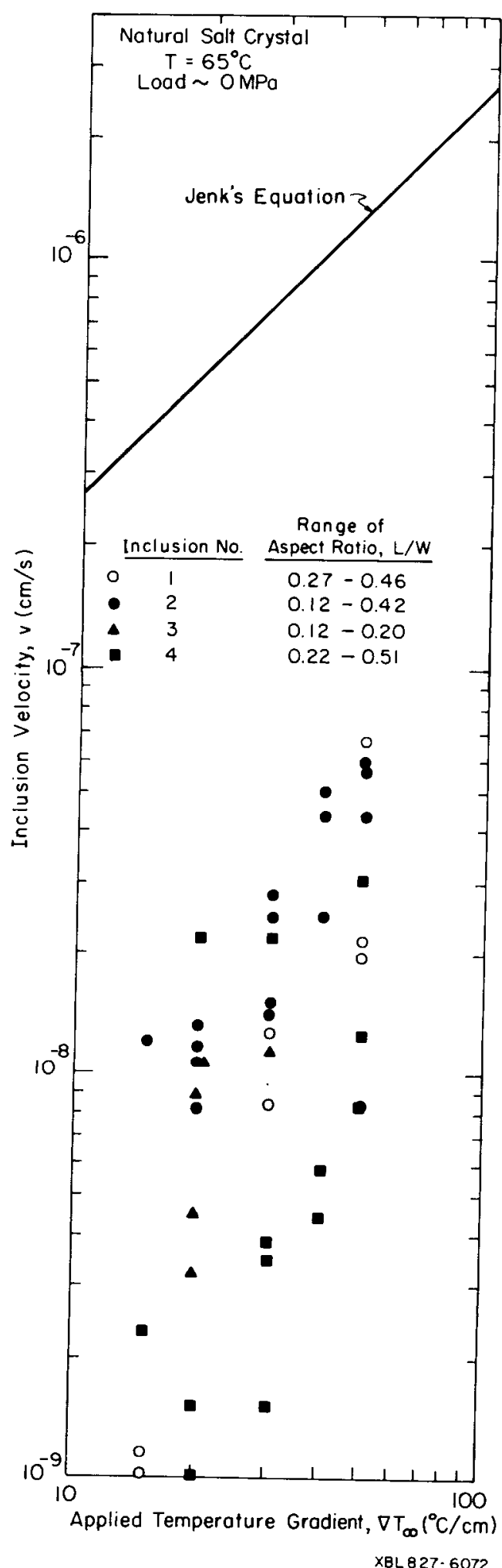

Figure 6-9. Variation of migration velocity of four inclusions in a natural salt crystal with the applied temperature gradient. 


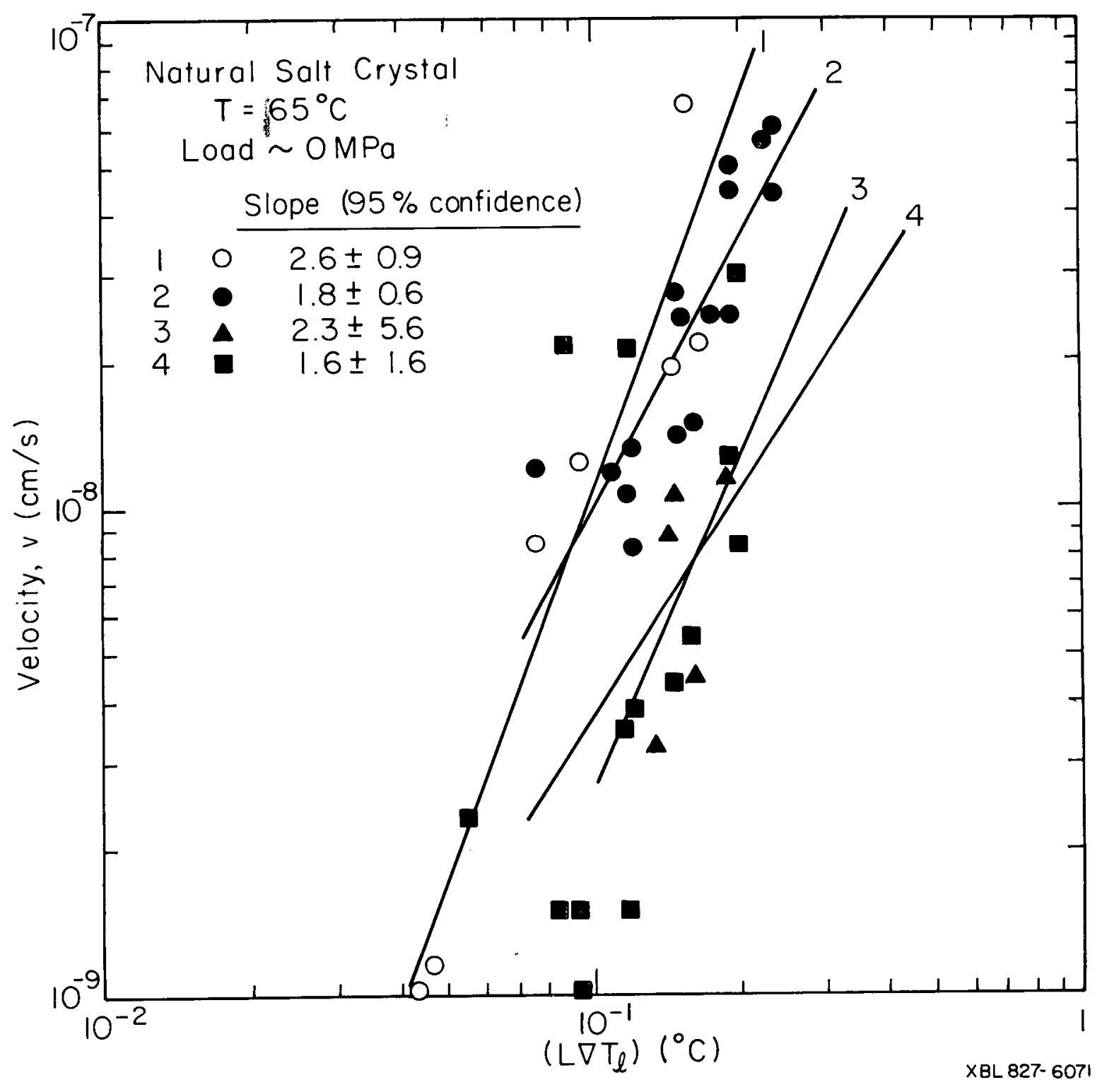

Figure 6-10. Variation of migration velocity of four inclusions in a natural salt crystal with the applied temperature gradient. The lines represent best fit curves from the theory [Eq. (4-16)]. 
showed an unusually slow movement compared to other inclusions (inclusion 4 could have been pinned down due to local impurity in the natural salt crystal which may have caused measurement errors).

A linear plot of $v$ vs $L \nabla T_{\ell}$ for inclusion 2 is shown in Figure 6-11. The plot is clearly parabolic, further confirming the non-linear interfacial kinetics. The other three inclusions also show a parabolic dependence between $v$ and $L \nabla T_{\ell}$. Figure $6-11$ indicates a minimum value of $\mathrm{LVT}_{\ell}$ where the migration ceases.

The response to a sudden increase in compressive mechanical loading produced, as expected, several fold increases in the migration speed of all four inclusions. This behavior is shown in Figure 6-12.

\subsection{GAS-LIQUID INCLUSIONS}

\subsubsection{Transport of Radioactivity}

Although it is not certain that gas-liquid inclusions exist at insitu high pressure (1ithostatic) conditions of subsurface salt deposits, microscopic observation of laboratory samples of natural salt verified presence of two-phase inclusions.

Gas-liquid inclusions may also be formed when all-liquid inclusions migrating up the temperature gradient impinge on the wall of the stored wastes [12]. Upon opening up at the salt-canister interface, the brine partially evaporates, the inclusions can reseal with some insoluble gas trapped inside and return down the temperature gradient. In so doing, the inclusion may have picked up some radioactivity from the waste form. 


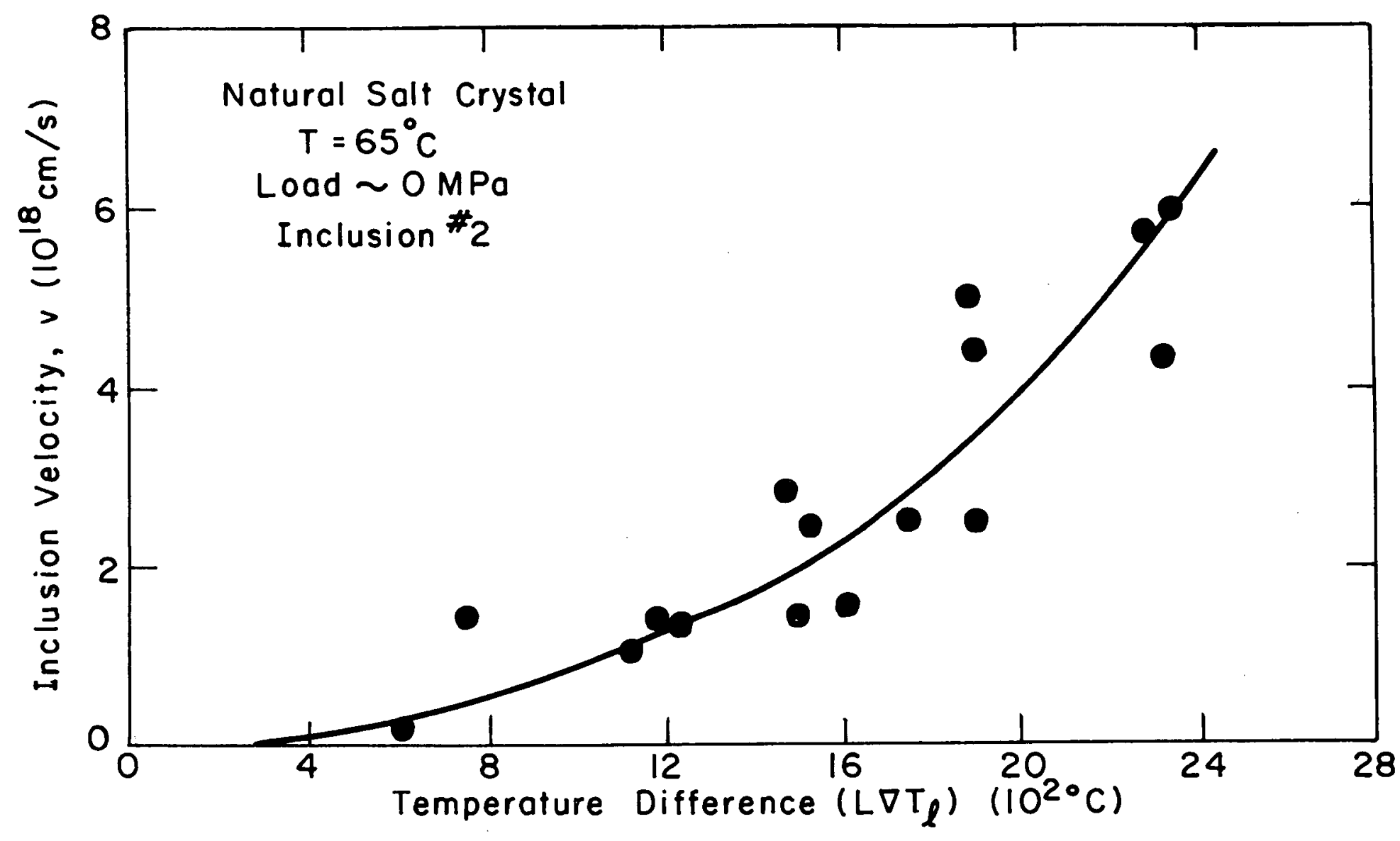

Figure 6-11. Linear plot of $v$ vs $L \nabla / T_{\ell}$ for an inclusion in a natural salt crystal. 


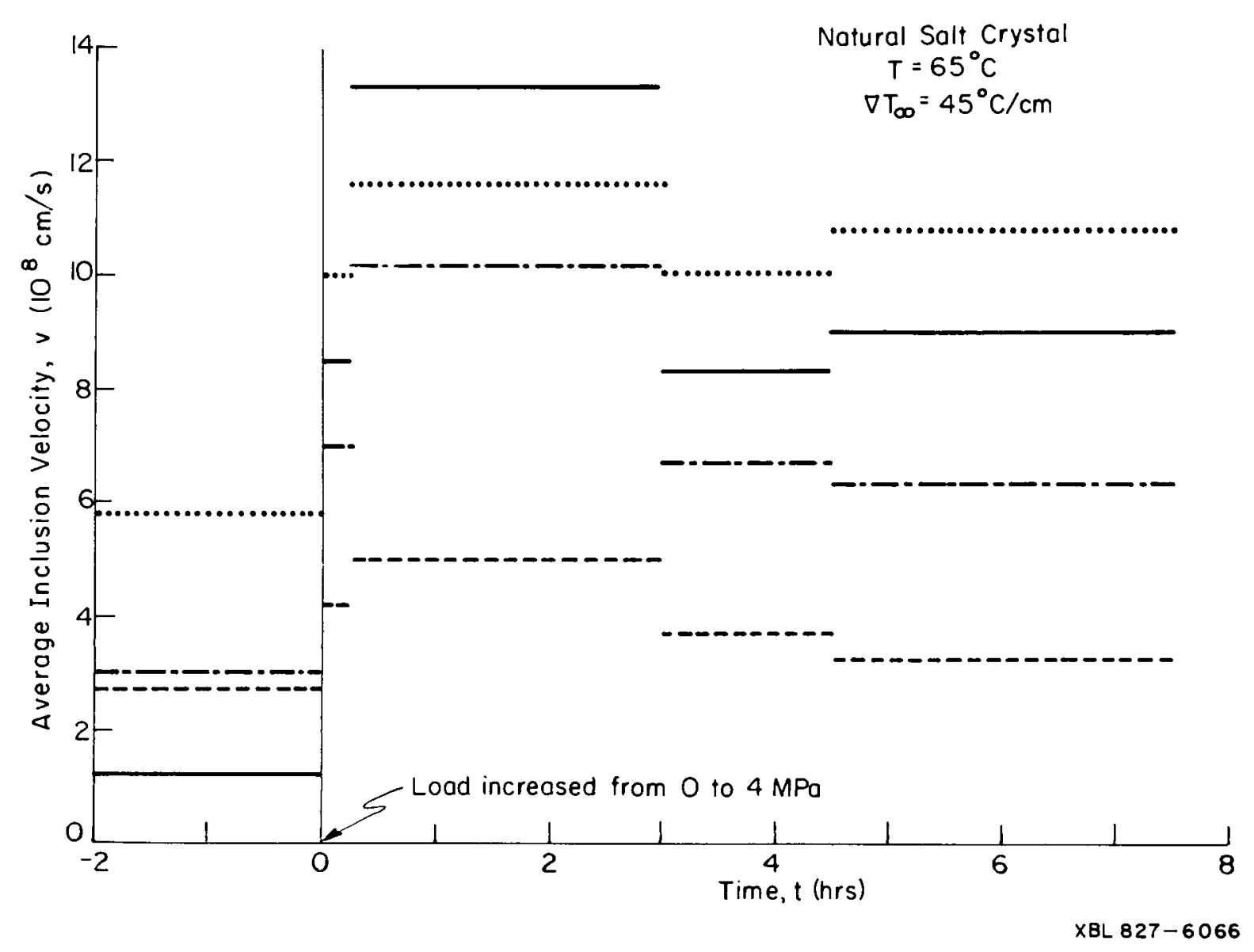

Figure 6-12. Effect of increasing applied axial load on the velocity of four inclusions in natural salt single crystal. 
The sequence of events by which an all-liquid inclusion transform into a gas-liquid one and simultaneously picks up radioactivity upon reaching a contaminated wall was experimentally verified as follows:

Twenty-five microliters of carrier-free $\mathrm{Ce}^{144}$ in $\mathrm{HCl}$ solution with a specific activity of 20 microcuries/microliter were evaporated on a thin square copper chip of the size of the crystal end face; the chip was placed between hot copper electrode and crystal face with the contaminated side of the chip contacting the crystal (Refer to Figure 3-2). The salt crystal originally contained a large number of all liquid inclusions. A temperature gradient of $30^{\circ} \mathrm{C} / \mathrm{cm}$ was applied to the crystal for about a month, as a result most all-liquid inclusions reached the hot end of the crystal. Several trails of very small gas-liquid inclusions were observed migrating down the gradient; however, a clear one-to-one conversion of an all-liquid inclusion arriving at the not end into a gas-liquid inclusion was not observed.

The crystal was counted before and after the above procedure. Surface contamination on the crystal surface was removed prior to the counting. The residual counts could be attributed to $\mathrm{Ce}^{144}$ transported into the crystal probably by the gas-liquid inclusions which appeared as the all-liquid inclusions began to arrive at the hot end of the crystal.

\subsubsection{Comparison of Different Gas Phases}

According to the theoretical model of 01 ander et al [13], the migration velocity of a gas-liquid inclusion depends, among other parameters, on the inert gas phase itself. Since the diffusivity of water vapor through the central gas bubble depends on the gas phase proper- 
ties, and the thermal conductivity of the bubble affects the temperature distribution in the brine, it follows that when the inert gas phase is changed (from air to helium, for example) a different velocity is theoretically expected.

Figure 6-13 shows theoretical and experimental velocities of airwater inclusions in $\mathrm{NaCl}$ from 01 ander et al [13]. The two sets of curves (solid and dotted) are respectively with and without the interfacial resistance at the solid/brine interface accounted for in the theory. The interfacial resistance, which is based on the all-liquid inclusion data from Ref. [9], lowers the theoretically predicted velocities by an order of magnitude as compared to the case of no interfacial mass transfer resistance at solid/brine interface. The vertical bars represent the data on a number of inclusions of various size and volume fraction of gas. It is evident from the experimental data that like all-liquid inclusions, interfacial kinetics are important for gasliquid inclusions as well. Notice that the bubble size in calculating the theoretical curves in Figure $6-13$ is taken to be $11.2 \mu \mathrm{m}$, the mean size for the experimentally observed inclusions.

The effect of changing the gas phase as predicted by the theory is shown in Figure 6-14. The curves show migration velocity per unit temperature gradient for an inclusion of given volume fraction gas and bubble size. The theory predicts that the migration speed of the helium-water inclusion should be about 6 times that of the argon-water inclusion at $50^{\circ} \mathrm{C}$ and about 3 times at $100^{\circ} \mathrm{C}$. 


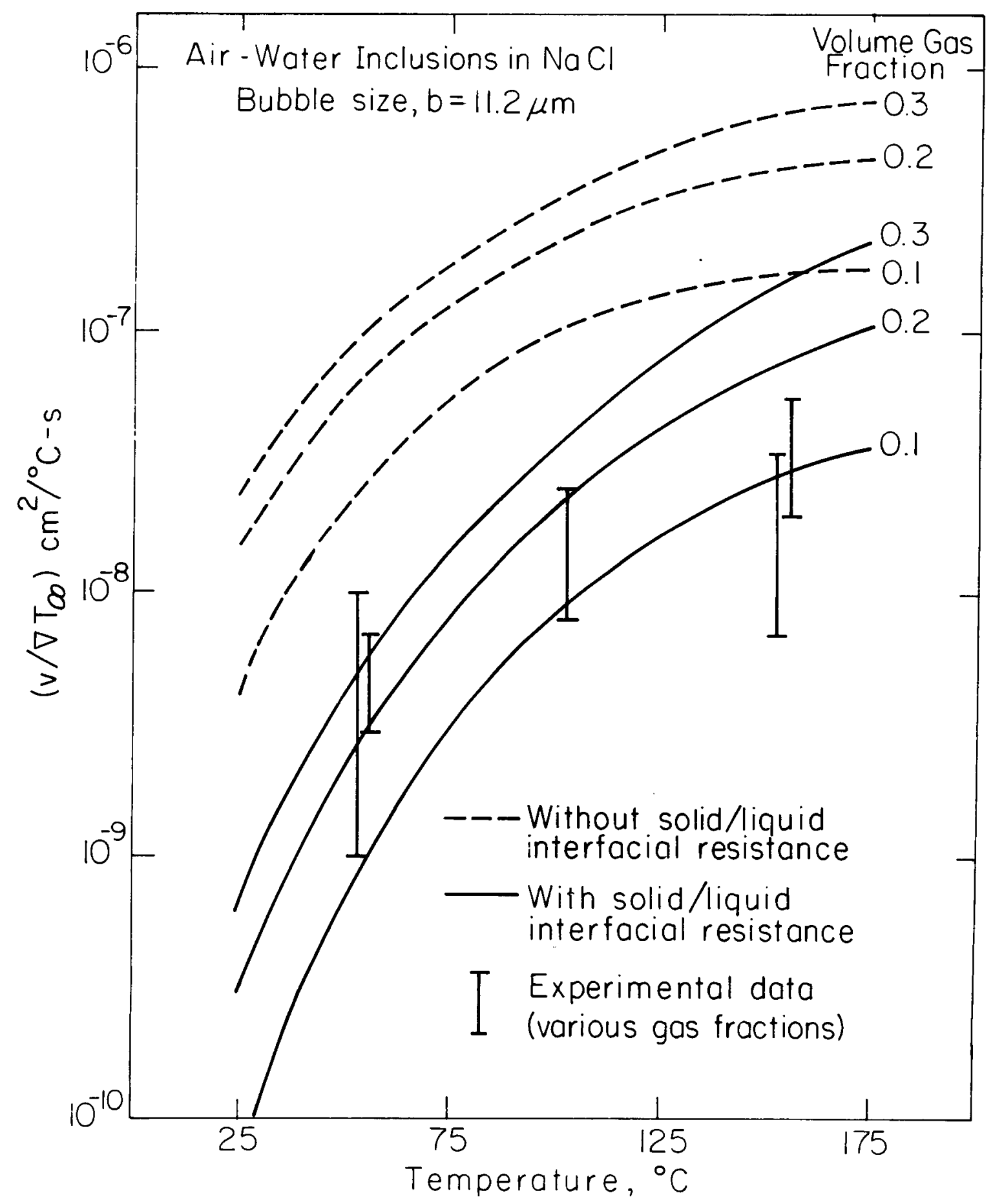

$X B\llcorner 822-5182$

Figure 6-13. Migration velocity of air-water inclusions in $\mathrm{NaCl}$ single crystal as predicted by the approximate model of 01 ander et al. The bars represent the experimental data for various gas fractions and bubble size. 


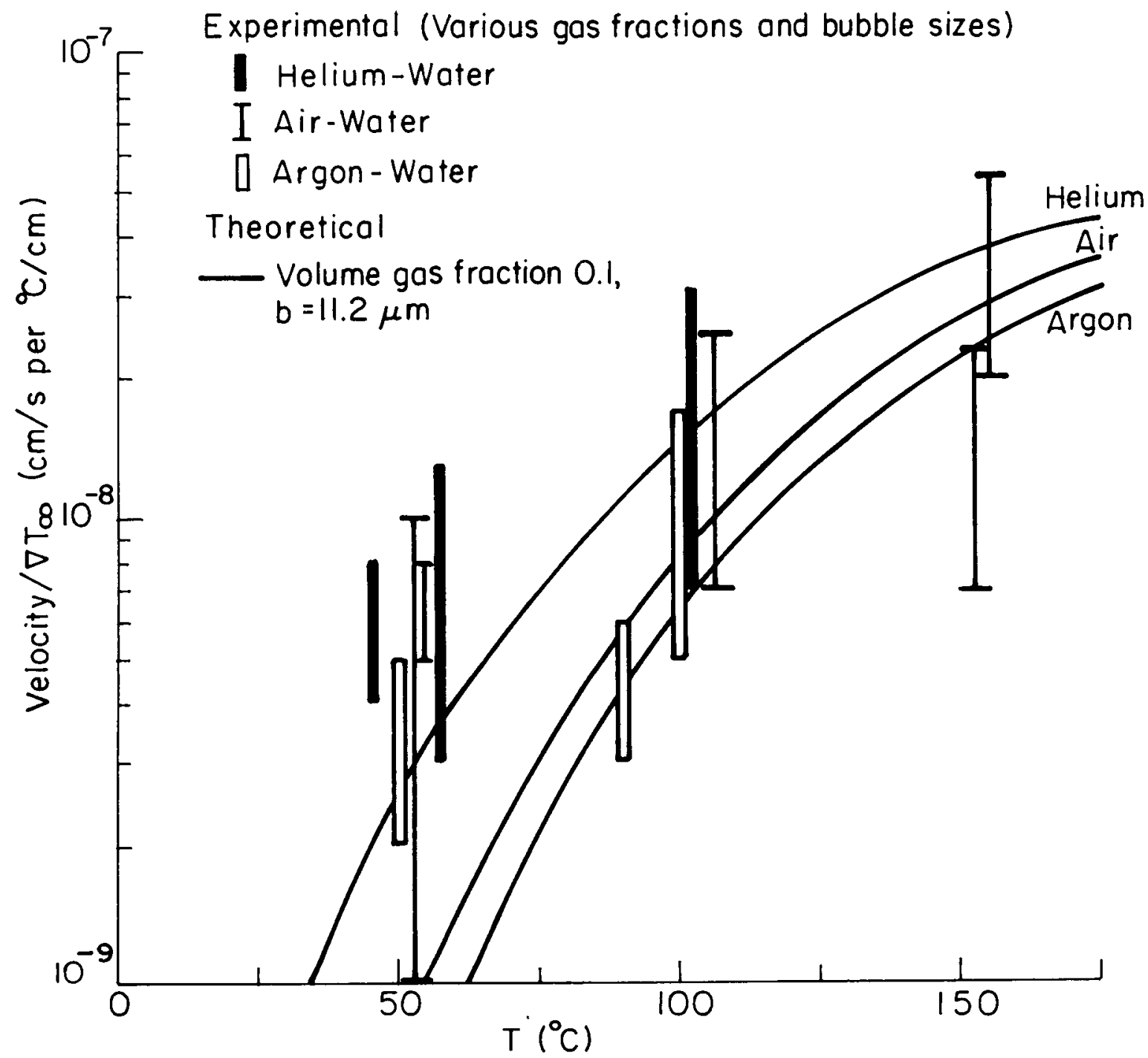

$X B L 827-6068$

Figure 6-14. Comparison of three different gas phase inclusions in $\mathrm{NaCl}$ single crystal. 
The experimental data of helium-water and argon-water (this work), and air-water (Ref. [13] are also shown superimposed on Figure 6-14 vertical bars. The data were obtained for a number of inclusions with different values of gas fraction and bubble size, whereas, the theoretical curves are for specific values of these parameters (i.e., $\mathrm{b}=11.2 \mu \mathrm{m}$ and volume fraction 0.1 ) with a best fit value of interfacial coefficient $k$ from the all-liquid inclusion data. It was not possible to control the bubble size and gas fraction to predetermined values, which limits a meaningful graphical comparison of the data and the theory. Nonetheless, the trend of $v_{\text {helium }}>v_{a i r}>v_{\text {argon }}$ is clear from the data.

\subsection{INCLUSIONS AT GRAIN BOUNDARIES}

In a bi-crystal sample fabricated of natural salt, several naturally occurring all-liquid and gas-liquid inclusions were observed attached to the large angle grain boundary. Figures $6-15$ and $6-16$ show these grain boundary inclusions at different locations on the grain boundary. A rough estimate showed that the fluid at the grain boundary constituted a maximum of 0.3 vol percent in the sample.

The direction of experimentally observed migration of grain boundary inclusions under an applied temperature gradient was as expected (i.e., the all-liquid inclusions moved up the gradient and the gas1 iquid inclusions moved down the gradient). The migration, however, did not take place in straight lines parallel to the direction of the temperature gradient. Unlike the inclusions in the single crystals, the grain boundary inclusions migrated by two-dimensional movements in a plane (the inclusions remain in the same plane of focus when observed 


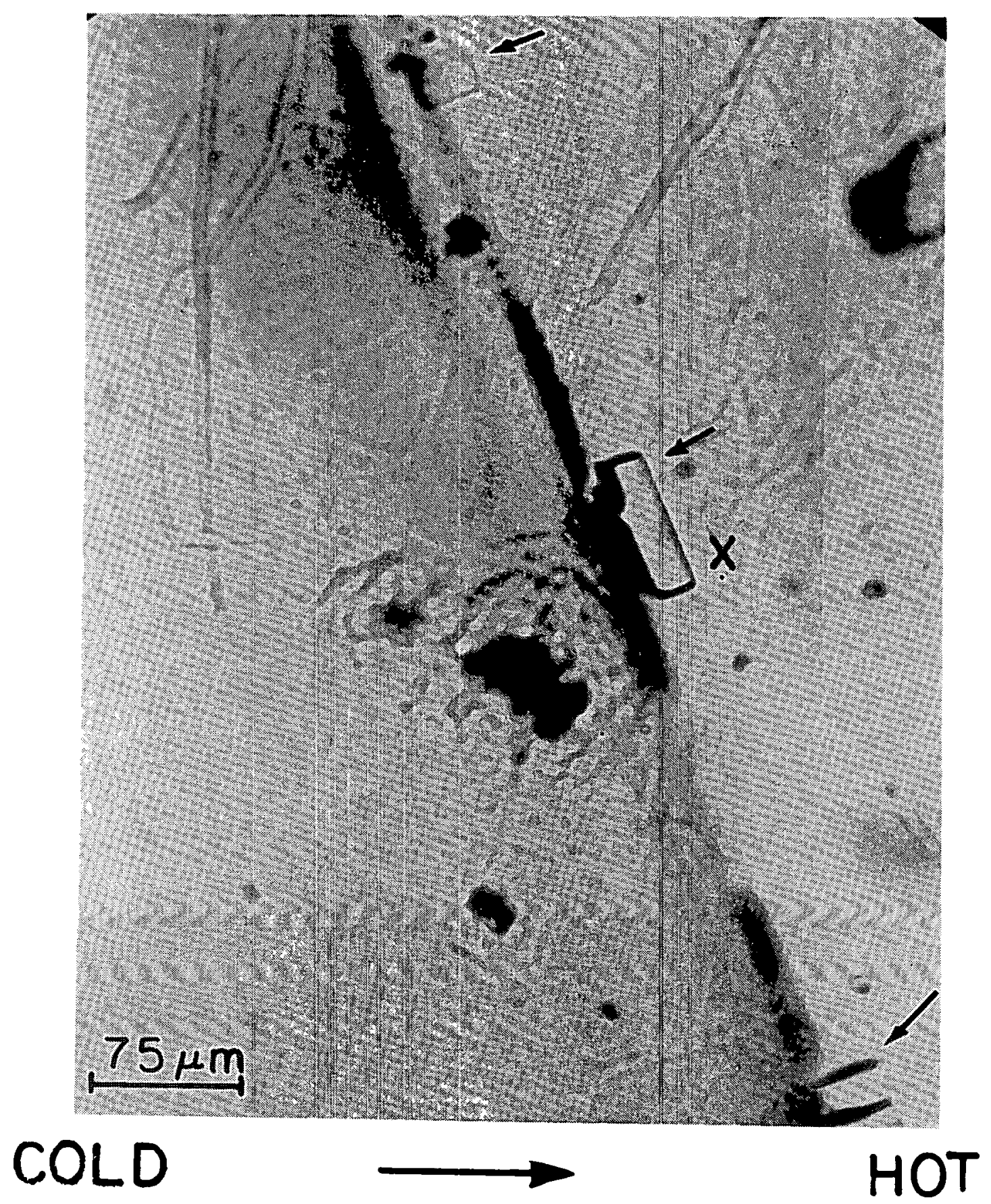

Figure 6-15. A11-1iquid inclusions at a large angle grain boundary in natural salt sample (shown by arrows). 


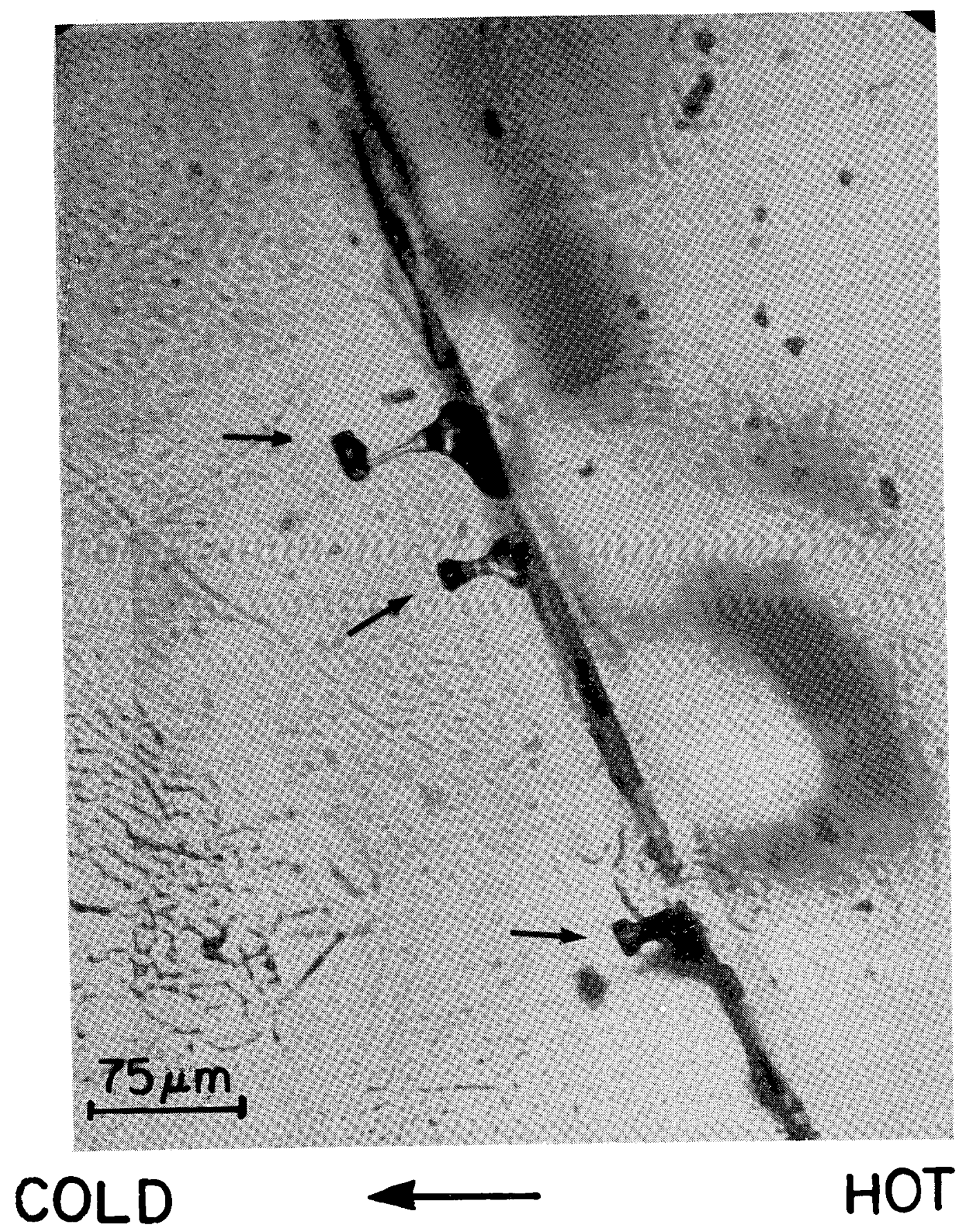

Figure 6-16. Gas-liquid inclusions at a large angle grain boundary in natural salt sample (shown by arrows). 
through the optical microscope) with a net drift up or down the gradient depending on the type of inclusion.

For an all-liquid inclusion marked by the $X$ in Figure $6-15$, the scenario just described is depicted in Figure $6-17$. The coordinates of a sharp corner of this inclusion are plotted in Figure 6-17 with respect to an arbitrary reference point as the origin. The grain boundary coincides with the $y$-axis. The numbers in parentheses indicate the time (in hours) of each observation starting from the initial position at $t=0 \mathrm{hrs}$. Successive positions of the inclusion in the plane of migration are joined by straight lines. These do not imply that the locus of migration between two successive readings was actually a straight-7ine. From Figure $6-17$, it is evident that the inclusion followed has a general tendency to move up the gradient, although not in a straight line. Several other grain boundary inclusions showed similar behavior. Once the inclusions moved far away from the grain boundary, they behaved in much the same way as single crystal inclusions. The erratic two dimensional migration of inclusions at and near a grain boundary can be attributed, in part, to the large mismatch between the grains which must exist at a large angle grain boundary. The solid lattice at the grain boundary is highly distorted. The grain boundary inclusion, migrating by dissolution-crystallization mechanism, seeks to conform to $\{100\} \mathrm{planes,} \mathrm{although} \mathrm{the} \mathrm{temperature} \mathrm{gradient} \mathrm{is}$ applied clearly in a direction other than $\langle 100\rangle$. This was confirmed by several inclusions which were platelet shaped far from the grain boundary, but tended to become chevron-shaped as they approached it. 


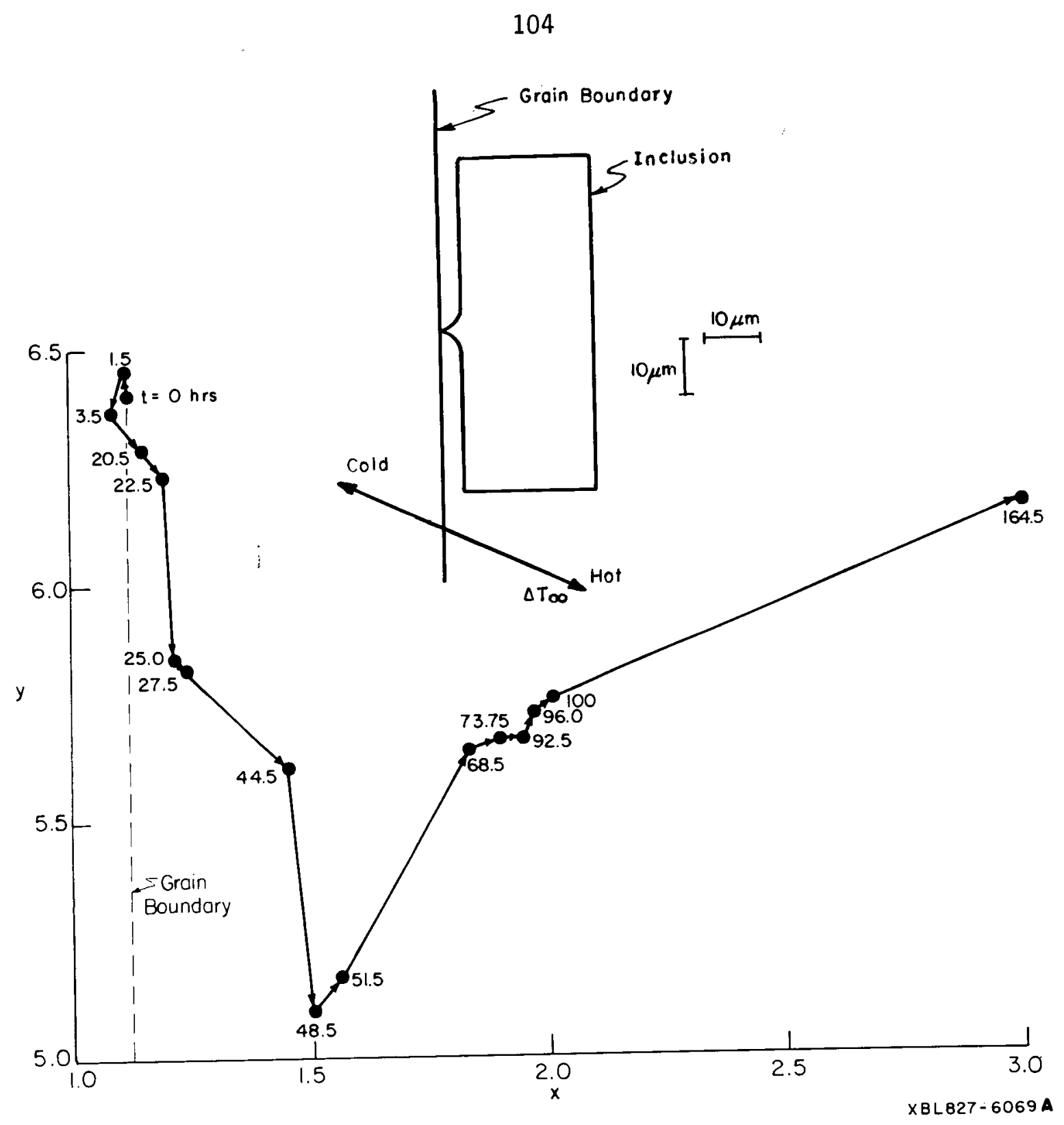

Figure 6-17. Two-dimensional motion of an all-1iquid inclusion at and near a large angle grain-boundary in natural salt sample supporting a temperature gradient. 
Finally, since an inclusion at a grain boundary is in a position of minimum energy, it tends to glide along the grain boundary from cold to hot regions (or hot to cold for gas-liquid inclusions) rather than detach itself completely from the grain boundary. This is seen in the behavior of the inclusion in Figure $6-17$ for times up to -27 hours. 
CHAPTER 7

CONCLUSIONS

Temperature gradient migration of intragranular all-liquid and gas-liquid inclusions in salt crystals has been examined experimentally and theoretically. An optical microscope hot stage attachment capable of nonuniformly heating and mechanically loading the salt sample was used for this purpose.

Micron-size inclusions in synthetic as well as natural single crystals showed that the slow interfacial step, which is probably associated with dissolution at the hot face of the inclusion, is more important than liquid diffusion as a resistance to salt transport, hence in determining the migration velocities.

The migration velocity varies approximately as the square of the temperature gradient rather than 1 inearly as suggested by the theory of Anthony and $\mathrm{Cl}$ ine, and Geguzin et al. The nonlinear dependence is in accord with the Burton-Cabrerra-Frank (BCF) model of crystallization catalyzed by dislocations emerging at the interface. Because of the small sizes of the inclusions produced in synthetic single crystals and the low dislocation density of this material, the dissolving faces of the inclusions are intersected by a small number of dislocations. Random variations in this number account for significant variations in the velocity of a single inclusion with time and for the scatter in the velocities measured for a number of different inclusions subjected to the same conditions. When the dislocation population is increased by mechanical stressing, the rate-limiting process in thermal gradient 
migration of inclusions in brine depends both on the size of the inclusion and on the dislocation density of the solid in which it moves. Diffusion control is expected for inclusions large enough to be intersected by a large number of defects. When interfacial kinetics is controlling, the variation of the inclusion speed with the temperature gradient the large variability of inclusion speeds measured under identical macroscopic conditions, and the effect of mechanical loading of the crystal on the speed are best rationalized by the BCF model.

Interfacial stability of a migrating all-liquid inclusion is treated theoretically. The temperature gradient tends to force an inclusion to take up a roughly spherical shape but the great stability of low index $\{100\}$ planes, and the layer by layer growth/dissolution principle, keep the inclusion boundaries sharp with $\{100\}$ faces.

All-liquid inclusions in natural salt single crystals also show interfacial kinetic controlled migration with velocities at least two orders of magnitude lower than those given by Jenks Equation.

For gas-liquid inclusions, the approximate analytical model of 01 ander et al. was tested by comparing the migration of helium-water, air-water, and argon-water inclusions. The general trend, predicted theoretically, that the migration velocity should decrease as the air is replaced by heavier argon, and increase as it is replaced by lighter helium, was confirmed experimentally.

In a real repository in natural salt, both intragranular and intergranular water will be mobilized when salt is subjected to a temperature gradient. The intragranular inclusions will eventually reach 
grain-boundaries under the influence of the temperature gradient. The fate of the inclusions and the accompanying water at the grain-boundaries is not quite clear. If one considers the grain-boundaries to be very "tight," such as can be fabricated by sintering two single crystals, the intragranular water driven by the thermal gradient will be impeded by the grain-boundary tension. A large temperature gradient will be necessary in such a case to pull away the inclusions from a grainboundary.

On the other hand, it is likely that the grain-boundaries in natural salt deposits will be weakened mechanical actions such as boring drillholes or excavating mines or repositories with the subsequent release of lithostatic pressure on salt in close proximity to the openings. Grain-boundaries in close proximity to the openings are thus rendered permeable and the intergranular brine may escape through these grain-boundary pores.

The migration studies in synthetic and natural single crystals reported in this work provide basic understanding of the mechanism of inclusion migration. However, unlike single crystals, the natural salt is polycrystalline with high levels of impurities and imperfections. It is therefore important to extend the migration experiments in natural salt specimens.

Preliminary observations of thermal-gradient-induced migration of liquid inclusions along and near a grain boundary in a natural salt sample indicate that it also travels toward higher temperatures. However, the path followed is not in a straight line as intracrystalline migration tends to be. Instead, the inclusion motion was irregular but 
over time did translocate toward the higher temperature zones. The results are interesting but do not provide a quantitative bas is for prediction.

For brine migration studies that would provide such results, a polycrystalline natural salt sample to be used in a laboratory has to be far larger than the sample size used in this work. This is because typical grain size in salt is about $1 \mathrm{~cm}$. To get a fair representation of grain boundary effect, the samples must be at least several centimeters in size. For such samples, the optical microscope method can not be used due to the following reasons:

(i) The high levels of impurities and imperfections in natural salt together with the size requirements make the samples opaque. Even the chemical polishing turns them only semitransparent at best, making it very difficult to observe inclusions within the samples.

(ii) The second reason has to do with the optical limitations of the microscope. At high magnifications necessary to optically observe inclusions, the distance between the point of focus and the objective lens of the microscope is quite small, generally 1 to $5 \mathrm{~mm}$. Since the sample must be at least $1 \mathrm{~cm}$ in height due to the grain size requirement, it is obviously not possible to observe the whole interior of the sample without the objective lens hitting the top surface of the sample.

Due to the above reasons, a radioactive tracer technique to monitor the migration must be developed. This method tags the migrating brine within the sample with an inert radioactive material and the migration itself is observed by radioactive detectors rather than the optical microscope. 


\section{REFERENCES}

[1] Benedict, M., and T. Pigford, and H. Levi, 1981. Nuclear Chemical Engineering, Second Edition, Chapter 11, McGraw-Hill Book Company, NY.

[2] Isherwood, D. J., 1979. Fluid Inclusions in Salt: An Annotated Bibliography, UCID-18102, Lawrence Livermore Laboratory, Albuquerque, NM.

[3] Roedder, E. and H. E. Belkin, 1980. "Application of Studies of Fluid Inclusions in Permian Salt, New Mexico, to Problems of Siting the Waste Isolation Pilot Plant", Scientific Basis for Nuclear Waste Management, G. J. McCarthy, editor, Vol. 1, No. 313, Plenum Press, NY.

[4] Jenks, G. H. and H. C. Claiborne, 1981. Brine Migration in Salt and Its Implications in the Geologic Disposal of Nuclear Waste, ORNL-5815, Oak Ridge National Laboratory, Oak Ridge, TN.

[5] Holser, W. T., 1963. "Chemistry of Brine Inclusions in Permian Salt From Hutchinson, Kansas", Symposium on Salt, Northern Ohio Geologic Society, Inc., Cleveland, OH, :pp. 86-95.

[6] Lorenz, J. et a1, 1981. "Geology, Mineralogy, and Some Geophysical and Geochemical Properties of Sal,t Deposits", Physical Property Data for Rock Salt, NBS-167, National Bureau of Standards, Washington, DC.

[7] 01 ander, D. R., 1976. Fundamental Aspects of Nuclear Reactor Fuel Elements, Chapter 14, TID-26711-P1, Technical Information Center, Energy Research and Development Administration, Oak Ridge, TN.

[8] Geguzin, Y. E., and M. A. Krioglaz, 1973. Migration of Macroscopic Inclusions in Solids, translated from Russian, Studies in Soviet Sciences, Consultants Bureau, NY. 
[9] 01 ander, D. R. et a1, 1982. "Thermal Gradient Migration of Brine Inclusions in Synthetic Alkali Halide Crystals", Journal of Applied Physics, Vol. 53, p. 669.

[10] Anthony, T. R. and H. E. C7ine, 1971. "Thermal Migration of Liquid Droplets Through Solids", Journal of Applied Physics, Vol. 442, p. 3380 .

[11] Geguzin, Y. E. et al, 1975. "Response to a Temperature Gradient From Liquid Inclusions in a Crystal", Soviet Physics Crystallography, Vol. 20, p. 234.

[12] Anthony, T. R. and H. E. Cline, 1972. "The Thermomigration of Biphase Vapor Liquid Droplets Through Solids", Acta Metallurgica, Vol. 20, p. 247.

[13] 01ander, D. R. et al, 1981. "Migration of Gas Liquid Inclusions in Single Crystals of Potassium and Sodium Chloride", Nuclear Science and Engineering, Vol. 79, p. 212.

[14] Johnston, W. F., 1967. "Dislocation Etch Pits in Non-Metallic Crystals", Progress in Ceramic Science, Vol. 2, No. 1, J. E. Burke, editor, Pergamon Press, NY.

[15] Mendelson, S., 1961. "Dislocation Etch Pits Formation in Sodium Chloride", Journal of Applied Physics, Vol. 32, p. 1579.

[16] Moran, P. R., 1963. "Dislocation Etch Techniques for Some Alkali Halide Crysta1s", Journal of Applied Physics, Vo1. 29, p. 1768.

[17] Cline, H. E. and T. R. Anthony, 1972. "Effects of the Magnitude and Crystallographic Direction of a Thermal Gradient on Droplet Migration in Solid", Journal of Applied Physics, Vol. 43, p. 10.

[18] O'Hara, M. and R. C. Reid, 1973. Modeling Crystal Growth Rates From Solutions, Chapter 4, Prentice Hal1, Englewood Cliffs, NJ. 
[19] Strickland-Constable, R. F., 1968. "Kinetics and Mechanism of Crystallization", Chapter 6, Academic Press, London.

[20] Frank, F. C., 1949. "The Influence of Dislocations on Crystal Growth", Discussions of Faraday Society, Vol. 5, p. 48.

[21] Botsaris, G. D., 1965. "Effects of $\gamma$-Irradiation and Additives on Growth of Potassium Chloride Crystals from Aqueous Solutions", Ph.D. Thesis, Massachusetts Institute of Technology.

[22] Wilcox, W. R., 1971. "The Role of Mass Transfer in Crystallization Process", Preparation and Properties of Solid State

Materials, R. A. Lefever, editor, Vol.1, Dekker, NY, p. 37.

[23] Pigford, T. H., 1981. Migration of Brine Inclusions in Salt, UCB-NE-4001, University of California, Berkeley, CA.

[24] Anthony, T. R. and H. E. Cline, 1973. "The Stability of Migrating Droplets in Solids", Acta Metallurgica, Vol. 21, p. 117.

[25] Stoner, E. C., 1945. "The Demagnetization Factors for Ellipsoids", Philosophical Magazine, Vol. 36, Ser. 7, p. 803.

[26] Mullins, W. W. and R. F. Sekerka, 1963. "Morphological Stability of a Particle Growing by Diffusion or Heat Flow", Journal of Applied Physics, Vor. 34, p. 323.

[27] Mullins, W. W. and R. F. Sekerka, 1964. "Stability of Planar Interface During Solidification of a Dilute Binary Alloy", Journal of Applied Physics, Vol. 35, p. 444.

[28] Kotlier, G. R. and W. A. Tiller, 1967. "The Effect of Interface Attachment Kinetics on the Perturbation Analys is of a Cylinder Crystallizing from a Binary Alloy Melt", Crystal Growth, H. S. Peiser, editor, Pergamon Press, NY. 
[29] Sekerka, R. F., 1967. "A Time-Dependent Theory of Stability of a Planar Interface During Dilute Binary Alloy Solidification", Crystal Growth, H. S. Peiser, editor, Pergamon Press, NY, pp. 691-702.

[30] Sekerka, R. F., 1968. "Morphological Stability", Journal of Crystal Growth, Vol. 3, p. 71.

[31] Delves, R. T., 1975. "Theory of Interface Stability", Crystal Growth, B. R. Pamplin, editor, Pergamon Press, NY, pp. 40-103.

[32] Seidensticker, R. G., 1967. "Stability Considerations in Temperature Gradient Zone Melting", Crystal Growth, H. S. Peiser, editor, Pergamon Press, NY, pp. 733-737.

[33] Olander, D. R. et a 1, 1980. Thermal Gradient Migration of Brine Inclusions in Salt, ONWI-208, Office of Nuclear Waste Isolation, Battelle, Columbus, $\mathrm{OH}$.

[34] Garside, J., 1977. "Kinetics of Crystallization from Solution", Current Topics in Material Science, Vol. 2, E. Kaldis, editor, North Holland, Amsterdam, p. 484.

[35] Lemaire, P. J. and H. K. Bowen, 1982. "Migration of Small Pores in Potassium Chloride due to a Temperature Gradient", American Ceramic Society Journal, Vol. 65, p. 49.

[36] Bennema, P. and G. H. Gilmer, 1973. "Kinetics of Crystal Growth", Crystal Growth: An Introduction, P. Hartman, editor, North Holland, Amsterdam, p. 263.

[37] Balooch, M. and D. R. 01 ander, 1979. Migration of Brine Inclusions in Single Crystals of NaCl, LBL-10252, Lawrence Berkeley Laboratory, Berkeley, CA. 


$$
115 \mid 116
$$

[38] Jenks, G. H., 1979. Effects of Temperature, Temperature Gradients, Stress, and Irradiation on Migration of Brine Inclusions in a Salt Repository, ORNL-5526, Oak Ridge National Laboratory, Oak Ridge, TN.

[39] Bradshaw, R. L. and F. Sanchez, 1968. Brine Migration Studies, ORNL-4316, Oak Ridge National Laboratory, Oak Ridge, TN. 
.

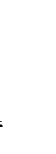


APPENDIX A

TEMPERATURE GRADIENTS IN ALL-LIQUID INCLUSION

In Chapter 3 the global temperature of an inclusion within the salt crystal was discussed. This temperature is calculated by the linear interpolation of experimentally established end temperatures of the salt crystal. Physical property data needed in the velocity expression [Eq. (4-16)] are calculated at this global temperature of the inclusion.

In a microscopic sense, on the other hand, a square platelet-shaped inclusion embedded in a solid supporting an external temperature gradient, has a more complicated temperature field. A complete temperature distribution inside the inclusion can be obtained as a function of the aspect ratio by solving Laplace's equation in both solid and liquid and using heat flux and temperature continuity conditions at the cavity boundaries. Numerical solutions obtained with the code HEATING5 are shown in Fig. A-l in terms of a thermal gradient amplification factor defined by

$$
A=\nabla T_{\ell} / \nabla T_{\infty}
$$

This factor is a function of the aspect ratio of the inclusion $L / W$ and the off-axis position $x$. On the axis of the inclusion, the amplification factor is bounded by 


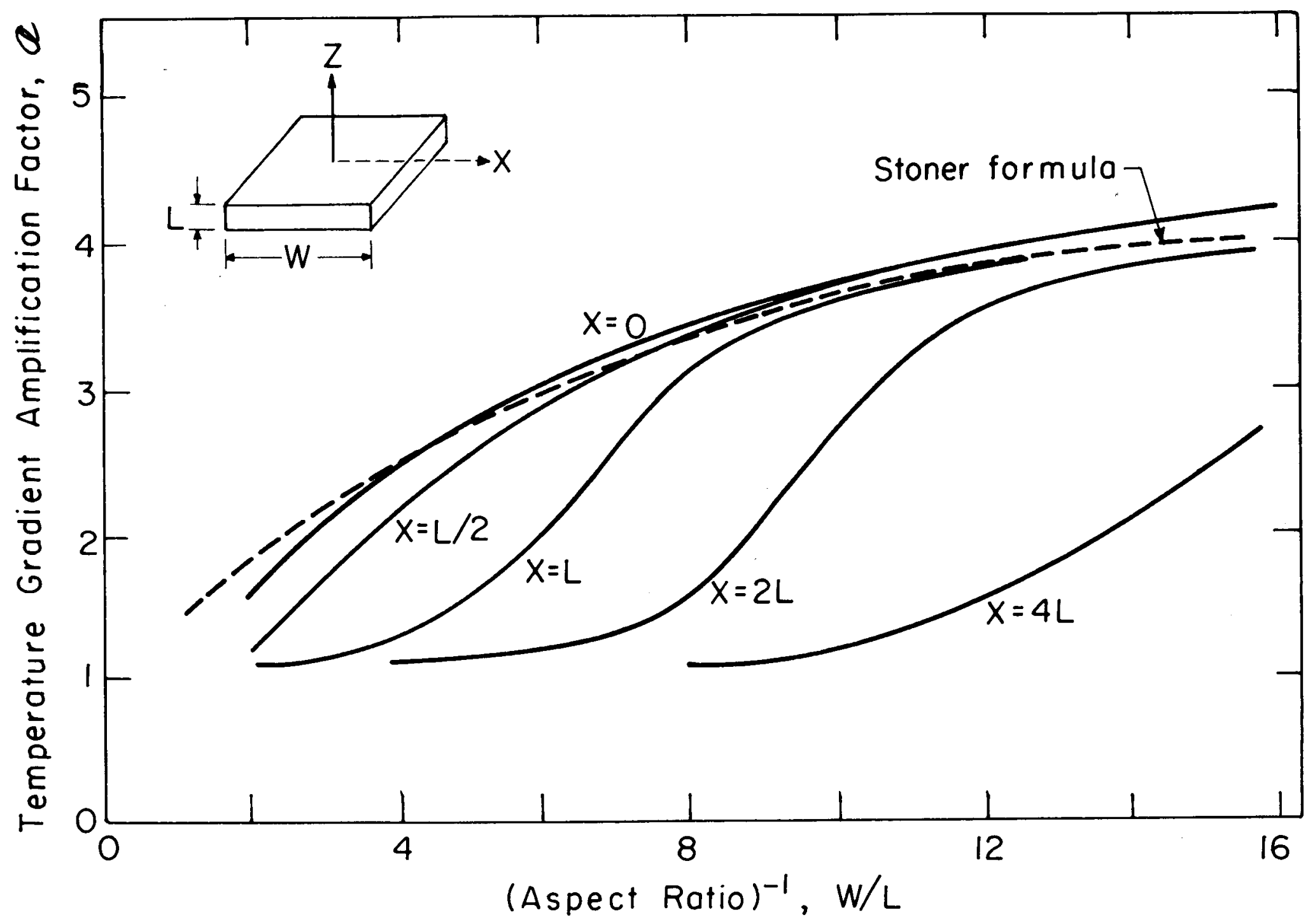

Figure A-1. Temperature gradient amplification factor in an al1-1iquid inclusion. 


$$
f(x=0)= \begin{cases}3 /\left(2+k_{1} / k_{s}\right) & \text { for } L / W=1, \\ k_{s} / k_{1} & \text { for } L / W=0,\end{cases}
$$

where $k_{s}$ and $k_{\ell}$ are the thermal conductivities of the solid and liquid, respectively; their ratio is $\sim 7$ for $\mathrm{NaCl}$ and $\sim 10$ for $\mathrm{KCl}$. The value of the amplification factor for the cubical inclusion is essentially equal to that for a sphere. The formula obtained by Stoner (1945) for prolate spheroids,

$$
\mathcal{A}(X=0)=\left[(1-F)+F\left(k_{1} / k_{s}\right)\right]^{-1},
$$

where

$$
F=\frac{1}{1-(L / W)^{2}}\left\{1-\frac{(L / W) \cos ^{-1}(L / W)}{\left[1-(L / W)^{2}\right]^{1 / 2}}\right\}
$$

has been used to represent the gradient on the axis of the square platelets. Note that Eqs $(A-3)$ and (A-4) exhibit the limiting behavior indicated by $\mathrm{Eq} .(\mathrm{A}-2)$.

The variation of the thermal gradient amplification factor with off-axis location is just as important as its dependence upon the inclusion aspect ratio. Figure $A-I$ shows that $A$ is largest on the axis $(X=0)$ but decreases to unity at the edge of the inclusion $(X=W / 2)$. For example, consider an inclusion in $\mathrm{NaCl}$ with an aspect ratio $\mathrm{W} / \mathrm{L}$ of 6. It can be seen from Figure $A-1$ that the temperature gradient on the inclusion axis is $\sim 3$ times larger than $\nabla T_{\infty}$, but at $1 / 3$ of the distance between the axis and the edge $(X=L)$, the amplification factor has been reduced to $\sim 2$. At two-thirds of the way to the edge $(X=2 L)$, 
$\nabla T_{\ell}$ is approximately equal to $\nabla T_{\infty}$. In this particular example, there is an uncertainty (or variation) of a factor of 3 in relating $\nabla T_{\ell}$ to $\nabla T_{\infty} \cdot$

\section{REFERENCE}

Stoner, E. C., 1945. "The Demagnetization Factors for Ellipsoids", Philosophical Magazine, Vol. 36, Ser. 7, p. 803. 


\section{APPENDIX B}

IMPURITY EFFECT AND THE ORDER OF INTERFACIAL KINETICS

In this appendix the limiting cases of Eq. (4-16) are derived. It is also shown that the value of exponents relating $v$ and $L \nabla T_{\ell}$ which are higher than 2 are due to non-zero values of $\xi^{*}$. In other words, impurity effects discussed in Section 4.1.2.3 which are manifest as a critical undersaturation for dissolution $\xi^{*}$, predict that $v$ should increase with $L \nabla T_{1}$ more rapidly than $\left(L \nabla T_{\ell}\right)^{2}$.

Equation (4-16) can be written as

$\underset{\text { where }}{v}=A \mathcal{D}\left[\left\{\sqrt{(1-x)^{2}+\frac{4 \mathrm{~L} \nabla \mathrm{T}_{\ell}}{\mathrm{D}} B}-1\right\}^{2}-x^{2}\right]$

$$
\begin{aligned}
& A=\frac{D_{\ell} C^{\text {sat }}}{4 L \rho_{s}} \\
& B=\left(\frac{1}{c^{\text {sat }}} \frac{d C^{\text {sat }}}{d T}-\sigma\right) \\
& x=\frac{\xi^{*}}{D} \\
& D=\frac{D_{\ell} c^{\text {sat }}}{k L}
\end{aligned}
$$

Diffusion-Controlled Limit:

When diffusion is slow and rate controlling, and interfacial mass transfer is rapid, the coefficient $k$ is very large and undersaturation $\xi^{*}$ is very small. Thus $x \simeq 0$ and $D$ is sufficiently small so that $\frac{4 L \nabla T_{\ell}}{C} B \gg 1$. Equation $(B-1)$ can then be written as 


$$
v \simeq A-D\left(\sqrt{\frac{4 L \nabla T_{\ell}}{D} B-1}\right\}^{2} \simeq 4 L \nabla T_{\ell} A B
$$

Substituting $A$ and $B$ into $(B-2)$ yields

$$
v=\frac{D_{l} C^{s a t}}{\rho_{s}}\left(\frac{1}{c^{s a t}} \frac{d C^{s a t}}{d T}-\sigma\right) \quad \nabla T_{\ell}
$$

Equation (B-3) is the same as Eq. (4-6) which gives purely diffusioncontrolled migration velocity for an inclusion.

Interfacial-Controlled Limit

When diffusion is fast but interfacial mass transfer is slow and rate controlling, the diffusivity $D_{\ell}$ is large but interfacial coefficient $k$ is small. Thus, the dimensionless parameter $D$ is large and two limiting cases, with and without a critical undersaturation due to impurities are considered separately.

\section{Case 1: No Impurity Effect}

For growth/dissolution in a pure crystal, surface diffusion growth theory (see Section 4.1.2.2) does not predict existence of critical undersaturation or supersaturation. Therefore, in this case $\xi^{\star}=0$ and hence $x=0$. Equation $(B-1)$ then becomes

$$
v=A C\left[\left\{1+\frac{4 L \nabla T_{\ell}}{\Phi} B\right\}^{1 / 2}-1\right]^{2}
$$

Since $D$ is large, the bracketed terms can be written by the series expansion 
$v \simeq A \mathcal{D}\left[1+\frac{1}{2} \frac{4 L \nabla T_{\ell}}{\mathcal{D}} B+\cdots-1\right]^{2}$

Substituting $A$ and $B$ in the above equation and simplifying yields

$v=\frac{k}{\rho_{S}}\left(\frac{1}{c^{s a t}} \frac{d C^{s a t}}{d T}-\sigma\right)^{2}\left(L \nabla T_{\ell}\right)^{2}$

Equation (B-5) is the same as Eq. (4-17) which gives purely interfacial-controlled migration velocity for an inclusion. The exponent of 2 for $\left(L \nabla T_{\ell}\right)$ encompasses the BCF theory.

\section{Case 2: Impurity Effect}

Impurity effects, discussed in Section 4.1.2.3, are manifest as a critical undersaturation or supersaturation. Therefore, in this case, $\xi^{\star} \neq 0$.

For $\xi^{*} \neq 0, v$ varies with $L \nabla T_{\ell}$ with a power greater than 2, as can be demonstrated by differentiating Eq. (B-1) with respect to $\left(L \nabla T_{1}\right)$.

$$
\begin{gathered}
\frac{d v}{d\left(L \nabla T_{\ell}\right)}=A-D \cdot 2\left[\sqrt{1-2 x+x^{2}+\frac{4 B}{\bar{D}} L \nabla T_{\ell}}-1\right] . \\
\frac{1}{2}\left\{1-2 x+x^{2}+\frac{4 B}{\bar{D}} L \nabla T_{\ell}\right\}^{-1 / 2} \cdot \frac{4 B}{D}
\end{gathered}
$$

On a $\log -\log$ plot one is interested in the slope given by $\frac{d(\ln v)}{d\left(\ln \left(\operatorname{LT} T_{\ell}\right)\right)}$.

Since

$$
\frac{d(\ln v)}{d\left(\ln \left(L \nabla T_{1}\right)\right)}=\frac{L \nabla T_{\ell}}{v} \frac{d v}{d\left(L \nabla T_{\ell}\right)}
$$

Substituting $\frac{d v}{d\left(L \nabla T_{\ell}\right)}$ from Eq. (B-6) into Eq. (B-7), and using Eq. (B-1) 
results in $\frac{d \ln v}{d\left(\ln \left(L \nabla T_{\ell}\right)\right)}=$

$$
\frac{\left[\sqrt{1-2 x+x^{2}+\frac{4 B}{\mathrm{D}} L \nabla T_{\ell}}-1\right] \cdot \frac{4 \mathrm{~B}}{\mathrm{D}} L \nabla \mathrm{T}_{\ell}}{\left\{1-2 x+x^{2}+\frac{4 \mathrm{~B}}{\mathrm{D}} L \nabla \mathrm{T}_{\ell}\right\}^{1 / 2} \cdot\left[\left\{\sqrt{\left.\left.1-2 x+x^{2}+\frac{4 L \nabla \mathrm{T}_{\ell}}{\mathrm{D}} B-1\right\}^{2}-x^{2}\right]}\right.\right.}
$$

Since $x=\frac{\xi^{\star}}{D}$, and $\mathscr{D}_{\text {is }}$ very large, the value of $x$ is small but non-zero. Therefore, in this case $\left[-2 x+x^{2}+\frac{4 L \nabla T_{\ell}}{\Phi} B\right] \ll 1$. Thus, the term under the square root sign in the numerator and the denominator of Eq. (B-8) can be expanded and the result is

$$
\frac{d(\ln v)}{d\left(\ln \left(L \nabla T_{l}\right)\right)}=\frac{\frac{4 B L \nabla T_{\ell}}{D}\left[1-x+\frac{x^{2}}{2}+\frac{2 B}{D} L \nabla T_{\ell}+\cdots-1\right]}{1 \cdot\left[\left[1-x+\frac{x^{2}}{2}+\frac{2 B}{D} L \nabla T_{l}+\cdots-1\right\}^{2}-x^{2}\right]}
$$

or,

$$
\frac{d(\ln v)}{d\left[\ln \left(L \nabla T_{\ell}\right)\right]}=\frac{\frac{4 B L \nabla T_{\ell}}{90}\left[-x+\frac{x^{2}}{2}+\frac{2 B L \nabla T_{\ell}}{9}\right]}{\left[\frac{x^{2}}{2}+\frac{2 B L \nabla T_{\ell}}{\mathrm{D}}\right]\left[-2 x+\frac{x^{2}}{2}+\frac{2 B L \nabla T_{\ell}}{9}\right]}
$$

Neglecting $x^{2}$ terms in Eq. (B-9) gives

$$
\frac{\mathrm{d} \ln v}{\mathrm{~d}\left[\ln \left(L \nabla T_{\ell}\right)\right]}=2 \frac{-x+\frac{2 \mathrm{BL} \nabla T_{\ell}}{\mathrm{D})}}{-2 \mathrm{x}+\frac{2 \mathrm{BL} \nabla \mathrm{T}_{\ell}}{\mathrm{D}}}=2\left[\frac{1-\frac{1}{2} \frac{\xi^{*}}{\mathrm{BL} \nabla T_{\ell}}}{1-\frac{\xi^{*}}{B L \nabla T_{\ell}}}\right]
$$

For $\xi^{\star} / B L \nabla T_{\ell}<1$, the square bracketed term on the right hand side of $(B-10)$ is always greater than unity. Typical values for the term $\left(\xi^{*} / \mathrm{BL} \nabla \mathrm{T}_{\ell}\right)$ for $\mathrm{NaCl}$ and $\mathrm{KCl}$ are $\sim 0.01$. Thus, with impurity effect applicable, exponents of $\left(L \nabla T_{\ell}\right)$ which are greater than 2 are expected. 


$$
125 / 126
$$

In the limit of $\xi^{\star} \rightarrow 0$ (i.e., interfacial-controlled migration without impurity effect), the square-bracketed term on the right-hand side of $(B-10)$ reduces to unity. Then $v$ varies with $\left(L \nabla T_{\ell}\right)^{2}$ as expected. 



\section{DISTRIBUTION LIST}

ACRES AMERICAN INC

A. S. BURGESS

₹ ROBERT H. CURTIS

R. STRUBLE

AEROSPACE CORP

PETER J. ALEXANDRO

BARRETT R. FRITZ

AGBABIAN ASSOCIATES

CHRISTOPHER M. ST JOHN

ALABAMA DEPT OF ENERGY CAMERON MCDONALD

ALABAMA STATE GEOLOGICAL SURVEY THORNTON L. NEATHERY

AMARILLO PUBLIC LIBRARY

AMERICAN EMBASSY - SWEDEN

AMERICAN ROCK WRITING RESEARCH JOHN NOXON

ANALYSIS AND TECHNOLOGY INC T. MAZOUR

APPLIED MECHANICS INC GRAHAM G. MUSTOE

ARGONNE NATIONAL LABORATORY

DAVID F. FENSTER

WYMAN HARRISON

J. HOWARD KITTEL

MARTIN SEITZ

MARTIN I. STEINDLER

STEVEY. TSAI

ARINC RESEARCH CORP H. P. HIMPLER

ARIZONA PUBLIC SERVICE COMPANY HENRY W. RILEY, JR.

ARIZONA STATE UNIVERSITY PAUL KNAUTH

ARKANSAS GEOLOGICAL COMMISSION WILLIAM V. BUSH NORMAN F. WILLIAMS

ARTHUR D. LITTLE INC AVIVA BRECHER CHARLES R. HADLOCK

ATKINS RESEARCH \& DEVELOPMENT - UNITED KINGDOM

T. W. BROYD

ATOMIC ENERGY CONSULTANTS DONALD G. ANDERSON

ATOMIC ENERGY CONTROL BOARD

-CANADA

KEN SHULTZ

ATOMIC ENERGY OF CANADA LTD

T. CHAN

M. O. LUKE

ANN QUINN

F. P. SARGENT

ATOMIC ENERGY RESEARCH ESTABLISHMENT

- UNITED KINGDOM

D. P. HODGKINSON

AUSTRALIAN ATOMIC ENERGY COMMISSION

BATTELLE COLUMBUS DIVISION

JOHN T. MCGINNIS

JEFFREY L. MEANS

NEIL E. MILLER

STEPHEN NICOLOSI

BATTELLE MEMORIAL INSTITUTE

JAMES DUGUID

BATTELLE NORTHWEST LABORATORIES CHARLES R. COLE

BE INC

K. J. ANDERSON
BECHTEL GROUP INC

LESLIE J. JARDINE

WILLIAM LI

T. R. MONCAN

CHING LIU WU

BELGISCHE GEOLOGISCHE DIENST - BELGIUM NOEL VANDENBERGHE

BENDIX FIELD ENGINEERINC CORP

BILL GRAHAM

CHARLES A. JONES

DONALD LIVINGSTON

MICHAEL H. MOBLEY

JOHN C. PACER

ANTHONY ZAIKOWSKI

BERKELEY GEOSCIENCES/HYDROTECHNIQUE ASSOCIATES

BRIAN KANEHIRO

BHABHA ATOMIC RESEARCH CENTRE - INDIA V. SUKUMORAN

BLACK \& VEATCH

M. JOHN ROBINSON

BOEING ENGINEERING AND CONSTRUCTION

COMPANY

R. B. CAIRNS

BRENK SYSTEMPLANUNG - W. GERMANY H. D. BRENK

BRIGHAM YOUNG UNIVERSITY HAROLD B. LEE LIBRARY

BROOKHAVEN NATIONAL LABORATORY M. S. DAVIS

P. W. LEVY

CLAUDIO PESCATORE

PETER SOO

HELEN TODOSOW (2)

BROOME COMMUNITY COLLEGE BRUCE OLDFIELD

BUNDESANSTALT FUR GEOWISSENSCHAFTEN

UND ROHSTOFFE - W. GERMANY MICHAEL LANGER HELMUT VENZLAFF

BUNDESMINISTERIUM FUR FORSCHUNG UND TECHNOLOGIE - W. GERMANY ROLF-PETER RANDL

BUREAU DE RECHERCHES GEOLOGIQUES ET MINIERES - FRANCE BERNARD FEUGA PIERRE F. PEAUDECERF

BUTLER UNIVERSITY PAUL VAN DER HEIJDE

CALIFORNIA ASSEMBLY COMMITTEE ON

NATURAL RESOURCES GENE VARANINI

CALIFORNIA DEPT OF CONSERVATION PERRY AMIMITO

CALIFORNIA DIVISION OF MINES \& GEOLOGY ROBERT H. SYDNOR

CANYONLANDS NATIONAL PARK PETER L. PARRY

CAPITAL AREA GROUND WATER

CONSERVATION COMMISSION A. N. TURCAN, IR.

CAPITAL UNIVERSITY VICTOR M. SHOWALTER

CAYUGA LAKE CONSERVATION ASSOCIATION INC D. S. KIEFER

CELSIUS ENERGY COMPANY NICK THO

CENTER FOR ENVIRONMENTAL

INFORMATION INC

FREDERICK W. STOSS
CENTER FOR INTERDISCIPLINARY STUDIES DAVID M. ARMSTRONC

CENTRE D INFORMATIQUE GEOLOGIQUE -FRANCE

GHISLAIN DEMARSILY

CHALMERS UNIVERSITY OF TECHNOLOGY

-SWEDEN

BERT ALLARD

CHEVRON OIL FIELD RESEARCH COMPANY BIORN PAULSSON

CITIZNS INSTITUTE FOR A POSITIVE ENERGY POLICY

LINDSAY AUDIN

CITY OF MONTICELLO RICHARD TERRY

CLIFFS ENGINEERING INC GARY D, AHO

COLORADO GEOLOGIC INC MIKE E. BRAZIE

COLORADO GEOLOGICAL SURVEY JOHN W. ROLD

COLORADO OUTWARD BOUND SCHOOL DAVID L. BURGER PETER ANTHONY ONEIL

COLORADO SCHOOL OF MINES W. HUSTRULID DONALD LANGMUIR

COLUMBIA UNIVERSITY TERRY ENGELDER M. ASHRAF MAHTAB

COMMISSION OF THE EUROPEAN COMMUNITIES ALDO CRICCHIO

CONGRESSIONAL INFORMATION SE- VICE LINDLEY C. MCGREW

CONNECTICUT DEPT OF ENVIRONMENTAL PROTECTION KEVIN MCCARTHY

CONNECTICUT STATE DEPARTMENT OF HEALTH SERVICES MARGERY A. COHEN

CONROY ENGINEERING PETER CONROY

COPPE/UFR] LUIZ OLIVEIRA

CORNELL UNIVERSITY

ARTHUR L. BLOOM FRED H. KULHAWY ROBERT POHL

CORTLAND COUNTY HEALTH DEPT J. V. FEUSS

D.R.E.

KARL J. ANANIA

DAMES \& MOORE

RON KEAR

JEFFREY KEATON

CHARLES R. LEWIS

DAN L. WARD INC DAN L. WARD

DAPPOLONIA CONSULTING ENGINEERS INC LISA K. DONOHUE ABBY FORREST AMINA HAMDY PETER C. KELSALL CARLE. SCHUBERT

DAWCON MANAGEMENT CONSULTING SERVICE

DAVID A. WEBSTER

DAY MILLING COMPANY JACK DAY 
DEAF SMITH COUNTY LIBRARY

DELAWARE GEOLOGICAL SURVEY ROBERT R. JORDAN

DEPT OF ENERGY, MINES AND RESOURCES -CANADA

A. S. JUDGE

DESEREI NEWS GORDON WHITE

DISPOSAL SAFETY INC. BENJAMIN ROSS

DUGOUT RANCH ROBERT \& HEIDI REDD

DYNATECH R/D COMPANY STEPHEN E. SMITH

E.I. DU PONT DE NEMOURS \& CO D. H. TURNO

E.L.H. PUBLICATIONS - THE RADIOACTIVE EXCHANGE HELMINSKI \& WILKEN

E.R. JOHNSON ASSOCIATES INC E. R. JOHNSON G. L. JOHNSON

EARTH RESOURCE ASSOCIATES INC SERGE GONZALES

EARTH SCIENCE AND ENGINEERINC INC LOU BLANCK

EARTH SCIENCES CONSULTANIS INC HARRY L. CROUSE

EAST COMPANY INC RAYMOND PEREZ

EBASCO SERVICES INC ZUBAIR SALEEM RAYMOND H. SHUM

ECOLOGY \& ENVIRONMENT INC MICHAEL BENNER

ECOLOGY CENTER OF LOUISIANA ROSS VINCENT

EDISON ELECTRIC INSTITUTE R. E. L. STANFORD

EDS NUCLEAR INC C. SUNDARARAJAN

EG \& G IDAHO INC SCOTT HIRSCHBERCER ROBERT M. NEILSON, JR.

ELECTRIC POWER RESEARCH INSTITUTE CHAIM BRAUN

ELEKTRIZTAETS-GES. LAUFENBURC -SWITZERLAND H. N. PATAK

ELSAM - DENMARK A. V. JOSHI ARNE PEDERSEN

ENERGY FUELS NUCLEAR INC GEORGE A. JONES

ENERGY RESEARCH GROUP INC MARC GOLDSMITH

ENCINEERS INTERNATIONAL INC V. RAJARAM

ENVIROLOGIC SYSTEMS INC IIM V. ROUSE

ENVIRONMENT CANADA CLAUDE BARRAUD

ENVIRONMENTAL POLICY INSTITUTE DAVID M. BERICK

ENVIROSPHERE COMPANY ROGER G. ANDERSON K. E. LIND-HOWE

ERTEC WESTERN INC DAN MELCHIOR

EXXON NUCLEAR COMPANY INC CERALD L. RITTER
EXXON NUCLEAR IDAHO COMPANY INC NATHAN A. CHIPMAN ROGER N. HENRY GARY WAYMIRE

FENIX \& SCISSON INC JOSE A. MACHADO CHARLENE U. SPARKMAN

FLORIDA DEPT OF ENVIRONMENTAL REGULATION HAMILTON OVEN

FLORIDA INSTITUTE OF TECHNOLOGY JOSEPH A. ANGELO, JR.

FLORIDA POWER \& LIGHT COMPANY JAMES R. TOMONTO

FLORIDA STATE UNIVERSITY JOSEPH F. DONOGHUE

FLUOR ENGINEERS \& CONSTRUCTORS INC THOMAS O. MALLONEE, JR. ADELL PITTS

FORD, BACON \& DAVIS INC ROBERT D. BAIRD ROBERT F. OVERMYER BURTON J. THAMER

FOSTER-MILLER ASSOCIATES INC NORBERT PAAS

FOUNDATION SCIENCES INC LOU BATTAMS

FREIE UNIVERSITAET BERLIN HANSKARL BRUEHL

FRIENDS OF THE EARTH GORDON ANDERSON RENEE PARSONS

FUTURE RESOURCES ASSOCIATES INC. ROBERT J. BUDNITZ

FW ENERGY APPLICATIONS INC O. BARRATT

GABIE BETTS BURTON MEMORIAL LIBRARY

GARTNER LEE ASSOCIATES LTD - CANADA ROBERT E. J. LEECH

GENERAL ATOMIC COMPANY MICHAEL STAMATELATOS

GENERAL COURT OF MASSACHUSETTS TIMOTHY I. BURKE

GEO/RESOURCE CONSULTANTS INC ALVIN K. JOE, JR.

GEOLOGICAL SURVEY OF CANADA JEFFREY HUME LIBRARY JOHN SCOTT

GEOLOGICAL SURYEY OF NORWAY SIGURD HUSEBY

GEORGIA INSTITUTE OF TECHNOLOGY MELVIN W. CARTER GEOFFREY G. EICHHOLZ ALFRED SCHNEIDER CHARLES E. WEAVER

GEOSTOCK - FRANCE R. BARLIER

GEOTECHNICAL ENGINEERS INC RONALD C. HIRSCHFELD

GEOTHERMAL ENERGY INSTITUTE DONALD F. X. FINN

GEOTRANS IAMES MERCER

GESELLSCHAFT F. STRAHLEN U. UMWELTFORSCHUNG M.B.H. - W. GERMANY WOLFGANG BODE NORBERT FOCKWER H. MOSER

GILBERT/COMMONWEALTH JERRY L. ELLIS
GOLDER ASSOCIATES

DONALD M. CALDWELL

MELISSA MATSON

EILEEN POETER

J. W. VOSS

GOLDER ASSOCIATES - CANADA

CLEMENT M. K. YUEN

GRAND COUNTY HIGH SCHOOL LIBRARY

GRAND COUNTY PUBLIC LIBRARY

GRAND JUNCTION SENTINEL GARY SCHMITZ

GRIMCO DONALD H. KUPFER

GSE NUCLEAR MOHSEN NIROOMAND-RAD

GSE/NUCLEAR OMAHA PÚBLIC POWER DISTRICT

JOHN K. NEJAD

GTC GEOLOGIC TESTING CONSULTANTS LTD -CANADA

JOHN F. PICKENS

GULF INTERSTATE ENGINEERING THOMAS J. HILL

GUIF STATES UTILITIES COMPANY E. LINN DRAPER

GUSTAVSON ASSOCIATES RICHARD M. WINAR

H \& R TECHNICAL ASSOCIATES INC WILLIAM R. RHYNE

H-TECH LABORATORIES INC BRUCE HARTENBAUM

HAHN-MEITNER-INSTITUT FUR KERNFORSCHUNG BERLIN KLAUS ECKART MAASS

HALEY AND ALDRICH INC JANICE HIGHT

HAMILTON COLLEGE DAVID K. SMITH

HANFORD ENGINEERING DEVELOPMENT LABORATORY

ROBERT EINZIGER

R. L. KNECHT

W. E. ROAKE

HART-CROWSER AND ASSOCIATES MICHAEL BAILEY

HARVARD UNIVERSITY CHARLES W. BURNHAM RAYMOND SIEVER

HATTIESBURG PUBLIC LIBRARY

HIGH PLAINS WATER DISTRICT DON MCREYNOLDS DON D. SMITH

HOUGH-NORWOOD HEALTH CARE CENTER GEORGE H. BROWN, M.D.

ILLINOIS DEPT OF NUCLEAR SAFETY TERRY R. LASH

ILIINOIS STATE GEOLOCICAL SURVEY KEROS CARTWRICHT MORRIS W. LEIGHTON E. DONALD MCKAY, III

IMPERIAL COLLEGE OF SCIENCE AND TECHNOLOCY - ENGLAND B. K. ATKINSON

INDIANA GEOLOGICAL SURVEY MAURICE BIGGS

INDIANA UNIVERSITY HAYDN H. MURRAY CHARLES ]. VITALIANO

INSTITUT FUR TIEFLAGERUNG - W. GERMANY WERNT BREWITZ

H. GIES

KLAUS KUHN

E. R. SOLTER 
INSTITUTE FOR CHEMICAL TECHNOLOGY - W.

GERMANY

REINHARD ODOI

INSTITUTE OF GEOLOGICAL SCIENCES

-ENGLAND

"STEPHEN THOMAS HORSEMAN

INSTITUTE OF PLASMA PHYSICS

H. AMANO

INTER/FACE ASSOCIATES INC RON GINCERICH

INTERA ENVIRONMENTAL CONSULTANTS INC F. J. PEARSON, JR. LARRY RICKERTSEN ROBERT WILEMS

INTERNATIONAL ATOMIC ENERGY AGENCY -AUSTRIA

FRANK A. OHARA

INTERNATIONAL ENERGY ASSOCIATES LTD BLYTHE K. LYONS

INTERNATIONAL ENGINEERING COMPANY INC

MAX ZASLAWSKY

INTERNATIONAL RESEARCH AND

EVALUATION

R. DANFORD

INTERNATIONAL SALT COMPANY

LEWIS P. BUSH

JOHN VOIGT

IOWA STATE UNIVERSITY

MARTIN C. EDELSON

BERNARD 1. SPINRAD

IRT CORP

$$
\text { J. STOKES }
$$

ISMES - ITALY

F. GERA

IT CORP

MORRIS BALDERMAN

ITASCA CONSULTING GROUP, INC. ROGER HART

J.F.T. AGAPITO \& ASSOCIATES INC MICHAEL P. HARDY

J.L. MAGRUDER \& ASSOCIATES J. L. MAGRUDER

JACKSON STATE UNIVERSITY ESTUS SMITH

JACKSON-GEORGE REGIONAL LIBRARY

JACOBY \& COMPANY CHARLES H. JACOBY

JAY L. SMITH COMPANY INC JAY L. SMITH

JGC CORPORATION - JAPAN MASAHIKO MAKINO

JOHNS HOPKINS UNIVERSITY JARED L. COHON

JOINT STUDY COMMITTEE ON ENERGY T. W. EDWARDS, JR.

JONES COUNTY JUNIOR COLLEGE LIBRARY

JORDAN GORRILL ASSOCIATES JOHN D. TEWHEY

KAISER ENGINEERS INC

W. J. DODSON

H. L. JULIEN

KALAMAZOO COLLEG RALPH M. DEAL

KANSAS DEPT OF HEALTH AND

ENVIRONMENT

GERALD W. ALLEN

KANSAS STATE GEOLOGICAL SURVEY WILLIAM W. HAMBLETON

KARNBRANSLESAKERHET - SWEDEN LARS B. NILSSON

KELLER WREATH ASSOCIATES FRANK WREATH
KERNFORSCHUNGSZENTRUM KARLSRUHE GMBH - W. GERMANY

K. D. CLOSS

R. KOESTER

KERNFORSCHUNGSZENTRUM UND

UNIVERSITAT

GERHARD ONDRACEK

KIERSCH ASSOCIATES

GEOSCIENCES/RESOURCES CONSULTANTS

INC

GEORGE A. KIERSCH PHD.

KIHN ASSOCIATES

HARRY KIHN

KLM ENGINEERING INC

B. GEORGE KNIAZEWYCZ

KOREA INSTITUTE OF ENERGY AND

RESOURCES (KIER)

CHOO SEUNG HWAN

CHONG SU KIM

KQIL

KREX-TV

TOM LUNDSTRUM

KSL-TV

P.O. BOX 5555

KSTR

ROBERT COLLINS

KURA

LESLIE COLE

KUTV-TV

ROD DECKER

KUTZ-TV NEWSWATCH 2

MICHAEL GOLDFEIN

KYOTO UNIVERSITY - JAPAN

YORITERU INOUE

LACHEL HANSEN \& ASSOCIATES INC DOUGLASE. HANSEN

LAKE SUPERIOR REGION RADIOACTIVE WASTE PROJECT C. DIXON

LAWRENCE BERKELEY LABORATORY

JOHN A. APPS

EUGENE BINNALL

THOMAS DOF

NORMAN M. EDELSTEIN

M. S. KING

JANE LONG

CHIN FU TSANC

J. WANG

PAUL A. WITHERSPOON

HAROLD WOLLENBERG

LAWRENCE LIVERMORE NATIONAL

LABORATORY

TED BUTKOVICH

DAE H. CHUNG

EDNA M. DIDWELL

HUGH HEARD

FRANCOIS E. HEUZE

DONALD D. JACKSON

R. JEFF LYTLE

NAI-HSIEN MAO

THOMAS E. MCKONE

LAWRENCE D. RAMSPOTT (2)

R. N. SCHOCK

TECHNICAL INFORMATION DEPARTMENT L-53

WASTE PACKAGE TASK LIBRARY

THOMAS J. WOLERY

JESSE L. YOW, IR.

LEHIGH UNIVERSITY

D. R. SIMPSON

LOCKHEED ENGINEERING \& MANAGEMENT

COMPANY

STEVE NACHT
LOS ALAMOS NATIONAL LABORATORY

P. L. BUSSOLINI

WAYNE R. HANSEN

CLAUDE HERRICK

W. C. MYERS

K. K. S. PILLAY

ROBERT E. RIECKER

KURT WOLFSBERG

LOS ALAMOS TECHNICAL ASSOCIATES INC R. J. KINGSBURY

LOUISIANA DEPT OF NATURAL RESOURCES B. JIM PORTER

LOUISIANA DEPT OF TRANSPORTATION \& DEVELOPMENT GEORGE H. CRAMER, II

LOUISIANA GEOLOGICAL SURVEY RENWICK P. DEVILLE CHARLES G. GROAT SYED HAQUE

LOUISIANA GOVERNORS OFFICE DENNIS DAUGHERTY

LOUISIANA STATE UNIVERSITY JEFFREY S. HANOR JOSEPH DIDIER MARTINEZ

LOUISIANA TECHNICAL UNIVERSITY LIBRARY R. H. THOMPSON

LOWENBERG ASSOCIATES HOMER LOWENBERG

LUBBOCK COUNTY SOIL AND WATER

CONSERVATION DISTRICT DON LANGSTON

IYLE FRANCIS MINING COMPANY LYLE FRANCIS

M.J. OCONNOR \& ASSOCIATES LTD M. J. OCONNOR

MAINE BUREAU OF HEALTH DONALD C. HOXIE

MARYLAND DEPT OF HEALTH \& MENTAL HYGIENE MAX EISENBERG

MASSACHUSETTS DEPT OF ENVIRONMENTAL QUALITY ENGINEERING JOSEPH A. SINNOTT

MASSACHUSETTS HOUSE OF REPRESENTATIVES WILLIAM ROBINSON

MASSACHUSETTS INSTITUTE OF

TECHNOLOGY

W. F. BRACE

IOHN DEUTCH

TED GREENWOOD

RICHARD K. LESTER MARSHA LEVINE

MATERIALS RESEARCH LABORATORY LTD

-CANADA S. SINGH

MCDERMOTT INTERNATIONAL KAREN L. FURLOW

MCMASTER UNIVERSITY - CANADA

L. W. SHEMILT

MELLEN GEOLOGICAL ASSOCIATES INC FREDERIC F. MELLEN

MEMBERS OF THE GENERAL PUBLIC

L. ROBERT ANDERSON

KURT BALLING

BRET BLOSSER

HAROLD BOWEN, SR.

JAMES BOYD

THOMAS G. BRADFORD

ROGER H. BROOKS

CHRISTINE BROWN

VERD BYRNES 
HAZEL CHAPMAN, PH.D. LAWRENCE CHASE, PH.D. TOM \& SUSAN CLAWSON STEVE CONEWAY MARSHALL CROMWELL M. VAL DALTON UHL DALTON JOANN TEMPLE DENNETT KENNETH \& ALICE M. DROGIN ROBERT DUDEK

TIM DULL

CHARLESS. DUNN

JEAN EARDLEY

THAUMAS P. EHR

WARREN EISTER

CARL A. GIESE

SHIRLEY M. GIFFORD

MICHAEL J. GILBERT

STEVE \& SUE CILSDORF

DARYL GLAMANN

HARRY D. GOODE

OSWALD H. GREAGER

DOUGLAS H. GREENLEE

KENNETH CUSCOTT

C. F. HAJEK

A. M. HALE

DOROTHY L. HARDING

MICHAEL T. HARRIS

RONALD I. HARVEY

MARION HAZELTON

BENIAMIN K. HESS

MARGARET L. HOPKIN

CHARLES B. HUNT

KENNETH S. JOHNSON

CRAIG W. JONES

SCOTT KRAMER

THOMAS H. LANGEVIN

HARRY E. LEGRAND

LINDA LEHMAN

CLIVE MACKAY

W. D. MCDOUGALD

MAX MCDOWELL

JEFF MEADOWS

A. ALAN MOGHISSI

BARBARA MORRA

THEA NORDLING

CAROLINE PETTI

SHAILER S. PHILBRICK

RUS PURCELL

MARTIN RATHKE

TOM \& MARY REES

PETER I. SABATINI, JR.

IOANNE SAVOIE

OWEN SEVERANCE

HARRY W. SMEDES

NORMAN C. SMITH

PATRICIA SNYDER

P. E. STRALEY-GRECA

MARGUERITE SWEENEY

M. I. SZULINSKI

RAYMOND G. TAYLOR

MARK UDALL

W. VON BLACK

GARY WAGNER

BILL WALSH

MARTIN \& ELAINE WALTER

JIMMY L. WHITE

RICHARD J. WILLIS

LINDA WITTKOPF

SUSAN WOOLLEY

STEPHEN G. ZEMBA
MERRIMAN AND BARBER CONSULTING

ENGINEERS INC

GENE R. BARBER

MICHAEL BAKER, JR. INC

C. J. TOUHILL

MICHIGAN CENIER FOR ENVIRONMENTAL

HEALTH SCIENCES

JOHN L. HESSE

MICHIGAN DEPT OF NATURAL RESOURCES R. THOMAS SEGALL

MICHIGAN DEPT OF PUBIIC HEALTH

GEORGE W. BRUCHMANN

ERIC SCHWINC

MICHIGAN DISTRICT HEALTH DEPT NO. 4 EDGAR KREFT

MICHIGAN ENVIRONMENTAL PROTECTION COMMITTEE

DAVE CHAPMAN

MICHIGAN GEOLOGICAL SURVEY ROBERT C. REED

MICHIGAN PUBLIC SERVICE COMMISSION RON CALLEN

MICHIGAN STATE UNIVERSITY WILLIAM C. TAYLOR

MICHIGAN TECHNOLOGICAL UNIVERSITY ROBERT PATTERSON

MINNESOTA DEPT OF ENERGY AND

DEVELOPMENT

MINNESOTA DEPT OF HEALTH ALICE T. DOLEZAL HENNIGAN

MINNESOTA ENVIRONMENTAL QUALITY

BOARD

RICHARD PATON

MINNESOTA GEOLOGICAL SURVEY MATT 5. WALTON

MINNESOTA GOVERNORS TASK FORCE ON

HIGH-LEVEL RADIOACTIVE WASTE

MISSISSIPPI ATTORNEY GENERALS OFFICE MACK CAMERON

MISSISSIPPI BUREAU OF GEOLOGY MICHAEL B. E. BOGRAD

MISSISSIPPI CITIZENS AGAINST NUCLEAR DISPOSAL

STANLEY DEAN FLINT

MISSISSIPPI DEPT OF ENERGY AND

TRANSPORTATION

RONALD J. FORSYTHE (3)

MISSISSIPPI DEPT OF NATURAL RESOURCES CHARLES L. BLALOCK CURTIS W. STOVER

MISSISSIPPI DEPT OF WILDLIFE

CONSERVATION KENNETH L. GORDON

MISSISSIPPI EMERGENCY MANAGEMENT AGENCY

IAMES E. MAHER

MISSISSIPPI HOPUSE OF REPRESENTATIVES MACK MCINNIS

MISSISSIPPI LIBRARY COMMISSION SARA TUBB

MISSISSIPPI POWER \& LIGHT ROBERT SHADDIX

MISSISSIPPI STATE BOARD OF HEALTH EDDIE S. FUENTE GUY R. WILSON

MISSISSIPPI STATE HOUSE OF

REPRESENTATIVES

TERRELL BRELAND

E. FRED DOBBINS

HILLMAN TEROME FRAZIER

JERRY OKEEFE
MISSISSIPPI STATE SENATE

MARTIN T. SMITH

THEODORE SMITH

MISSISSIPPI STATE UNIVERSITY

TROY J. LASWELL

VICTOR L. ZITTA

MISSISSIPPIANS AGAINST DISPOSAL ALICIA D. FERCUSON

MITRE CORP

LESTER A. ETTLINGER

MITSUBISHI METAL CORP TATSUO ARIMA

MOAB NUCLEAR WASTE INFORMATION OFFICE

MICHAELENE PENDLETON (2)

MOAB TIMES-INDEPENDENT SAMUEL I. TAYLOR

MONTANA BUREAU OF MINES AND GEOLOGY

EDWARD C. BINGLER

MONTICELLO NUCLEAR WASTE INFORMATION OFFICE CARL EISEMANN (2)

MORRISON-KNUDSEN COMPANY INC STEPHANIE NICHOLS MICHELLE L. PAURLEY

NAGRA - SWITZERLAND HANS ISSLER

NATIONAL ACADEMY OF SCIENCES JOHN T. HOLLOWAY HAROLD L. JAMES

NATIONAL AERONAUTICS AND SPACE ADMINISTRATION

MICHAEL R. HELFERT MICHAEL ZOLENSKY

NATIONAL BUREAU OF STANDARDS RILEYM. CHUNG

NATIONAL HYDROLOGY RESEARCH

INSTITUTE - CANADA DENNIS I. BOTTOMLEY K. U. WEYER

NATIONAL PARK SERVICE CECIL D. LEWIS, JR.

NATIONAL PARK SERVICE PLANNING \& RESOURCE PRESERVATION RICHARD A. STRAIT (3)

NATIONAL PARKS \& CONSERVATION

ASSOCIATION

T. DESTRY JARVIS

TERRI MARTIN

NATIONAL SCIENCE FOUNDATION ROYAL E. ROSTENBACH

NAVAL WEAPONS STATION EARLE GENNARO MELLIS

NEW JERSEY INSTITUTE OF TECHNOLOGY BEN STEVENSON

NEW MEXICO BUREAU OF GEOLOGY BILL HATCHELL

NEW MEXICO BUREAU OF MINES AND MINERAL RESOURCES FRANK E. KOTTLOWSK

NEW MEXICO ENVIRONMENTAL EVALUATION GROUP ROBERT H. NEILL

NEW MEXICO INSTITUE OF MINING JOHN L. WILSON

NEW YORK DEPT OF HEALTH DAVID AXELROD, M.D.

NEW YORK ENERCY RESEARCH \&

DEVELOPMENT AUTHORITY JOHN P. SPATH (8)

NEW YORK GEOLOGICAL SURVEY ROBERT H. FAKUNDINY 
NEW YORK LEGISLATIVE COMMISSION ON SC̈IENCE \& TECHNOLOGY JAMES T. MCFARLAND

NEW YORK STATE ASSEMBLY STANLEY FINK

NEẄ YORK STATE ATTORNEY GENERALS OFFICE

EZRA I. BIALIK

NEW YORK STATE GEOLOGICAL SURVEY JAMES R. ALBANESE ROBERT H. FICKIES

NEW YORK STATE HEALTH DEPT JOHN MATUSZEK

NEW YORK STATE PUBLIC SERVICE COMMISSION FRED HAAG

NEW YORK STATE SENATE RESEARCH SERVICE DAVID WHITEHEAD

NORTH CAROLINA STATE SENATE

J. R. ALLSBROOK

W. CRAIG LAWINC

NORTH CAROLINA STATE UNIVERSITY M. KIMBERLEY

NORTH DAKOTA GEOLOGICAL SURVEY DON L. HALVORSON

NORTHEAST LOUISIANA UNIVERSITY ROBERT E DOOLEY

NORTHEAST UTILITIES SERVICE COMPANY PATRICIA ANN OCONNELL

NORTHWESTERN UNIVERSITY BERNARD I. WOOD

NTR GOVERNMENT SERVICES THOMAS V. REYNOLDS

NUCLEAR ASSURANCE CORP JOHN V. HOUSTON JEAN RION

NUCLEAR ENERGY AGENCY/OECD - FRANCE ANTHONY MULLER

NUCLEAR SAFETY RESEARCH ASSOCIATION IZUMI KURIHARA

NUCLEAR WASTE WATCHERS HELEN LETARTE

NUS CORP

W. G. BEL.TER

RODNEYJ. DAVIS

N. BARRIE MCLEOD

BARRYN. NAFT

DOUGLAS D. ORVIS

YONG M. PARK

NUTECH ENGINEERS INC GARRISON KOST

NWT CORP

W. L. PEARL

OAK RIDGE NATIONAL LABORATORY

I. O. BIOMEKE

H. C. CLAIBORNE

ALIEN G. CROFF

LESLIE R. DOLE

CATHYS. FORE

DAVID C. KOCHER

T. F. LOMENICK

E. M. OBLOW

ELLEN D. SMITH

STEPHEN S. STOW

OFFICE OF ENVIORMENTAL AFFAIRS L. HALL BOHLINGER (3)

OFFICE OF PLANNING \& BUDGET CONNIE CRANDELL

OKLAHOMA GEOLOGICAL SURVEY CHARLES I. MANKIN

ONTARIO HYDRO - CANADA
I. A. CHADHA
K. A. CORNELL
C. F. LEE

ONTARIO MINISTRY OF THE ENVIRONMENT CANADA

JAAK VIIRLAND

ORANGE COUNTY COMMUNITY COLLEGE

LAWRENCE E. OBRIEN

OREGON STATE UNIVERSITY JOHN C. RINGLE

ORGANISATION FOR ECONOMIC COOPERATION AND DEVELOPMENT -FRANCE

PETER D. JOHNSTON

OTHA INC

IOSEPH A. LIEBERMAN

P.O.W.E.R.

TIM REVELL

PACIFIC NORTHWEST LABORATORY

DON J. BRADLEY

H. C. BURKHOLDER

JOHN B. BURNHAM

T.D. CHIKALLA

HARVEY DOVE

FLOYD N. HODGES

J. H. JARRETT

CHARLES T. KINCAID

MAX R. KREITER

J. E. MENDEL

J. M. RUSIN

R. JEFF SERNE

RICHARD STRICKERT

I. H. WESTSIK, JR.

PARSONS BRINCKERHOFF QUADE \&

DOUGLAS INC

T. R. KUESEL

ROBERT PRIETO

MARK E. STEINER

PARSONS-REDPATH

BRUNO LORAN

KRISHNA SHRIYASTAVA

GLEN A. STAFFORD

PB-KBB INC

IUDITH G. HACKNEY

PENNSYLVANIA STATE UNIVERSITY

MARY BARNES

MICHAEL GRUTZECK

DELLA M. ROY

WILLIAM B. WHITE

PENNSYLYANIA TOPOGRAPHIC \&

GEOLOGICAL SURVEY

ARTHUR A. SOCOLOW

PERRY COUNTY

W. F. BOWEN

PERRY COUNTY CITIZENS AGAINST NUCLEAR

WASTE DISPOSAL

WARREN STRICKLAND

PETTIS WALLEY

PHILADELPHIA ELECTRIC COMPANY JOHN I. TUCKER

PHYSIKALISCH-TECHNISCHE BUNDESANSTALT - W. GERMANY

PETER BRENNECKE

HORST SCHNEIDER

PINE FOREST REGIONAL LIBRARY

PIRGIM

RICHARD LEVICK

POBERESKIN INC. MEYER POBERESKIN

POINT BEACH NUCLEAR PLANT [AMES I. ZACH

POLIUTION AND ENVIRONMENTAL PROBLEMS

CATHERINE QUIGG

POTASH CORP OF SASKATCHEWAN MINING

ITD - CANADA

PARVIZMOTTAHED
PRESEARCH INC

RHONNIE L. SMITH

PRESQUE ISLE COURTHOUSE

PSE \& $\mathbf{C}$

JOHN J. MOLNER

PUBLIC LAW UTILITIES GROUP DORIS FALKENHEINER

PUBLIC SERVICE INDIANA ROBERT S. WEGENC

PURDUE UNIVERSITY PAUL S. LYKOUDIS

R.J. SHLEMON AND ASSOCIATES INC R. J. SHLEMON

RADIAN CORP BARBARA MAXEY

RALPH M. PARSONS COMPANY IERROLD A. HAGEL

RANDALL COUNTY LIBRARY

RE/SPEC INC

GARY D. CALLAHAN

PAUL F. GNIRK

WILLIAM C. MCCLAIN

RED ROCK 4-WHEELERS GEORGE SCHULTZ

RENSSELAER POLYTECHNIC INSTITUTE BRIAN BAYLY

RESOURCE SYSTEMS INSTITUTE KIRK R. SMITH

RHOADS MEMORIAL IIBRARY

RHODE ISLAND GOVERNORS ENERGY OFFICE BRUCE VILD

RHODE ISLAND GOVERNORS OFFICE JOHN A. IVEY

RICHTON CITY HALL R. RAHAIM

RIO ALGOM CORP DUANE MATLOCK

RISO NATIONAL LABORATORY - DENMARK LARS CARLSEN

ROCKWELL HANFORD OPERATIONS

RONALD C. ARNETT

JAMES L, ASH

HARRY BABAD

KUNSOO KIM

KARL M. LA RUE

STEVEN J. PHILLIPS

MICHAEL J. SMITH

DAVID L. SOUTH

RICHARD T. WILDE

ROCKWEUI INTERNATIONAL ENERGY SYSTEMS GROUP

LAWRENCE J. SMITH

ROGERS \& ASSOCIATES ENGINEERING CORP ARTHUR A. SUTHERLAND

ROGERS, GOLDEN \& HALPERN IACK A. HALPERN

ROY F. WESTON INC

MARTIN HANSON

WILLIAM IVES

RONALD MACDONALD

MICHAEL V. MELLINGER

VIC MONTENYOHL

SAM PANNO

JILL. RUSPI

DOUGLAS W. TONKAY

LAWRENCE A. WHITE

ROYAL INSTITUTE OF TECHNOLOGY -SWEDEN ROGER THUNVIK

RPC INC

IAMES VANCE 
S.E. LOGAN \& ASSOCIATES INC STANLEY E. LOGAN

S.M. STOLLER CORP ROBERT W. KUPP

SALT LAKE CITY PUBLIC LIBRARY

SALT LAKE CITY TRIBUNE JIM WOOLF

SALT LAKE COUNTY LIBRARY SYSTEM WHITMORE LIBRARY

SAN DIEGO GAS \& ELECTRIC COMPANY LOUIS BERNATH

SAN JOSE STATE UNIVERSITY SCHOOL OF ENGINEERINC

R. N. ANDERSON

SAN JUAN RECORD JOYCE MARTIN

SANDIA NATIONAL LABORATORIES

C. D. BROYLES

MARGARET S. CHU

THOMAS O. HUNTER

I. KEITH IOHNSTONE

A. R. LAPPIN

R.W. LYNCH

MARTIN A. MOLECKE

IAMES T. NEAL

NESTOR R. ORTIZ

SCOTT SINNOCK

LYNN D. TYLER

WOLFGANG WAWERSIK

WENDELL D. WEART

WIPP CENTRAL FILES

SARGENT \& LUNDY ENGINEERS

LAWRENCE L. HOLISH

SAVANNAH RIVER LABORATORY

CAROL IANTZEN

1. WENDELL MARINE

WILLIAM R. MCDONELI

DONALD ORTH

SCANDPOWER INC

DAN POMEROY

SCIAKY BROTHERS

JOHN C. JASPER

SCIENCE APPLICATIONS INC

JEFFREY ARBITAL.

JERRY J. COHEN

NADIA DAYEM

BARRY DIAL

MICHAEL B. GROSS

JAMES E. HAMMELMAN

DEAN C. KAUL

DAVID H. LESTER

PETER E. MCGRATH

JOHN E. MOSIER

HOWARD PRATT

MICHAEL E. SPAETH

M. D. VOEGELE

KRISHAN K. WAHI

ROBERT A. YODER

SCRIPPS INSTITUTE OF OCEANOGRAPHY

(A-015)

HUBERT STAUDIGEL

SENATE RESEARCH SERVICE

DAVID WHITEHEAD

SENECA COUNTY DEPT OF PLANNING \&

DEVELOPMENT

SERATA GEOMECHANICS INC

FRANK TSAI

SERIOUS TEXANS AGAINST NUCLEAR

DISPOSAL (S.T.A.N.D)

DELBERT DEVIN

SHAFER EXPLORATION COMPANY

WILLIAM E. SHAFER
SHANNON \& WILSON INC HARVEY W. PARKER

SHELL OIL COMPANY PHILIP BERGER

SHIMIZU CONSTRUCTION COMPANY LTD JUNJI TAKAGI

SHIMIZU CONSTRUCTION COMPANY LTD -JAPAN TAKASHI ISHII

SIERRA CLUB MARVIN RESNIKOFF BROOKS YEAGER

SIERRA CLUB - COLORADO OPEN SPACE COUNCIL ROY YOUNG

SIERRA CLUB - MISSISSIPPI CHAPTER

SIERRA CLUB LEGAL DEFENSE FUND H. ANTHONY RUCHEL

SLICKROCK COUNTRY COUNCIL LUCY K. WALLINGFORD

SOCIETY OF PROFESSIONAL ARCHEOLOGISTS L. M. PIERSON

SOGO TECHNOLOGYINC TIO C. CHEN

SOKAOGON CHIPPEWA COMMUNITY ARLYN ACKLEY

SOUTH DAKOTA GEOLOGICAL SURVEY RICHARD BRETZ

SOUTH DAKOTA SCHOOL OF MINES AND TECHNOLOGY CANER ZANBAK

SOUTH SALT LAKE LIBRARY

SOUTHERN GOVERNORS ASSOCIATION

SOUTHERN LEGISLATIVE CONFERENCE

SOUTHERN METHODIST UNIVERSITY GEORGE W. CRAWFORD MELISSA DEBOWSKI

SOUTHERN STATES ENERGY BOARD I. F. CLARK NANCY KAISER

SOUTHERN UTAH RESIDENTS CONCERNED ABOUT THE ENVIRONMENT

SOUTHERN UTAH STATE COLLEGE LIBRARY SOUTHWEST RESEARCH AND INFORMATION CENTER

DON HANCOCK ALISON P. MONROE

SPRINGVILLE CITY LIBRARY

SRI INTERNATIONAL (PS 285) DIGBY MACDONALD

ST. JOSEPH COLLEGE CLAIRE MARKHAM

STANFORD UNIVERSITY KONRAD B. KRAUSKOPF GEORGE A. PARKS IRWIN REMSON

STATE FARM INSURANCE IIM ENGLEBRICHT

STATE UNIVERSITY OF NEW YORK AT BINGHAMTON FRANCIS T. WU

STATE UNIVERSITY OF NEW YORK COLLEGE AT CORTLAND JAMES E. BUGH

STAUFFER CHEMICAL COMPANY RANDY L BASS.BASSETT

STONE \& WEBSTER ENGINEERING CORP SUE NEWHAMS

ARLENE C. PORT

EVERETT M. WASHER
STUDIO GEOLOGICO FOMAR - ITALY A. MARTORANA

STUDSVIK ENERGITEKNIK AB - SWEDEN ROLF SJOBLOM

SWANSON ENVIRONMENTAL INC PETER G. COLLINS

SWEDISH GEOLOGICAL LEIF CARLSSON

SYRACUSE UNIVERSITY WALTER MEYER J. E. ROBINSON

SYSTEMS SCIENCE AND SOFTWARE PETER LAGUS

T.M. GATES INC TODD M. GATES

TECHNICAL INFORMATION PROJECI DONALD PAY

TECHNICAL RESEARCH CENTRE OF FINLAND SEPPO VUORI

TECHNICAL SERVICES AND INSTRUMENTATION INC BURTON ANDREPONT

TEKNEKRON RESEARCH INC DOUGLAS K. VOGT

TERRA TEK INC KHOSROW BAKHTAR

TERRA THERMA INC ADRIAN BROWN

TERRAFORM ENGINEERS INC FRANCIS S. KENDORSKI

TERRAMETRICS INC HOWARD B. DUTRO

TEXAS A \& M UNIVERSITY

P. DOMENICO

IOHN HANDIN

ROY W. HANN, JR.

EARL HOSKINS

STEVE MURDOCK

GARY ROBBINS

JAMES E. RUSSELL

TEXAS BUREAU OF ECONOMIC GEOLOGY WILLIAM L. FISHER

TEXAS DEPT OF HEALTH DAVID K. LACKER

TEXAS DEPT OF WATER RESOURCES W. KLEMT T. KNOWLES

TEXAS ENERGY COORDINATORS OFFICE ARNULFO ORTIZ

TEXAS GOVERNORS OFFICE

STEVE FRISHMAN R. DANIEL SMITH

TEXAS STATE HOUSE OF REPRESENTATIVES PETE LANEY

TEXAS WORID OPERATIONS INC DAVID JEFFERY

THE AEROSPACE CORP KENNETH W. STEPHENS

THE ANALYTIC SCIENCES CORP

JOHN W. BARTLETT CHARLES M. KOPLIK

THE EARTH TECHNOLOGY CORP FRED A. DONATH IOSEPH G. GIBSON FIA VITAR MATT WERNER KENNETH L. WILSON

THE NORWEGIAN GEOTECHNICAL. INSTITUTE NICK BARTON

THOMSEN ASSOCIATES

C. T. GAYNOR, "I 
IIMES-PICAYUNE

"MARK SCHLEIFSTEIN

TIOGA COUNTY PLANNING BOARD

THOMAS A. COOKINGHAM

TRU WASTE SYSTEMS OFFICE

K. V. GILBERT

TUN ISMAIL ATOMIC RESEARCH CENTRE (PUSPATI)

SAMSURDIN BIN AHAMAD

U. S. NUCLEAR REGULATORY COMMISSION TILAK R. VERMA

U.H.D.E. - W. GERMANY FRANK STEINBRUNN

U.S. ARMY CORPS OF ENGINEERS DON BANKS ALAN BUCK

U.S. BUREAU OF LAND MANAGEMENT JIM BIGGINS

LYNN JACKSON

GENE NODINE

MARY PLUMB

GREGORY F. THAYN

U.S. BUREAU OF MINES ANTHONY IANNACCHIONE

U.S. BUREAU OF RECLAMATION JOHN BROWN REGE LEACH

U.S. DEPT OF COMMERCE PETER A. RONA

U.S. DEPT OF ENERGY CHED BRADLEY R. COOPERSTEIN LAWRENCE H. HARMON ROGER MAYES CARL NEWTON JAMES TURI

U.S. DEPT OF ENERGY - ALBUQUERQUE OPERATIONS OFFICE PHILIP LARRAGOITE JOSEPH M. MCGOUGH

U.S. DEPT OF ENERGY - CHICAGO OPERATIONS OFFICE NURI BULUT

GARY C. MARSHALI. C. MORRISON

CAROL MORRISON

PUBLIC READING ROOM R. SELBY

U.S. DEPT OF ENERGY - CRYSTALLINE ROCK PROJECT OFFICE

SALLY A. MANN

U.S. DEPT OF ENERGY - DALLAS SUPPORT OFFICE

CURTIS E. CARLSON, IR.

U.S. DEPT OF ENERGY - DIVISION OF WASTE REPOSITORY DEPLOYMENT JEFF SMILEY

U.S. DEPI OF ENERGY - GEOLOGIC REPOSITORY DIVISION

DON ALEXANDER

C. R. COOLEY (2)

JIM FIORE

MARK W. FREI

RALPH STEIN

U.S. DEPT OF ENERGY - GRAND JUNCTION

OFFICE

WAYNE ROBERTS

U.S. DEPT OF ENERGY - HEADQUARTERS

PUBLIC READING ROOM

HENRY F, WALTER

U.S. DEPT OF ENERGY - IDAHO OPERATIONS OFFICE

M. BARAINCA

IAMES F. LEONARD

PUBLIC READING ROOM
U.S. DEPT OF ENERGY - NEVADA OPERATIONS OFFICE

PUBLIC READINC ROOM

DONALD L. VIETH

U.S. DEPT OF ENERGY - NUCLEAR WASTE

POLICY ACT OFFICE

JANIE SHAHEEN

U.S. DEPT OF ENERGY - OAK RIDGE

OPERATIONS OFFICE

PUBLIC READING ROOM

U.S. DEPT OF ENERGY - OFFICE OF BASIC ENERGY SCIENCES MARK W. WITTELS

U.S. DEPT OF ENERGY - OFFICE OF ENERGY RESEARCH

FRANK I. WOBBER

U.S. DEPT OF ENERGY - OSTI (317)

U.S. DEPT OF ENERGY - RICHLAND

OPERATIONS OFFICE J. SCHREIBER

U.S. DEPT OF ENERGY - SALT REPOSITORY PROJECI OFFICE J. O. NEFF

U.S. DEPT OF ENERGY - SAN FRANCISCO OPERATIONS OFFICE

ENERCY RESOURCES CENTER PUBLIC READING ROOM

U.S. DEPT OF LABOR ALEX G. SCIULLI KELVIN K. WU

U.S. DEPT OF THE INTERIOR PAUL A. HSIEH

U.S. ENVIRONMENTAL PROTECTION AGENCY DIVISION OF CRITERIA \& STANDARDS DAN EGAN JAMES NEIHEISEL

U.S. ENVIRONMENTAL PROTECTION AGENCY

- REGION II IOYCE FELDMAN

U.S. GENERAL ACCOUNTING OFFICE WILLIAM DAVID BROOKS CHARLES D. MOSHER

U.S. GEOLOGICAL SURVEY VIRGINIA M. GLANZMAN JOHN A. GROW JACOB RUBIN

U.S. GEOLOGICAL SURVEY - ALEXANDRIA G. N. RYALS

U.S. GEOLOGICAL SURVEY - BATON ROUGE DARWIN KNOCHENMUS

U.S. GEOLOGICAL SURVEY - COLUMBUS A. M. LA SALA, IR

U.S. GEOLOGICAL SURVEY - DENVER M. S. BEDINGER JESS M. CLEVELAND ROBERT J. HITE RAYMOND D. WATTS

U.S. GEOLOGICAL SURVEY - JACKSON GARALD G. PARKER, JR

U.S. GEOLOGICAL SURVEY - MENLO PARK JOHN BREDEHOEFT MICHAEL CLYNNE ARTHUR H. LACHENBRUCH

U.S. GEOLOGICAL SURVEY - RESTON I-MING CHOU

NEIL PLUMMER

JOHN ROBERTSON

EDWIN ROEDDER

EUCENE H. ROSEBOOM, IR

DAVID B. STEWART

NEWELL I. TRASK, IR.
U.S. HOUSE OF REPRESENTATIVES B. IEANINE HULL

U.S. HOUSE SUBCOMMITTEE ON ENERGY AND

THE ENVIRONMENT

MORRIS K. UDALL

U.S. NATIONAL PARK SERVICE THOMAS C. WYLIE

U.S. NUCLEAR REGULATORY COMMISSION

J. CALVIN BELOTE

LEON BERATAN

GEORGE BIRCHARD

KIEN C. CHANG

EILEEN CHEN

PATRICIA A. COMELLA

ENRICO F. CONTI

F. ROBERT COOK

BARBARA A COOKE

JULIA ANN CORRADO

PAUL F. GOLDBERC

MALCOLM R. KNAPP

IOHN C. MCKINLEY

THOMAS J. NICHOLSON

NRC LIBRARY

EDWARD OCONNELL

LESLIE PEETERS

JAY E. RHODERICK

FREDERICK W ROSS

R. JOHN STARMER

NANCY STILL

JOHN TRAPP

MICHAEL WEBER

KRISTIN B. WESTBROOK

EVERETT A. WICK

ROBERT I. WRIGHT

UNION CARBIDE CORP

GARY M. ANGELINO

UNION OF CONCERNED SCIENTISTS

MICHAEL FADEN

CORDON THOMPSON

UNITED KINGDOM DEPT OF THE

ENVIRONMENT

F. S. FEATES

UNITED PRESS INTERNATIONAL

PETE GILLINS

UNIVERSITY OF AKRON

LORETTA J. COLE

UNIVERSITY OF ALBERTA - CANADA

J. R. BRANDT

F. W. SCHWARTZ

UNIVERSITY OF ARIZONA

JAAK DAEMEN

STANLEYN. DAVIS

JAMES G. MCCRAY

SHLOMO P. NEUMAN

WILLIS D. SAWYER, JR

UNIVERSITY OF BRITISH COLUMBIA -CANADA CRAIG FORSTER

R. ALLAN FREEZE

UNIVERSITY OF CALIFORNIA AT BERKEIFY

NEVILLE G. W. COOK

RICHARD E. GOODMAN

TODD LAPORTE

D. R. OLANDER

THOMASH. PIGFORD

UNIVERSITY OF CALIFORNIA AT LOS ANGELES D. OKRENT

KRIS PRESTON

UNIVERSITY OF CALIFORNIA AT RIVERSIDE

LEWIS COHEN

DON STIERMAN 
UNIVERSITY OF CINCINNATI ATTILA KILINC

UNIVERSITY OF DELAWARE FRANK A. KULACKI

UNIVERSITY OF FLORIDA DAVID E. CLARK DOLORES C. JENKINS M. J. OHANIAN

UNIVERSITY OF HAWAII AT MANOA DAVID EPP MURLI H. MANGHNANI

UNIVERSITY OF ILLINOIS AT URBANA

-CHAMPAIGN

MAGDI RAGHE

UNIVERSITY OF LOWELL JAMES R. SHEFF

UNIVERSITY OF MARYLAND MARVIN ROUSH

UNIVERSITY OF MASSACHUSETTS GEORGE MCGILL

UNIVERSITY OF MICHICAN WILLIAM KERR

UNIVERSITY OF MINNESOTA CHARLES FAIRHURST DONALD GILLIS

UNIVERSITY OF MISSISSIPPI GEORGE D. BRUNTON

UNIVERSITY OF MISSOURI AT COLUMBIA W. D. KELLER

UNIVERSITY OF MISSOURI AT KANSAS CITY EDWIN D. GOEBEL SYED E. HASAN

UNIVERSITY OF MISSOURI AT ROLLA ALLEN W. HATHEWAY ARVIND KUMAR NICK TSOULFANIDIS

UNIVERSITY OF NEW MEXICO HAROLD M. ANDERSON DOUGLAS G. BROOKINS RODNEY C. EWINC

UNIVERSITY OF NEWCASTLE UPON TYNE -ENGLAND

I. W. FARMER

UNIVERSITY OF OKLAHOMA DANIEL T. BOATRICHT

UNIVERSITY OF OTIAWA - CANADA TUNCER OREN

UNIVERSITY OF PITTSBURGH B. L. COHEN

UNIVERSITY OF RHODE ISLAND EDWARD P. LAINE

UNIVERSITY OF ROCHESTER DAVID ELMORE

UNIVERSITY OF SOUTHERN MISSISSIPPI CHARLES R. BRENT FRED HOWELL JAMES W. PINSON DANIEL A. SUNDEEN GARY C. WILDMAN

UNIVERSITY OF SOUTHWESTERN LOUISIANA RICHARD U. BIRDSEYE

UNIVERSITY OF TENNESSEE AT

CHATIANOOGA HABTE C. CHURNET

UNIVERSITY OF TEXAS JOHN M. SHARP, JR.

UNIVERSITY OF TEXAS AT AUSTIN BUREAU OF ECONOMIC GEOLOGY THOMAS C. GUSTAVSON MARTIN P. A. IACKSON DOUGLAS C. RATCLIFF THE GENERAL LIBRARIES E. G. WERMUND
UNIVERSITY OF TEXAS AT SAN ANTONIO DONALD R. LEWIS

UNIVERSITY OF TOKYO - JAPAN RYOHEI KIYOSE

UNIVERSITY OF TORONTO - CANADA N. S. BRAR

UNIVERSITY OF UTAH

IAMES W. BUNGER

THURE CERLING

MARRIOTT LIBRARY

GARYM. SANDQUIST

LEE STOKES

UNIVERSITY OF UTAH RESEARCH INSTITUTE LIBRARY

DUNCAN FOLEY

HOWARD P. ROSS

UNIVERSITY OF WASHINGTON CHRISTOPHER J. EARLE

KAI N. LEE

UNIVERSITY OF WATERLOO F. SYKES

UNIVERSITY OF WATERLOO - CANADA PETER FRITZ

UNIVERSITY OF WISCONSIN B. C. HAIMSON

UNIVERSITY OF WISCONSIN AT MILWAUKEE HOWARD PINCUS

UNIVERSITY OF WISCONSIN CENTER LIBRARY - DOCUMENTS

UPPER PEASE SOIL AND WATER

CONSERVATION DISTRICT W. H. MARSHALL

URS-BERGER TONY MORGAN

URS/JOHN A. BLUME \& ASSOCIATES, ENGINEERS ANDREW B. CUNNINGHAM

USAID/CAIRO EQYPT DAVID SNOW

UTAH DEPT OF NATURAL RESOURCES \& ENERGY

HAROLD D. DONALDSON MARK A. PAGE

UTAH DEPT OF TRANSPORTATION DAVID LLOYD

UTAH DIVISION OF ENVIRONMENTAL HEALTH

MARV H. MAXELL

UTAH DIVISION OF OIL, GAS \& MINING SALLY J. KEFER

UTAH DIVISION OF PARKS \& RECREATION JOHN KNUDSON GORDON W. TOPHAM

UTAH DIVISION OF WATER RESOURCES BARRY C. SAUNDERS

UTAH ENERGY OFFICE ROD MILLAR

UIAH ENVIRONMENTAL CENTER IUNE WICKHAM

UTAH CEOLOGICAL AND MINERAL SURVEY GENEVIEVE ATWOOD BILL LUND MACE YONETANI

UTAH MULTIPLE USE ADVISORY COUNCIL R. BRENT GRIGGS

UTAH NUCLEAR STUDY SOCIETY DAVE CONINE

UTAH OFFICE OF PLANNING \& BUDGET RANDY MOON

UTAH OFFICE OF THE GOVERNOR ALENE BENTLEY
UTAH SOUTHEASTERN DISTRICT HEALTH DEPARTMENT ROBERT L. FURLOW

UTAH STATE GEOLOGIC TASK FORCE DAVID D. TILLSON

UTAH STATE GOVERNMENT FRED NELSON

UTAH STATE PLANNING OFFICE KENT BRIGGS

UTAH STATE SENATE OMAR B. BUNNELL

UTAH STATE UNIVERSITY DEPT OF GEOLOGY 07 JOEL E. FLETCHER MERRILL LIBRARY AND LEARNINC JACK T. SPENCE

UTAHNS AGAINST THE DUMP COALITION

UTILITY DATA INSTITUTE FRED YOST

VANDERBILT UNIVERSITY FRANK L. PARKER

VEPCO B. H. WAKEMAN

VERMONT DEPT OF WATER RESOURCES AND ENVIRONMENTAL ENGINEERING CHARLES A. RATTE

VERMONT STATE NUCLEAR ADVISORY PANEL VIRGINIA CALLAN

VIRGINIA DEPT OF HEALTH WILLIAM F. GILLEY ROBERT G. WICKLINE

VIRGINIA DIVISION OF MINERAL RESOURCES ROBERT C. MILICI

VIRGINIA HOUSE OF DELEGATES A. VICTOR THOMAS

VIRGINIA POLYTECHNICAL INSTITUTE AND STATE UNIVERSITY GARY L. DOWNEY

WASATCH NATIONAL FOREST ART CARROLL

WASHINGTON HOUSE OF REPRESENTATIVES RAY ISAACSON

WASHINGTON STATE DEPT OF ECOLOGY DAVID W. STEVENS

WATTLAB BOB E. WATT

WEBSTER PARISH LIBRARY

WEST MICHIGAN ENVIRONMENTAL ACTION COUNCIL. FRANK RUSWICK, JR.

WEST VALLEY NUCLEAR SERVICES COMPANY INC CHRIS CHAPMAN ERICH I. MAYER

WESTERN MICHIGAN UNIVERSITY ROBERT KAUFMAN

WESTERN STATE COLLEGE FRED R. PECK

WESTINGHOUSE ELECTRIC CORP GEORGE V. B. HALL JAMES H. SALING JAMES R. SCHORNHOUST

WILLIAMS AND ASSOCIATES INC GERRY WINTER

WIPP PROJECT WESTINGHOUSE ELECTRIC CORPORATION

WISCONSIN GEOLOGICAL AND NATURAL HISTORY SURVEY MEREDITH E. OSTROM 
WOODWARD-CLYDE CONSULIANIS

F. R. CONWELLL (2)

TERRY A. GRANT

ASHOK PATWARDHAN

WESTERN REGION LIBRARY
WRIGHT STATE UNIVERSITY

A. A. BAKR

MICHAEL FARRELL
WYOMING GEOLOGICAL SURVEY

JAMES C. CASE

YALE UNIVERSITY

BRIAN SKINNER 


\section{COMMENT SHEET}

To the User: The purpose of this sheet is to give you the opportunity to provide feedback to DOE on the usefulness of this report and to critique it. Please submit your comments below and return the sheet.

Comments

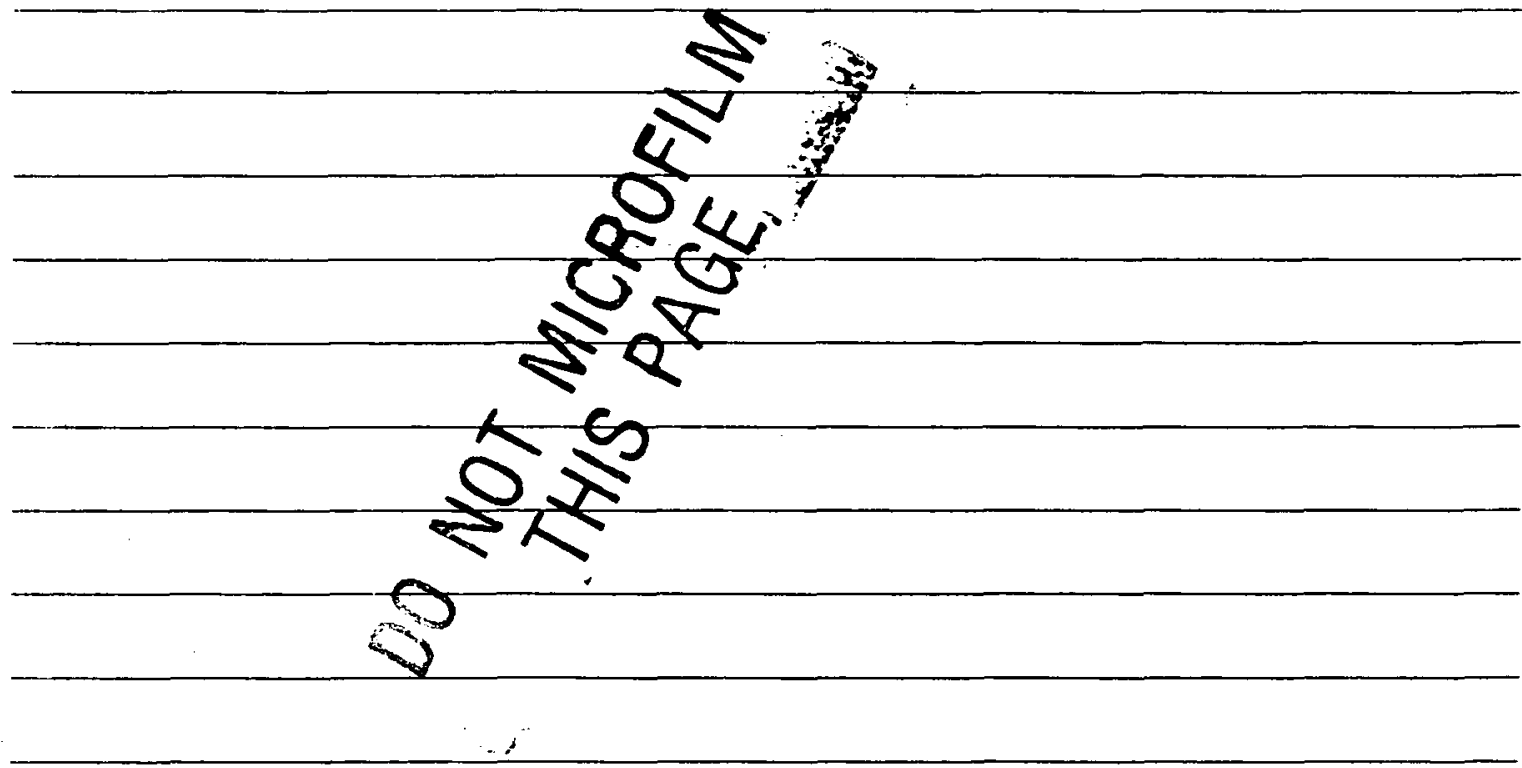

(Use additional sheet if necessary.)

Name

Date

\section{Organization}

Street

City State

Zip Code or Country

Telephone Number ( ) 

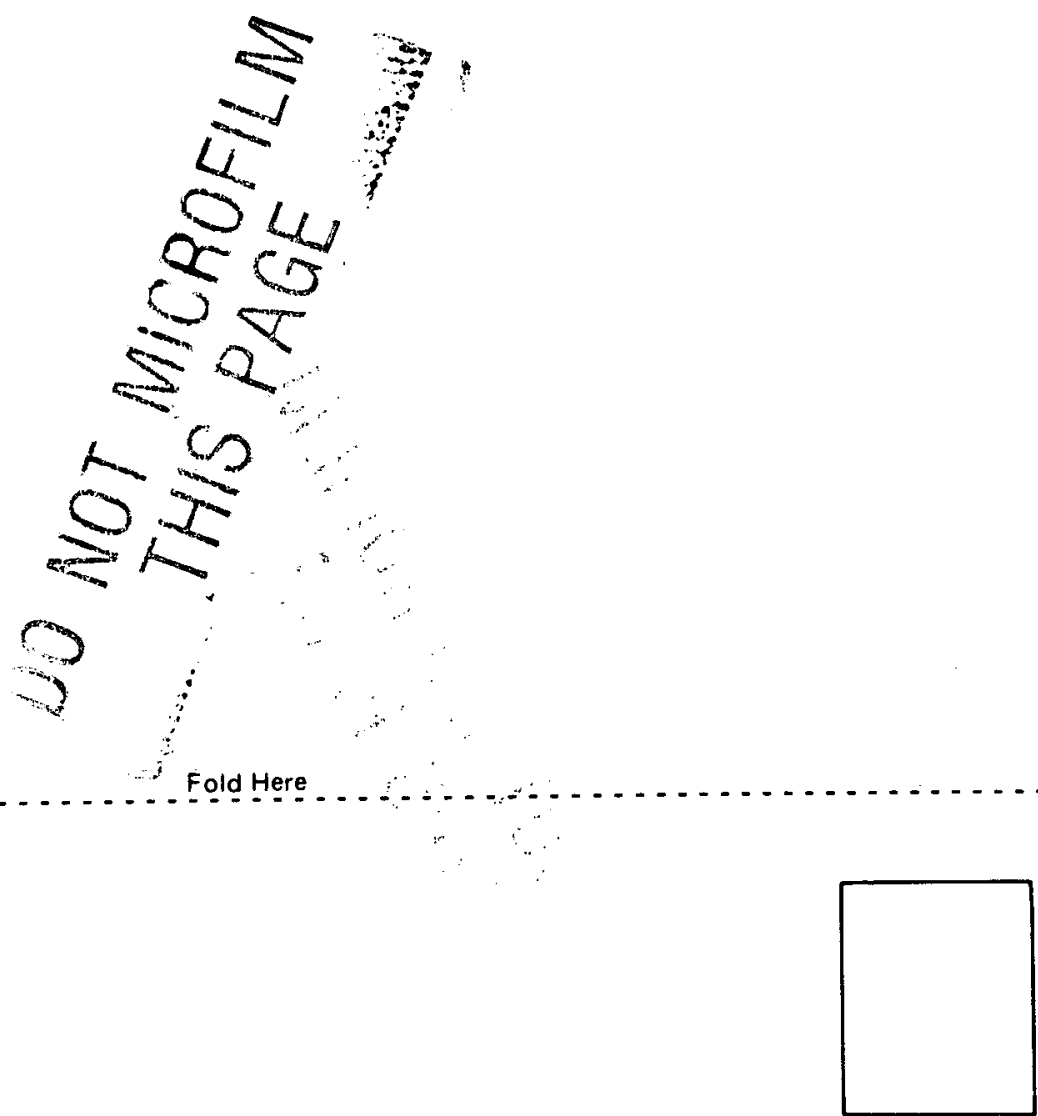

JEFFERSON O. NEFF, MANAGER

SALT REPOSITORY PROJECT

U.S. DEPARTMENT OF ENERGY

505 KING AVENUE

COLUMBUS, OHIO 43201.2693 USA 